\title{
Data report: penetrometer measurements of in situ temperature and pressure, IODP Expedition $308^{1}$
}

\author{
H. Long, ${ }^{2}$ P.B. Flemings, ${ }^{3}$ B. Dugan, ${ }^{4}$ J.T. Germaine, ${ }^{5}$ and D. Ferrell ${ }^{6}$
}

\section{Chapter contents}

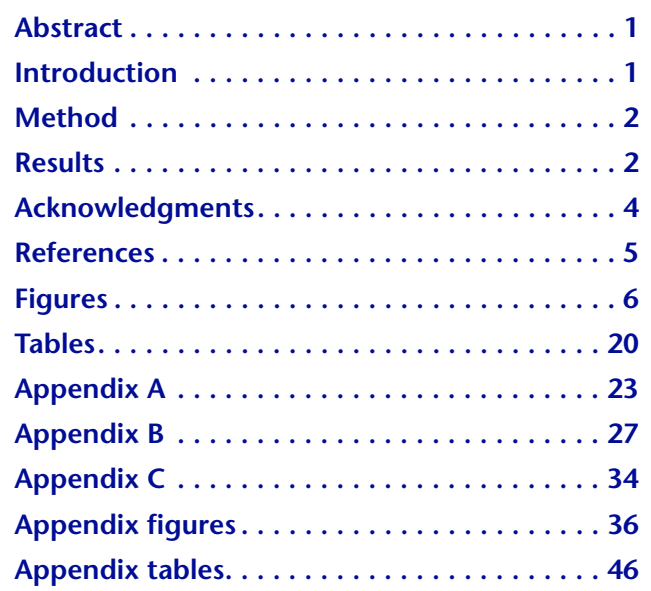

${ }^{1}$ Long, H., Flemings, P.B., Dugan, B., Germaine, J.T., and Ferrell, D., 2008. Data report: penetrometer measurements of in situ temperature and pressure, IODP Expedition 308. In Flemings, P.B., Behrmann, J.H., John, C.M., and the Expedition 308 Scientists, Proc. IODP, 308: College Station, TX (Integrated Ocean Drilling Program Management International, Inc.).

doi:10.2204/iodp.proc.308.203.2008

${ }^{2}$ ExxonMobil Upstream Research Company, 3120

Buffalo Speedway, Houston TX 77098, USA. hui.long@exxonmobil.com

${ }^{3}$ John A. and Katherine G. Jackson School of Geosciences, The University of Texas at Austin, 1 University Station C1100, Austin TX 78712-0254, USA.

${ }^{4}$ Department of Earth Science, Rice University, Houston TX 77005, USA.

${ }^{5}$ Department of Civil and Environmental Engineering, Massachusetts Institute of Technology, Cambridge MA 02139, USA. ${ }^{6}$ Integrated Ocean Drilling Program, Texas A\&M University, College Station TX 77845, USA.

\section{Abstract}

We conducted temperature and pore pressure measurements using the Davis-Villinger Temperature-Pressure Probe and the temperature/dual pressure probe penetrometers during Integrated Ocean Drilling Program Expedition 308. In Ursa Basin, 18 measurements were used to determine that the geothermal gradient at Site U1324 is bilinear. The temperature gradient is $18.6^{\circ} \mathrm{C} / \mathrm{km}$ in lithostratigraphic Unit I and $16.7^{\circ} \mathrm{C} / \mathrm{km}$ in Unit II. Based on nine measurements at Site U1322, the geothermal gradient is $21.9^{\circ} \mathrm{C} /$ $\mathrm{km}$. In Brazos-Trinity Basin IV, the geothermal gradient at Site $\mathrm{U} 1320$ is $23.1^{\circ} \mathrm{C} / \mathrm{km}$. In Ursa Basin, significant overpressures (overpressure ratio $=\sim 0.7$ ) are observed in the sediments above 200 meters below seafloor (mbsf) at Sites U1322 and U1324. At Site U1324, pore pressure decreases with increasing depth between 200 and 300 mbsf. Below 300 mbsf and within lithostratigraphic Unit II, overpressure is approximately constant ( 1 MPa). Unit II is composed of silty claystone interbedded with beds of silt and very fine sand. In Brazos-Trinity Basin IV, only two penetrometer deployments were made and the data are inconclusive.

\section{Introduction}

The objective of this report is to present in situ pressure and temperature data measured using downhole pressure penetrometers during Integrated Ocean Drilling Program (IODP) Expedition 308 (see the "Expedition 308 summary" chapter). These data have also been presented and interpreted in Long et al. (2007a) (see the "DOWNHOLE" folder in "Supplementary material"). Pressure and temperature data are critical for constraining fluid flow, heat flow, and hydraulic and thermal diffusivity. In addition, temperature affects sediment diagenesis and microbial activity. Expedition 308 is dedicated to the study of overpressure and fluid flow on the Gulf of Mexico continental slope. Knowledge of the pore pressure, and stress regime in general, is critical for evaluating submarine slope stability. It has been hypothesized that overpressure, pore pressures in excess of hydrostatic pressure, can weaken the strength of sediments and thus cause slope instability near the seafloor (Davis et al., 1983; Dugan and Flemings, 2002). Overpressure and the shallow-water flow frequently cause operational problems during drilling (Ostermeier et al., 2001). 
Three sites were drilled in Brazos-Trinity Basin IV and three sites were drilled in Ursa Basin during Expedition 308 (Figs. F1, F2, F3). To document the in situ pore pressure and temperature, we deployed two types of pressure penetrometers: the temperature/ dual pressure probe (T2P) and the Davis-Villinger Temperature-Pressure Probe (DVTPP) (Fig. F4). The DVTPP was deployed previously during Ocean Drilling Program Legs 190, 201, and 204 (D’Hondt, Jørgensen, Miller, et al., 2003; Long et al., 2007a; Moore, Taira, Klaus, et al., 2001; Tréhu, Bohrmann, Rack, Torres, et al., 2003). The T2P is a new tool under development as a cooperative effort between Pennsylvania State University, Massachusetts Institute of Technology (MIT), and IODP-Texas A\&M University (TAMU) (Expedition 308 Scientists, 2005; Flemings et al., 2006; see also the "PHYSPROP" folder in "Supplementary material").

\section{Method}

The DVTPP and T2P penetrometers interface with the colleted delivery system (CDS). The CDS is lowered by wireline and engages with the bottom-hole assembly (BHA). Once the CDS is engaged in the $\mathrm{BHA}$, the drill string is used to push the probe into the formation. The drill string is then raised 3-4 m and the CDS telescopes to decouple the probe from the drill string. The probe remains in the formation to measure pressure and temperature for 30-90 min. After measurement, the wireline pulls the CDS to its extended position and then pulls the penetrometer out of the formation. A detailed description of the deployment procedure is presented in "Appendix A." The data are downloaded from the data acquisition unit when the tool is retrieved.

When the penetrometers penetrate the formation, the temperature (resulting from friction on the tool) and pressure (resulting from deformation of the soil) are raised relative to their in situ values. Subsequently, the tools are left in place in order to dissipate toward the equilibrium values (Fig. F5). Temperature decay can be used to infer the formation temperature and thermal conductivity (Davis et al., 1997; Villinger and Davis, 1987). Decay of the penetration-induced pore pressure can be used to infer formation pressure, hydraulic diffusivity, and permeability (Baligh and Levadoux, 1986; Gupta and Davidson, 1986; Long et al., 2007a; Whittle et al., 2001).

Rates of pressure and temperature decay are functions of the probe diameter and the hydraulic/thermal diffusivity of the sediment (Bullard, 1954; Long et al., 2007a; Villinger and Davis, 1987). Pressure decay is much slower than temperature decay in low- permeability mudstones (Long et al., 2007a). Because of the restricted time available for deployment, we must interpret in situ pressure from partial dissipation records. If detailed soil properties are available, the in situ pressure and hydraulic diffusivity of the sediment can be inferred from modeling of soil behavior for different penetrometer geometries. However, in many cases soil properties are not available or there are insufficient resources to pursue soil modeling. In these cases, in situ pressure is inferred from simple extrapolation approaches such as inverse time $(1 / t)$ extrapolation (Davis et al., 1991; Lim et al., 2006; Long et al., 2007b; Villinger and Davis, 1987; Whittle et al., 2001) and inverse square root of time $(1 / \sqrt{t})$ extrapolation (Long et al., 2007b).

\section{Results}

Sites U1319, U1320, and U1321 were drilled in the Brazos-Trinity Basin IV (Figs. F1, F2). Sites U1319 and U1320 were cored and penetrometer measurements were made. Sites U1322, U1323, and U1324 were drilled in the Ursa Basin (Figs. F1, F3). Sites U1322 and U1324 were cored and penetrometer measurements were made.

We present the temperature and pressure data from the penetrometer deployments at the four sites in this report. In the main text, we present our best estimate of the in situ temperature and pressure. In "Appendix A," we describe how the DVTPP was calibrated and present a detailed description of each DVTPP deployment. In "Appendix B," we describe how the T2P was calibrated and we describe each T2P deployment. In "Appendix C," we present a discussion of the pressure state within the drill pipe based on the DVTPP pressure measurements.

The temperature and pressure data are available in Microsoft Excel format in the "APP_A" and "APP_B" folders in "Supplementary material." These data have been recalibrated and consequently are different and improved relative to the data discussed in the Expedition Reports section of this volume. The original raw data can be found in the "DOWNHOLE" folder in "Supplementary material." The penetrometer data are integrated with the rig instrumentation system data ("TruView data") in order to better understand and assess the quality of each measurement.

\section{Summary of deployments}

Twenty DVTPP deployments and twenty-eight T2P deployments were completed during Expedition 308 (Table T1). The deployment number (Table T1) reflects the deployment sequence of each tool during 
Expedition 308 (Expedition 308 Scientists, 2005). Deployments are divided into three types: Type I, Type II, and Type III (Table T1; Fig. F6).

Figure F7A illustrates ideal penetrometer deployments for the DVTPP and the T2P (Type I; Table T1). The tip pressure is at maximum during insertion and, subsequently, pressure declines with time. At the end of the deployment, the shaft pressure of the T2P is much greater than that of the tip pressure. This is because the shaft has a much larger diameter. As a result it disturbs a greater region around the penetrometer and this takes a greater amount of time to subside to the in situ pressure. A detailed comparison of the DVTPP and the T2P geometries and their consequent behavior during insertion and dissipation is presented by Long et al. (2007a).

Figure F7B presents deployments for both the DVTPP and the T2P that were slightly dislodged when the drill string was raised subsequent to penetration to decouple itself from the penetrometer through the CDS (Types IIA and IIB). In this situation, the tool pressure dropped abruptly when the bit was raised. Analysis of the temperature record from both tools and the accelerometer record from the DVTPP shows that coincident with the abrupt drop in pressure there was frictional heating and movement of the tool (Flemings et al., 2006; Long et al., 2007b). The pressure either decayed toward the formation pressure after it rebounded to a certain level (Type IIA; Table T1) or kept building during the dissipation phase (Type IIB; Table T1; Fig. F7B).

Type III includes all the unsuccessful deployments that failed to yield useful information about the in situ conditions. Type III deployment problems are three-fold. First, in early cases there was an internal hydraulic leak in the DVTPP and the tip pressure of the T2P. The leaks resulted in abrupt and erratic drops in pressure during the dissipation phase (Fig. F7C). Eventually, the internal hydraulic leak was repaired. Second, in the worst case the tool dislodgement weakened the seal around the probe and created communications with the borehole fluid, ruining the pressure and temperature measurements (see "Appendix A," "Appendix B"). Third, the tool did not record any reliable data because of electronic and/or mechanical failure. The latter was especially true for the T2P, as it was prone to bending because of its very narrow diameter tip.

During several deployments, the DVTPP was not fully decoupled from the BHA because of friction in the CDS (in "Appendix A," see DVTPP Deployments $1,2,3,8,12$, and 13). In these cases, the tool moved during the dissipation phase. Frictional heating caused by these tool movements may have compromised the temperature measurement. Continuous movement of the tool may also have affected the pressure measurements. In several T2P deployments, circulation of the drilling fluid resumed during the dissipation phase. In these cases, it is often possible to see a slight pressure and temperature increase at the onset of circulation. (in "Appendix B," see T2P Deployments 2, 3, 4, 5, and 12). In some cases, the onset of circulation resulted in further tool insertion (in "Appendix B," see T2P Deployments 6 and 7). The tool disturbance caused by pumping fluid may affect the accuracy of the pressure and temperature measurements.

\section{Data extrapolation}

During Expedition 308, T2P temperatures equilibrated to formation temperatures (see "Appendix B"). In contrast, temperatures measured with the DVTPP did not equilibrate to in situ temperatures (see "Appendix A"). The reason for this is that the DVTPP has a significantly larger geometry. We use inverse time $(1 / t)$ extrapolation to estimate the in situ temperature for the DVTPP deployments (Davis et al., 1997; Villinger and Davis, 1987).

Pressures measured by both the T2P and the DVTPP penetrometers did not reach in situ pressures during the dissipation phase (see "Appendix A," "Appendix B"). In the absence of detailed soil properties, we used two empirical approaches to infer the in situ pressure from the partial dissipation records: $1 / t$ extrapolation and $1 / \sqrt{t}$ extrapolation. Accuracy of the extrapolated in situ pressures depends on the tool that was used, pressure port, type of deployment, depth of deployment, and the pressure decay time (Long et al., 2007b). Long et al. (2007b) showed that $1 / t$ extrapolation more closely matches theoretical modeling results than the extrapolation does when pressure decays $<80 \%$ of the penetration-induced pressure. The error of a good (Type I) deployment with long dissipation time (e.g., $90 \mathrm{~min}$ ) should be within $0.1 \mathrm{MPa}$, whereas the error of a deep deployment with short decay time could be more than 0.5 MPa.

Table $\mathbf{T} 2$ presents the interpreted in situ pressure and temperature for the T2P and the DVTPP deployments during Expedition 308.

\section{In situ temperature}

\section{Brazos-Trinity Basin IV}

Figure F8 presents the in situ temperatures taken at Sites U1319 and U1320. The geothermal gradient at Site $\mathrm{U} 1320$ is $23.1^{\circ} \mathrm{C} / \mathrm{km}$. The only measurement at Site U1319 suggests a higher geothermal gradient than that at Site U1320. 


\section{Ursa Basin}

Figure F9 presents the in situ temperatures taken at Sites U1322 and U1324. The geothermal gradient at Site U1324 is bilinear. The thermal gradient is $18.6^{\circ} \mathrm{C} / \mathrm{km}$ in the sediments above 360 meters below seafloor (mbsf), corresponding to lithostratigraphic Unit I, which is predominantly composed of terrigenous clay and mud with a marked paucity of silt and sand (see the "Site U1324" chapter). The geothermal gradient is $16.7^{\circ} \mathrm{C} / \mathrm{km}$ in lithostratigraphic Unit II, which extends from 360 to 600.8 mbsf and includes interbedded silt and very fine sand with beds and laminae of mud and clay (see the "Site U1324" chapter). Sediments are predominantly clay and mud at Site U1322. The geothermal gradient is $21.9^{\circ} \mathrm{C} / \mathrm{km}$, which is significantly higher than that at Site U1324.

\section{In situ pressure}

We present our pressure results with respect to hydrostatic pressure and overburden stress. The hydrostatic pressure is calculated starting from the seafloor and assuming a seawater density of $1.024 \mathrm{~g} / \mathrm{cm}^{3}$. Bulk density data from shipboard moisture and density (MAD) measurements were integrated to calculate the overburden stress. The static pressure of the water column above seafloor was subtracted from the pressure results.

\section{Brazos-Trinity Basin IV}

We have only one pressure measurement at Site U1319. The T2P penetration was completed at 80.5 mbsf. The last recorded pressure of the T2P tip equals the overburden stress, whereas that of the shaft exceeds the overburden stress. This clearly shows that pressures had not dissipated to in situ pressure (Fig. F10B). The pressure dissipation time was only 35 min for this deployment. The $1 / \sqrt{t}$ extrapolation of the tip pressure, which should give a better estimation of in situ pressure (Long et al., 2007b), suggests that the formation pressure is $0.37 \mathrm{MPa}$ higher than hydrostatic (Fig. F10D). The $1 / \sqrt{t}$ extrapolated in situ pressure suggests that the formation pressure at 80.5 mbsf is $0.37 \mathrm{MPa}$ higher than the hydrostatic pressure (Fig. F10D). The shaft pressure was still higher than the overburden stress after $1 / t$ and $1 / \sqrt{t}$ extrapolation (Fig. F10C, F10D).

We made two T2P and two DVTPP deployments at Site U1320, but only one deployment can be used to estimate the in situ pressure. The last recorded pressure was slightly greater than the hydrostatic pressure (Fig. F11B). The estimated in situ pressure by both $1 / t$ and $1 / \sqrt{t}$ extrapolation suggests that forma- tion pressure at $126.3 \mathrm{mbsf}$ is close to hydrostatic pressure (Fig. F11C, F11D).

\section{Ursa Basin}

Figure F12 presents the pore pressure measurements at Site U1322, where sediments are predominantly clay and mud. The last recorded pressures are scattered, with some of them equal to or exceeding the overburden stress $\left(\sigma_{v}\right)$ (Fig. F12B). This indicates that pressures had not dissipated to the in situ pressure at the end of the deployments.

The $1 / t$ extrapolation predicts consistently higher pressure at the shaft sensor of the T2P than that at the tip sensor (Fig. F12C). Some shaft pressures are still equal to or even higher than the overburden stress (Fig. F12C). These indicate that $1 / t$ extrapolation of the shaft pressure overestimates the in situ pressure, consistent with theoretical modeling presented by Long et al. (2007b).

Application of $1 / \sqrt{t}$ extrapolation drives the shaft pressure closer to the tip pressure (Fig. F12D). The results make more physical sense because ultimately the shaft pressure and tip pressure converge at the in situ pressure. We believe the $1 / \sqrt{t}$ extrapolation provides more accurate in situ pressure estimate than the $1 / t$ extrapolation does for the shaft pressure.

Nevertheless, both extrapolation approaches predict significant overpressure and similar trends. The overpressure ratio $\left(\lambda^{*}=\left[u_{0}-u_{\mathrm{h}}\right] /\left[\sigma_{\mathrm{v}}-u_{\mathrm{h}}\right]\right)$ is as high as 0.75 . Overpressure starts to drop from $\sim 200$ mbsf.

Figure F13 presents the pore pressure measurements at Site U1324. Both extrapolation approaches predict significant overpressure in the sediments above 200 mbsf (Fig. F13C, F13D) that correspond to hemipelagic silty claystone. Within this section, the magnitude and trend of the overpressure are similar to those at Site U1322 (Fig. F14). The sediments below 300 mbsf have less overpressure (Fig. F13). The overpressure seems to be constant within lithostratigraphic Unit II, in which sediments are composed of silty claystone interbedded with beds of silt and very fine sand. The transition occurs at the section from 200 to 300 mbsf.

\section{Acknowledgments}

We thank the participants of Expedition 308 that made the deployment of the T2P possible. We also thank Derryl Schroeder and Mike Meiring for their help and assistance on the postcruise T2P pressure calibration. Kevin Grigar is thanked for helpful discussion on the geometry and operation of the CDS and the BHA. 
This research used samples and/or data provided by the Integrated Ocean Drilling Program (IODP). Funding for this research was provided by a Schlanger Ocean Drilling Fellowship, which is part of the U.S. National Science Foundation-sponsored U.S. Science Support Program for IODP (USSSP-IODP). In addition, the Pennsylvania State GeoFluids Consortium supported this research.

\section{References}

Baligh, M.M., and Levadoux, J.-N., 1986. Consolidation after undrained piezocone penetration, II. Interpretation. J. Geotech. Eng., 112(7):727-745.

Bullard, E.C., 1954. The flow of heat through the floor of the Atlantic Ocean. In Bullard, E.C., A Discussion on the Floor of the Atlantic Ocean. Proc. R. Soc. London, Ser. A, 222(1150):408-429.

D’Hondt, S.L., Jørgensen, B.B., Miller, D.J., et al., 2003. Proc. ODP, Init. Repts., 201: College Station, TX (Ocean Drilling Program). doi:10.2973/odp.proc.ir.201.2003

Davis, D., Suppe, J., and Dahlen, F.A., 1983. Mechanics of fold-and-thrust belts and accretionary wedges. J. Geophys. Res., 88(B2):1153-1172. doi:10.1029/ JB088iB02p01153

Davis, E.E., Villinger, H., MacDonald, R.D., Meldrum, R.D., and Grigel, J., 1997. A robust rapid-response probe for measuring bottom-hole temperatures in deep-ocean boreholes. Mar. Geophys. Res., 19(3):267-281. doi:10.1023/A:1004292930361

Davis, E.E., Horel, G.C., Macdonald, R.D., Villinger, H., Bennett, R.H., and Li, H., 1991. Pore pressures and permeabilities measured in marine sediments with a tethered probe. J. Geophys. Res., 96(B4):5975-5984. doi:10.1029/91JB00220

Dugan, B., and Flemings, P.B., 2002. Fluid flow and stability of the US continental slope offshore New Jersey from the Pleistocene to the present. Geofluids, 2(2):137-146. doi:10.1046/j.1468-8123.2002.00032.x

Expedition 308 Scientists, 2005. Overpressure and fluid flow processes in the deepwater Gulf of Mexico: slope stability, seeps, and shallow-water flow. IODP Prel. Rept., 208. doi:10.2204/iodp.pr.308.2005

Flemings, P.B., Germaine, J., Long, H., Dugan, B., Sawyer, D., Behrmann, J.H., and John, C., 2006. Measuring temperature and pressure with the temperature two pressure (T2P) probe in the Ursa Basin, Gulf of Mexico: development of a new pressure and temperature probe for the IODP (Paper OTC 17957). Proc.-Annu. Offshore Technol. Conf. http://www.otcnet.org/2006/ tech_prog/sched/documents/otc179571.pdf
Graber, K.K., Pollard, E., Jonasson, B., and Schulte, E. (Eds.), 2002. Overview of Ocean Drilling Program engineering tools and hardware. ODP Tech. Note, 31. doi:10.2973/odp.tn.31.2002

Gupta, R.C., and Davidson, J.L., 1986. Piezoprobe determined coefficient of consolidation. Soils Found., 26:12-22.

Lim, B.S., Tumay, M.T., and Seo, D.D., 2006. Status of consolidation from incomplete piezocone dissipat tests. In Puppala, A.J., Fratta, D., Alshibli, K., Pamukcu, S. (Eds.), Site and Geomaterial Characterization (GSP 149). Proc. Sess. GeoShanghai, 149:7. (Abstract)

Long, H., Flemings, P.B., and Germaine, J.T., 2007a. Interpreting in situ pressure and hydraulic properties with borehole penetrometers in ocean drilling: DVTPP and piezoprobe deployments at southern Hydrate Ridge, offshore Oregon. J. Geophys. Res., 112(B4):B04101. doi:10.1029/2005JB004165

Long, H., Flemings, P.B., Germaine, J., Dugan, B., and Sawyer, D., 2007b. In-situ pore pressure at IODP Site U1324, Ursa Basin, Gulf of Mexico (Paper OTC 18772). Proc.Annu. Offshore Technol. Conf. http://www.otcnet.org/ 2007/technical/schedule/documents/otc187721.pdf

Mikada, H., Moore, G.F., Taira, A., Becker, K., Moore, J.C., and Klaus, A. (Eds.), 2005. Proc. ODP, Sci. Results, 190/ 196: College Station, TX (Ocean Drilling Program). doi:10.2973/odp.proc.sr.190196.2005

Ostermeier, R.M., Pelletier, J.H., Winker, C.D., and Nicholson, J.W., 2001. Trends in shallow sediment pore pressures. Proc.-SPE/IADC Drill. Conf., 1-11.

Sawyer, D.E., Flemings, P., and Dugan, B., 2007. Lateral variations in core, $\log$, and seismic attributes of a mass transport complex in the Ursa Region, IODP Expedition 308, Northern Gulf of Mexico (Paper OTC 19098). Proc.-Annu. Offshore Technol. Conf. http://www.otcnet.org/2007/technical/schedule/documents/ otc190981.pdf

Tréhu, A.M., Bohrmann, G., Rack, F.R., Torres, M.E., et al., 2003. Proc. ODP, Init. Repts., 204: College Station, TX (Ocean Drilling Program). doi:10.2973/ odp.proc.ir.204.2003

Villinger, H., and Davis, E.E., 1987. A new reduction algorithm for marine heat flow measurements. J. Geophys. Res., 92(B12):12846-12856. doi:10.1029/ JB092iB12p12846

Whittle, A.J., Sutabutr, T., Germaine, J.T., and Varney, A., 2001. Prediction and interpretation of pore pressure dissipation for a tapered piezoprobe. Geotechnique, 51(7):601-617. doi:10.1680/geot.51.7.601.51388

Initial receipt: 15 June 2007

Acceptance: 16 April 2008

Web publication: 29 October 2008

MS 308-203 
Figure F1. Bathymetric map of study areas.

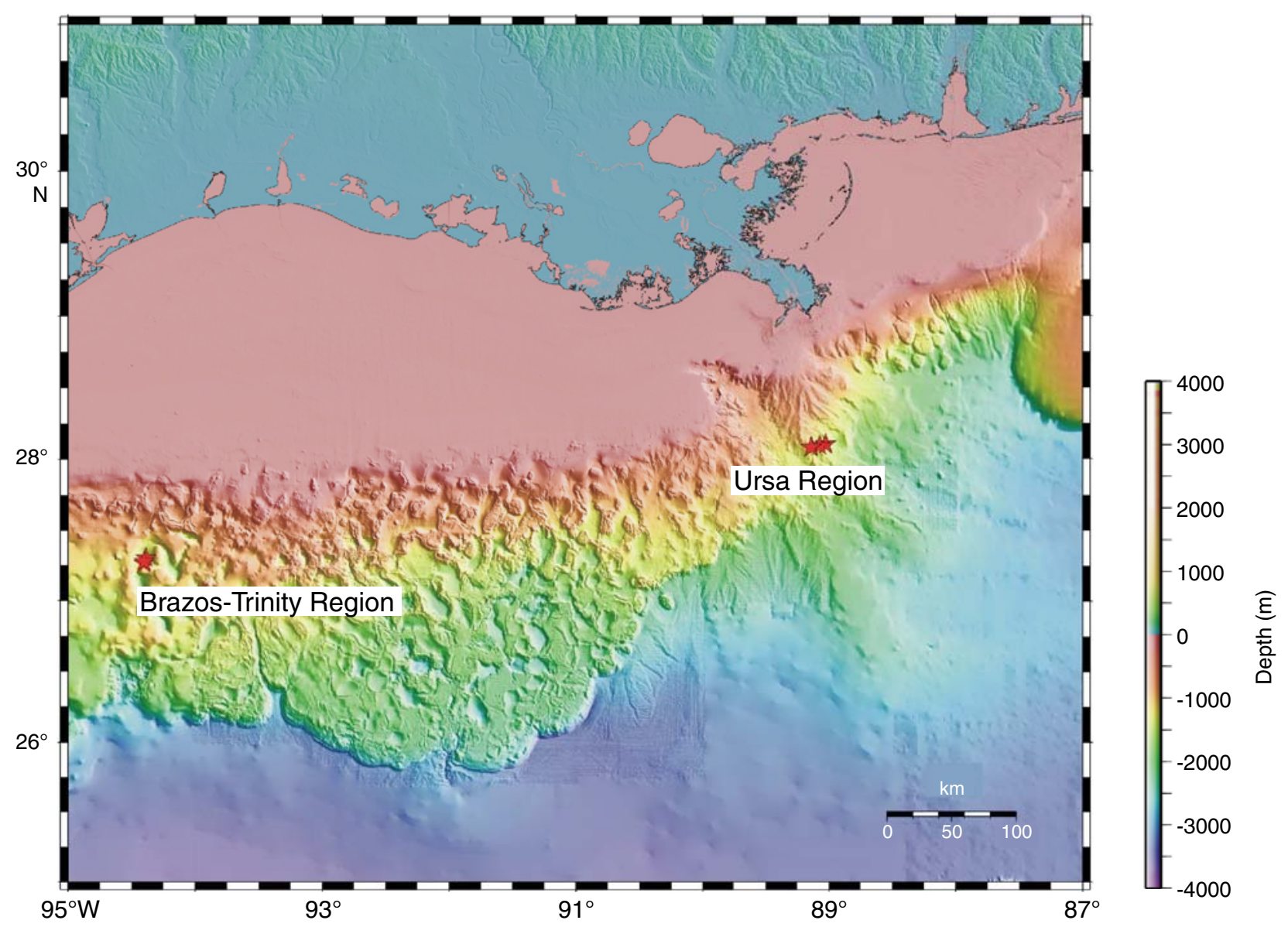


Figure F2. Seismic cross section of Brazos-Trinity Basin IV showing locations of Sites U1319, U1320, and U1321. $\mathrm{SF}=$ seafloor .

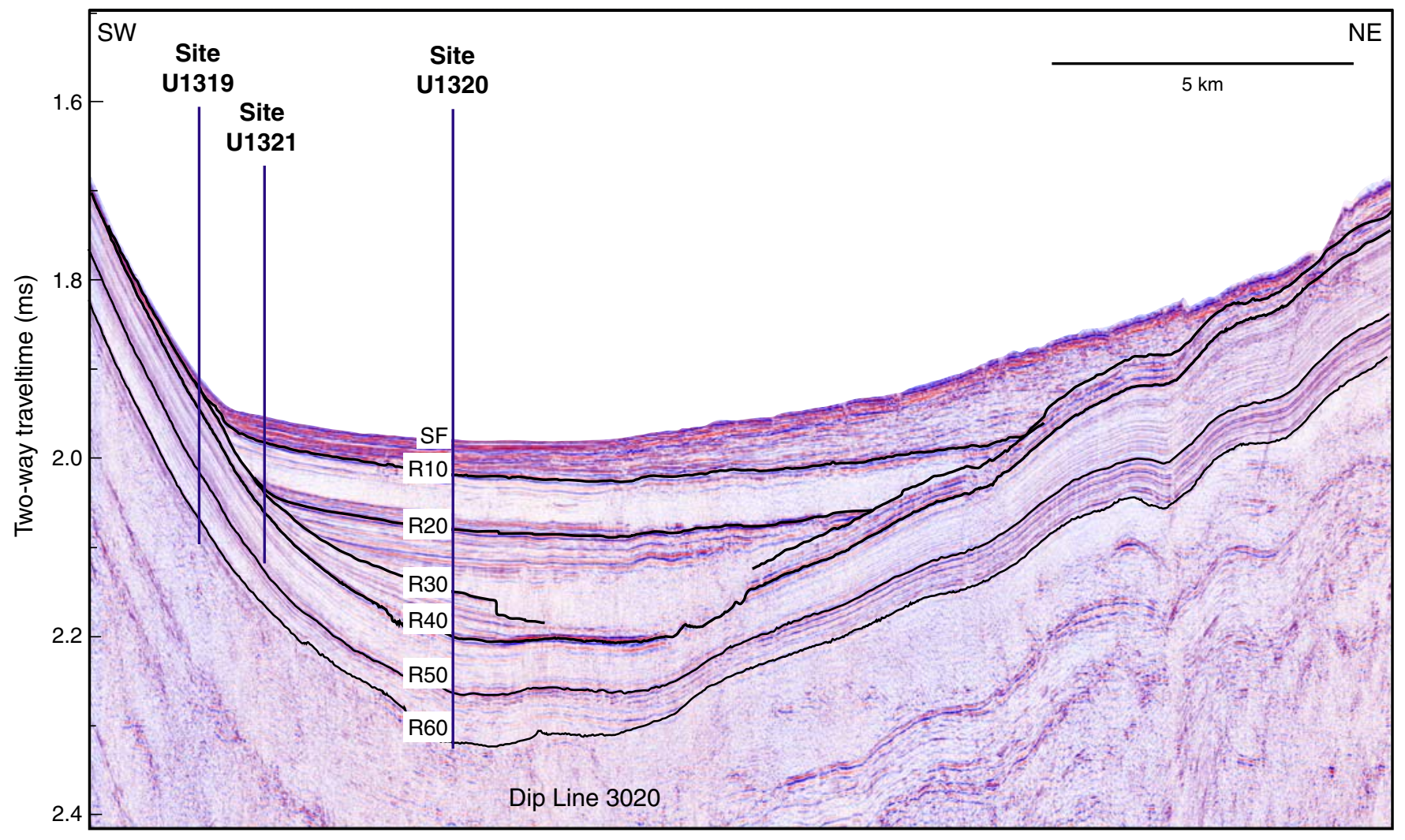


Figure F3. Seismic and interpreted cross section of Ursa Basin and locations of Sites U1322, U1323, and U1324 (Sawyer et al., 2007). A. East-west seismic cross section A-A'. B. Interpreted cross section A-A'. Light and dark gray = mud-rich levee, rotated channel-margin slides, and hemipelagic drape; yellow = sand-rich channel fill; light blue = Blue Unit; red = detachment surfaces. Mass transport deposits have occurred in the mud-rich levee deposits above the Blue Unit, which is composed of sand and mud. MTD = mass transfer deposits.
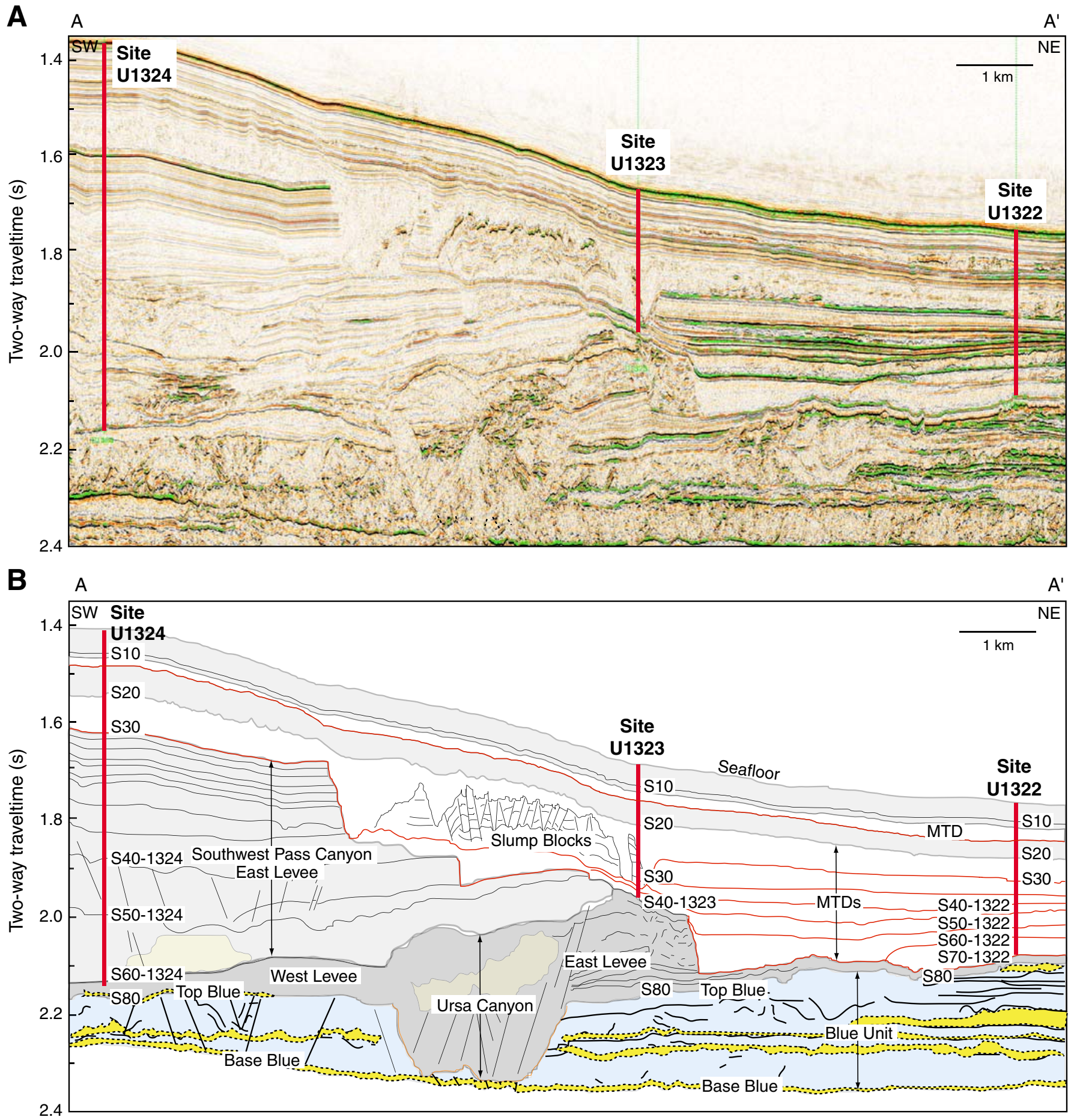
Figure F4. Davis-Villinger Temperature-Pressure Probe (DVTPP) and temperature/dual pressure (T2P) probe penetrometers.
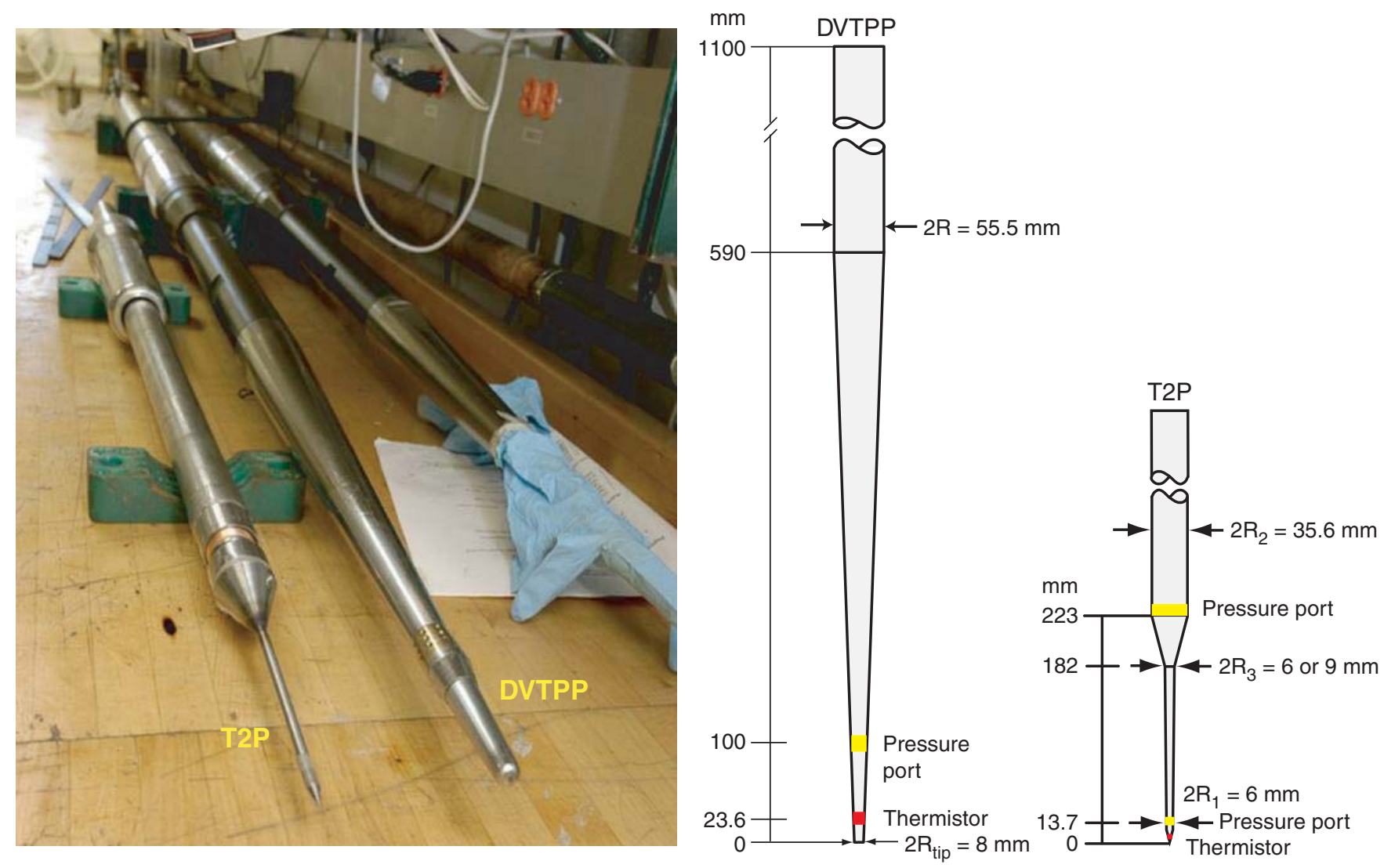
Figure F5. Procedure for probe penetration. Drill string pushes the probe into the formation. After penetration, the drill string is raised and the colleted delivery system telescopes to decouple the drill string from the tool. The probe stays in the formation to monitor the temperature and pressure. A good measurement is indicated by an abrupt increase in pressure and temperature during penetration and then a slow dissipation of pressure and temperature as the tool stays in the formation.

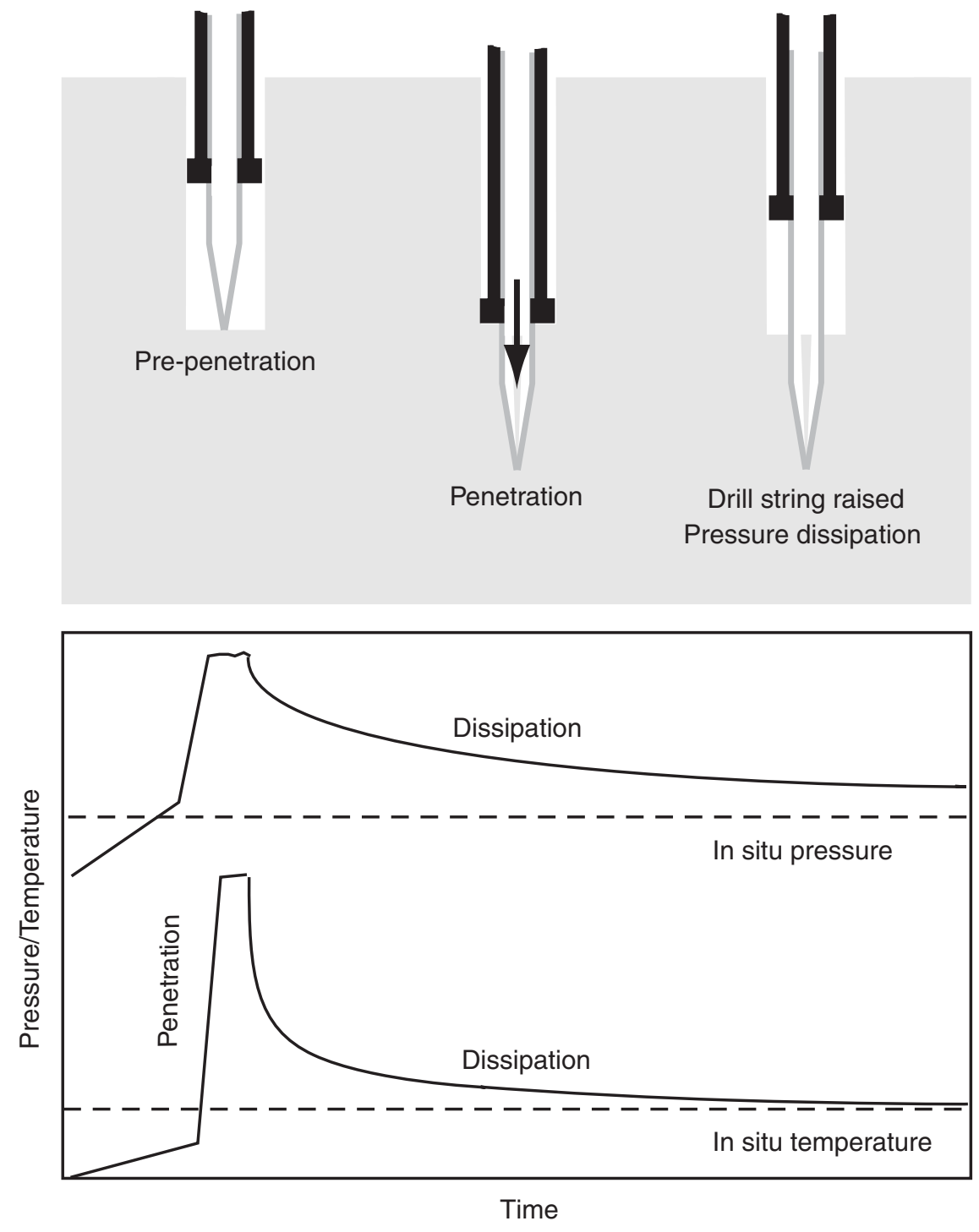


Figure F6. Summary of temperature/dual pressure (T2P) probe and Davis-Villinger Temperature-Pressure Probe (DVTPP) deployments during Expedition 308. Type I, II, and III deployments are defined in Figure F7. Type I and II deployments can give insight into in situ conditions. Type III deployments do not provide useful information about in situ conditions.
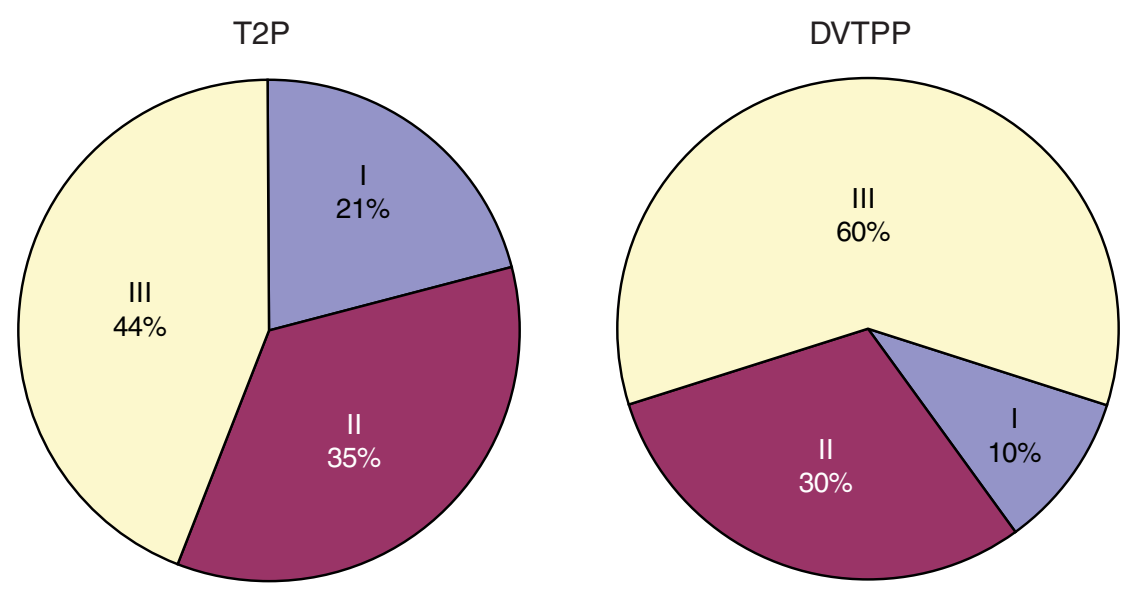

Type I: ideal penetrometer deployment

Type II: penetrometer slightly dislodged during deployment

Type III: unsuccessful deployment 
Figure F7. Characteristic deployments of Davis-Villinger Temperature-Pressure Probe (DVTPP) and temperature/dual pressure (T2P) probe. A. Type I deployment showing typical pressure record for a penetration test with clear pressure buildup and clean pressure dissipation. B. Type II deployment showing dramatic drop in pressure caused by decoupling of the drill string from the tool. Type II deployments can either show pressure decaying toward in situ pressure after the pressure drop (Type IIA) or pressure building to in situ pressure after the pressure drop (Type IIB). C. Type III deployment showing abrupt and erratic changes in pressure during the dissipation phase ("leak" deployment). Type III deployments include unsuccessful deployments resulting from hydraulic leaks, electronics failure, or tool damage and communication with borehole fluid.
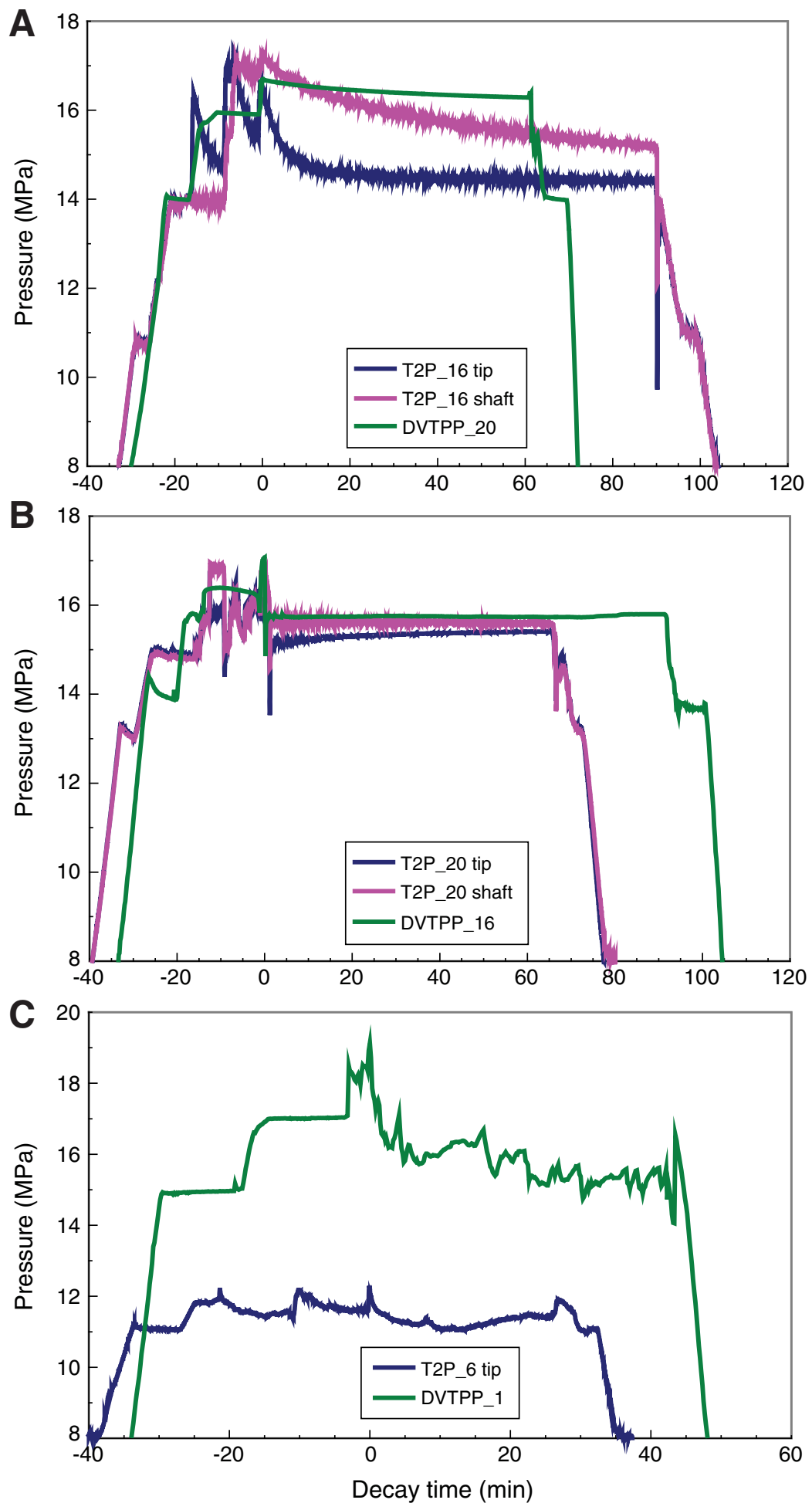
Figure F8. In situ temperature in Brazos-Trinity Basin IV, Sites U1319 and U1320. Temperature/dual pressure (T2P) probe temperature reached equilibrium with the formation temperature at the end of the deployment (Table T2). Davis-Villinger Temperature-Pressure Probe (DVTPP) temperature did not equilibrate with the formation temperature at the end of the deployment. In situ temperatures were estimated using $1 / t$ extrapolation (Table T2). Red = temperature measurements subjected to influence of tool movements during dissipation phase.

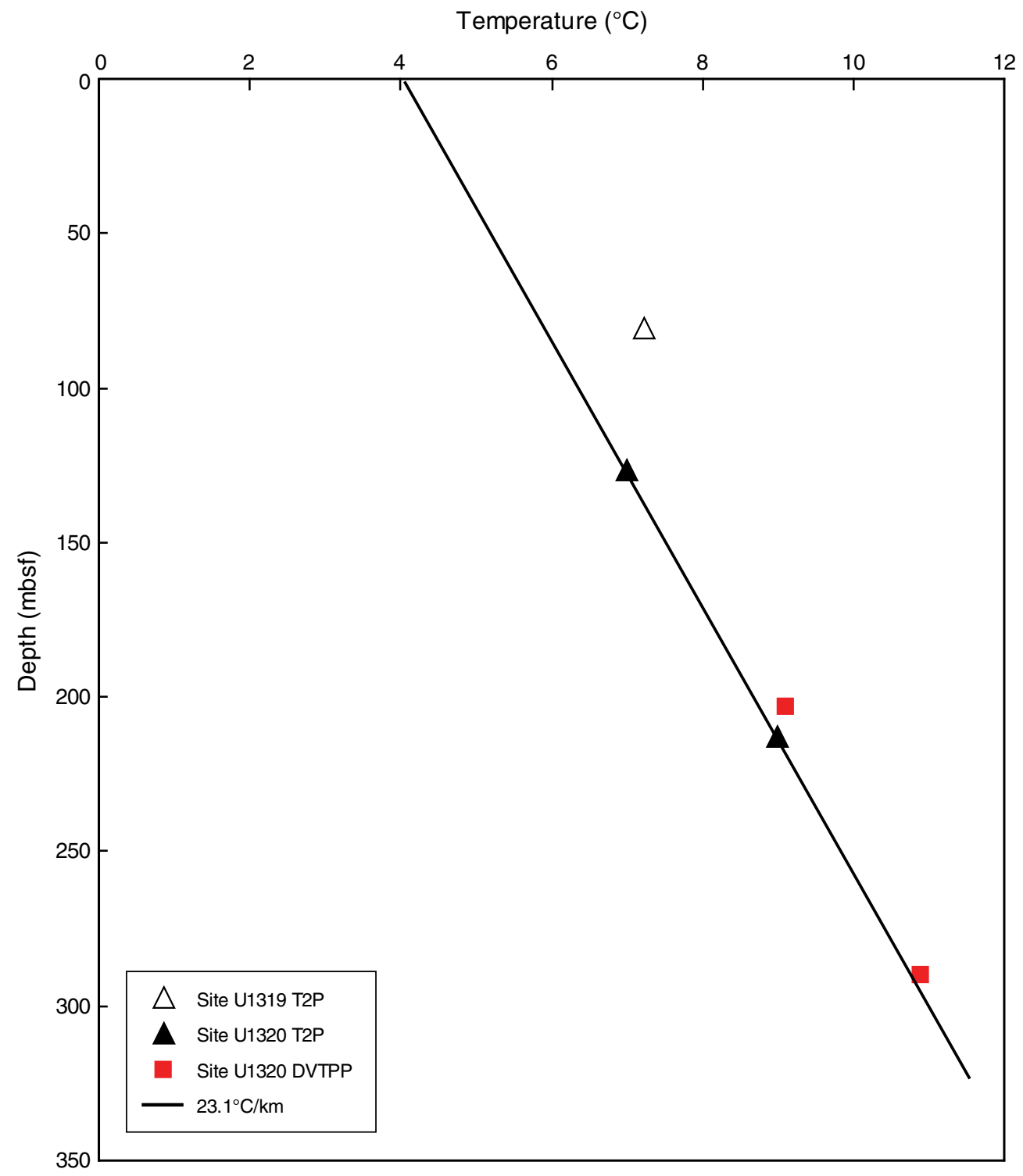


Figure F9. Temperature data for Ursa Basin, Sites U1322 and U1324. Temperature/dual pressure (T2P) probe temperature reached equilibrium with the formation temperature at the end of the deployment (Table T2). DavisVillinger Temperature-Pressure Probe (DVTPP) temperature did not equilibrate with the formation temperature at the end of the deployment. In situ temperatures were estimated using 1/t extrapolation (Table T2). Red symbols = temperature measurements subjected to influence of tool movements during dissipation phase.

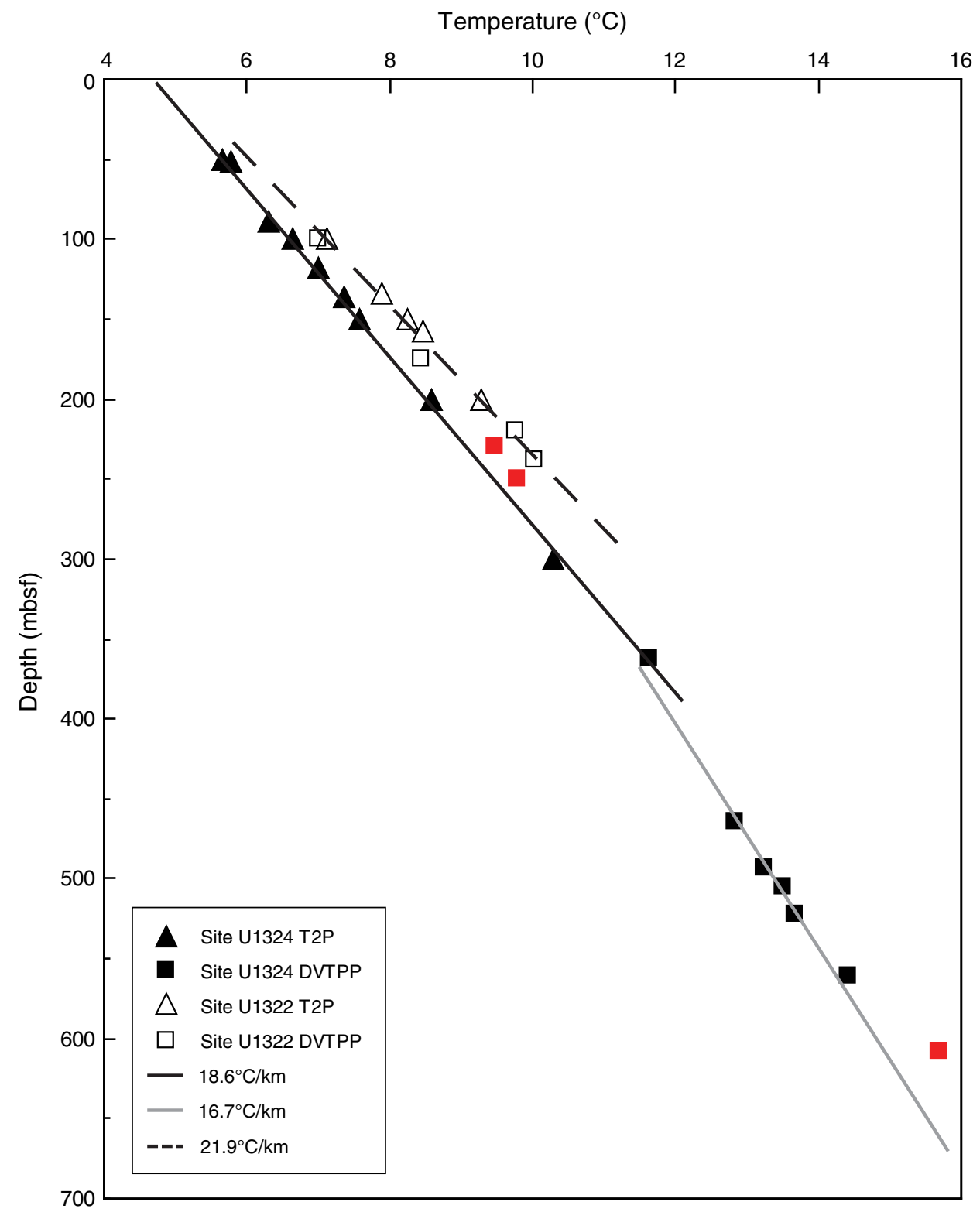


Figure F10. Pore pressure measurements, Site U1319. Hydrostatic pressure calculated starting from the seafloor assuming a seawater density of $1.024 \mathrm{~g} / \mathrm{cm}^{3}$. Bulk density data from shipboard moisture and density (MAD) measurements were integrated to calculate the overburden stress. The static pressure resulting from the water column above seafloor was subtracted from the pressure results. A. Porosity obtained from shipboard MAD measurement. B. Last recorded penetrometer pressure measurement (Table T2). C. In situ pore pressure estimated by $1 / t$ extrapolation (Table T2). D. In situ pore pressure estimated by $1 / \sqrt{t}$ extrapolation (Table T2). T2P = temperature/dual pressure probe.

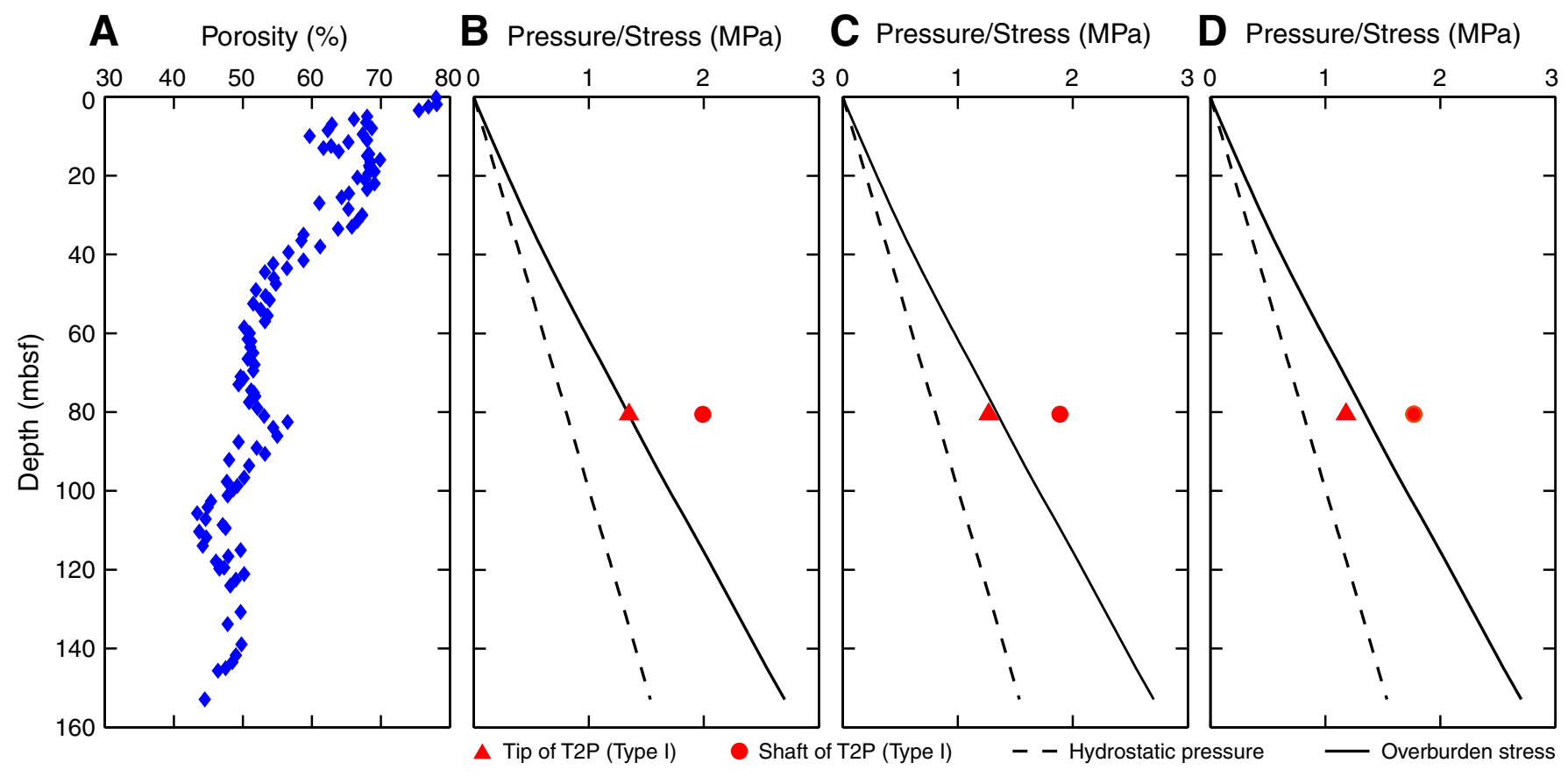


Figure F11. Pore pressure measurements, Site U1320. Hydrostatic pressure calculated starting from the seafloor assuming a seawater density of $1.024 \mathrm{~g} / \mathrm{cm}^{3}$. Bulk density data from shipboard moisture and density (MAD) measurements were integrated to calculate the overburden stress. The static pressure caused by the water column above seafloor was subtracted from the pressure results. A. Porosity obtained from shipboard MAD measurement. B. Last recorded penetrometer pressure measurement (Table T2). C. In situ pore pressure estimated by $1 / t$ extrapolation (Table T2). D. In situ pore pressure estimated by $1 / \sqrt{t}$ extrapolation (Table T2). T2P = temperature/dual pressure probe.

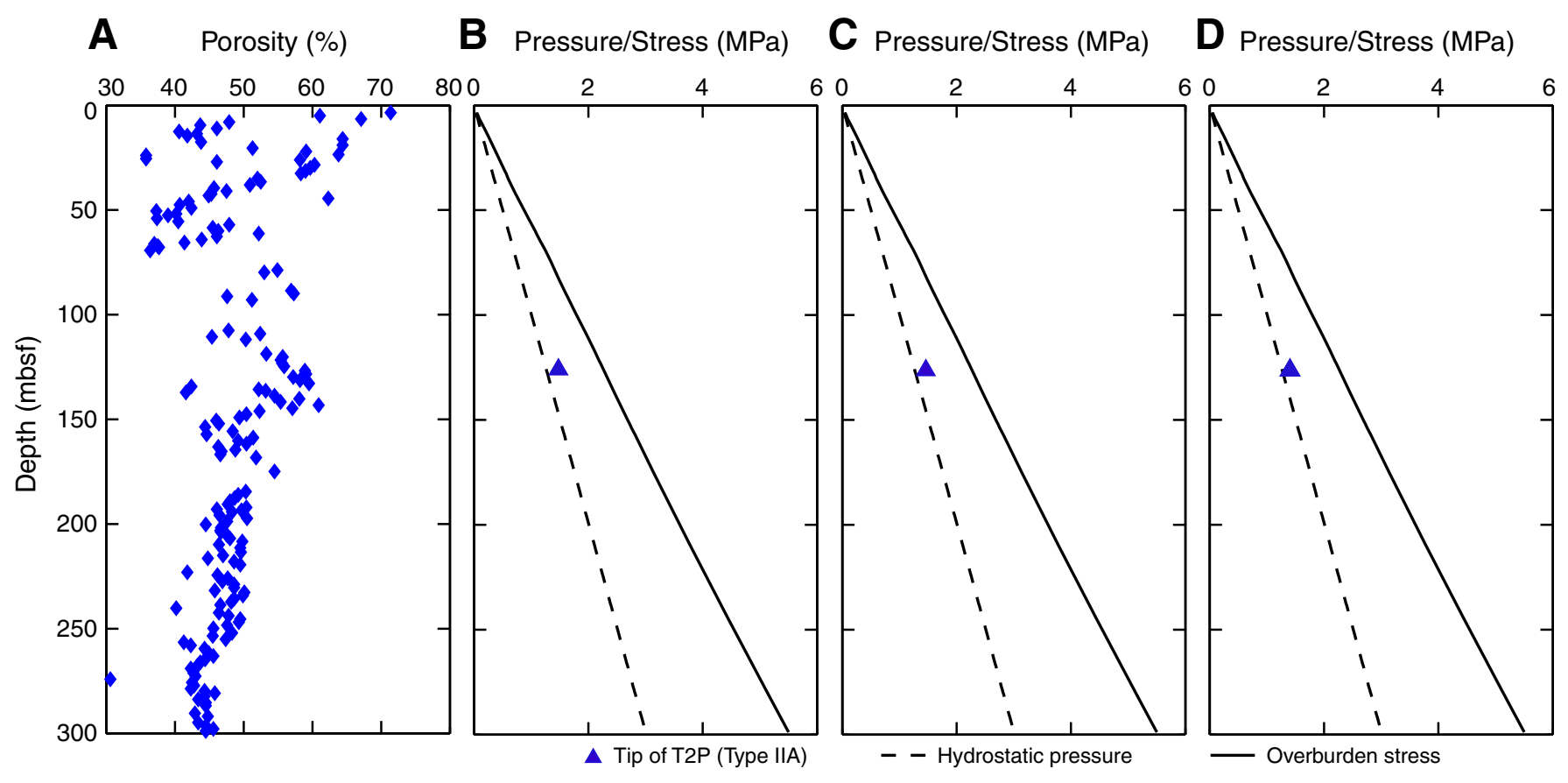


Figure F12. Pore pressure measurements, Site U1322. Hydrostatic pressure calculated starting from the seafloor assuming a seawater density of $1.024 \mathrm{~g} / \mathrm{cm}^{3}$. Bulk density data from shipboard moisture and density measurements (MAD) were integrated to calculate the overburden stress. The static pressure caused by the water column above seafloor was subtracted from the pressure results. A. Porosity obtained from shipboard MAD measurement. B. Last recorded penetrometer pressure measurement (Table T2). C. In situ pore pressure estimated by $1 / t$ extrapolation (Table T2). D. In situ pore pressure estimated by $1 / \sqrt{t}$ extrapolation (Table T2). Red = Type I deployment, blue $=$ Type IIA deployment, green $=$ Type IIB deployment. $\mathrm{T} 2 \mathrm{P}=$ temperature/dual pressure probe, DVTPP = Davis-Villinger Temperature-Pressure Probe.

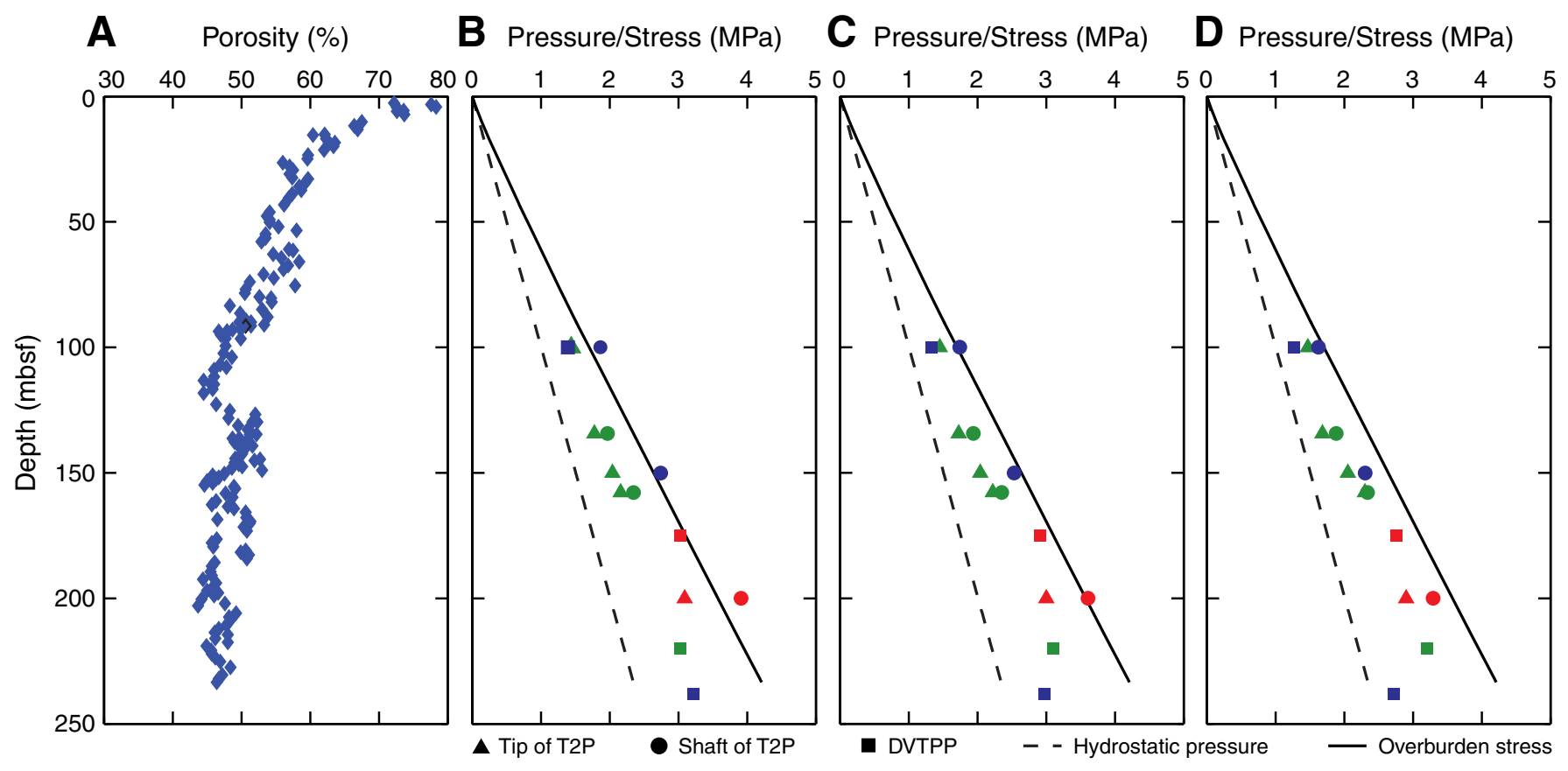


Figure F13. Pore pressure measurements, Site U1324. Hydrostatic pressure calculated starting from the seafloor assuming a seawater density of $1.024 \mathrm{~g} / \mathrm{cm}^{3}$. Bulk density data from shipboard moisture and density measurements (MAD) were integrated to calculate the overburden stress. The static pressure caused by the water column above seafloor was subtracted from the pressure results. A. Porosity obtained from shipboard MAD measurement. B. Last recorded penetrometer pressure measurement (Table T2). C. In situ pore pressure estimated by $1 / t$ extrapolation (Table T2). D. In situ pore pressure estimated by $1 / \sqrt{t}$ extrapolation (Table T2). Red = Type I deployment, blue $=$ Type IIA deployment, green $=$ Type IIB deployment. $\mathrm{T} 2 \mathrm{P}=$ temperature $/$ dual pressure probe, DVTPP = Davis-Villinger Temperature-Pressure Probe .

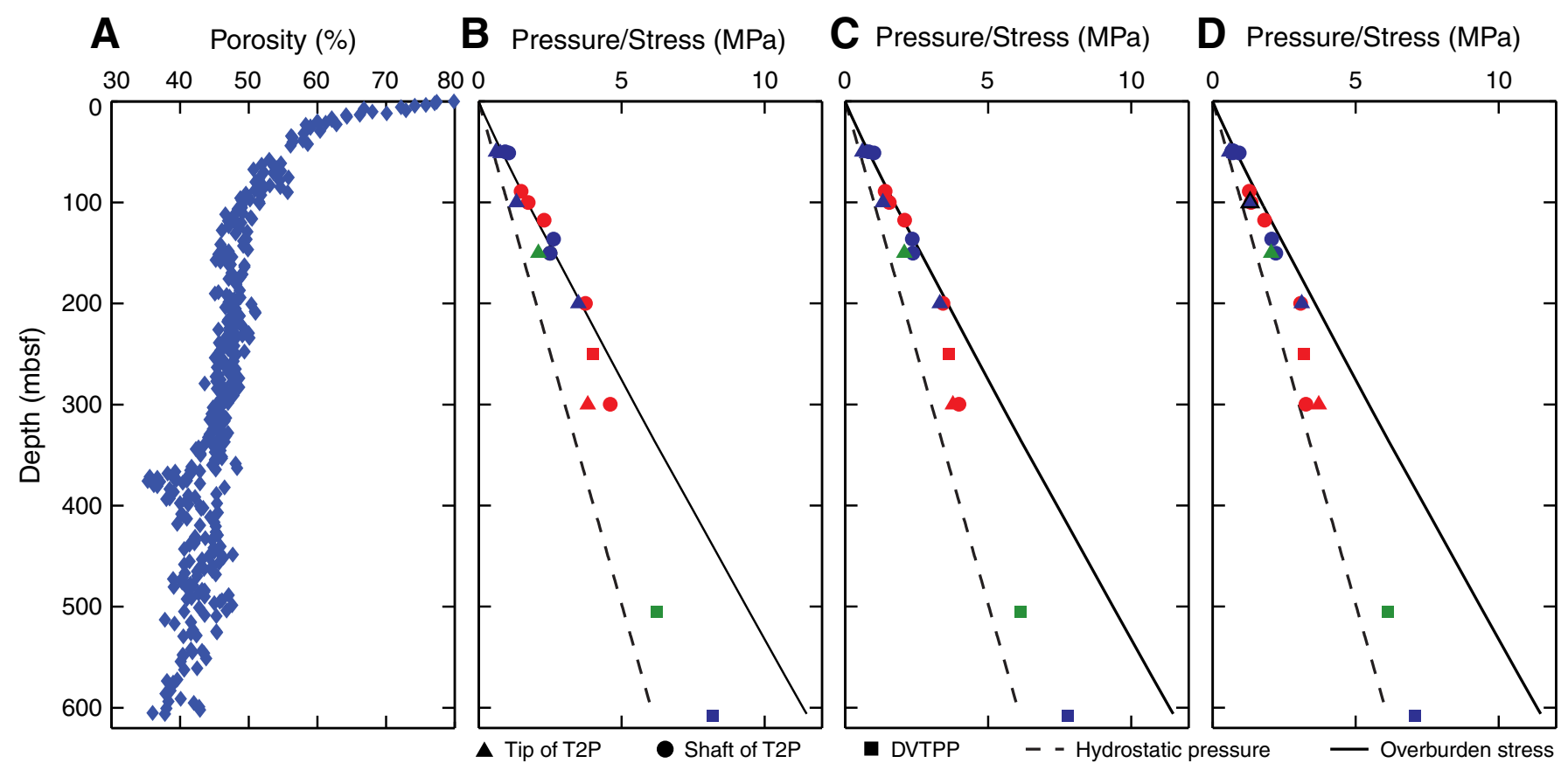


Figure F14. In situ pressure estimates by $1 / \sqrt{t}$ extrapolation in the upper 250 mbsf at Sites U1322 and U1324. The hydrostatic pressure is calculated starting from the seafloor assuming a seawater density of $1.024 \mathrm{~g} / \mathrm{cm}^{3}$. Bulk density data from shipboard moisture and density measurements were integrated to calculate the overburden stress. The static pressure caused by the water column above seafloor was subtracted from the pressure results. T2P = temperature/dual pressure probe, DVTPP = Davis-Villinger Temperature-Pressure Probe.

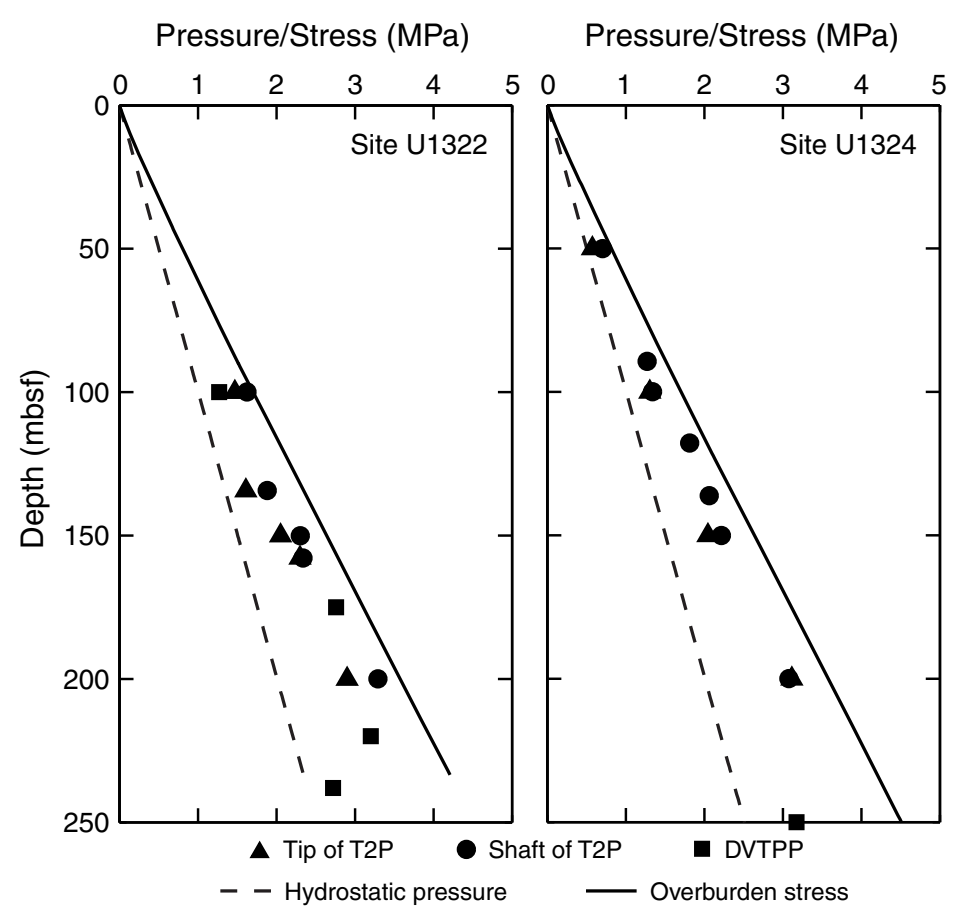


Table T1. Summary of the DVTPP and T2P deployments during IODP Expedition 308. (See table notes.) (Continued on next page.)

\begin{tabular}{|c|c|c|c|c|c|c|c|c|c|c|}
\hline \multirow{2}{*}{$\begin{array}{l}\text { Deployment } \\
\text { number }\end{array}$} & \multirow[b]{2}{*}{ Hole } & \multirow{2}{*}{$\begin{array}{c}\text { File } \\
\text { name }\end{array}$} & \multicolumn{2}{|c|}{ Depth } & \multirow{2}{*}{$\begin{array}{l}\text { TruView } \\
\text { data }\end{array}$} & \multirow{2}{*}{$\begin{array}{c}\text { Decay } \\
\text { time } \\
\text { (min) }\end{array}$} & \multirow[b]{2}{*}{ Type } & \multirow{2}{*}{$\begin{array}{l}\text { Date } \\
(2005)\end{array}$} & \multirow[b]{2}{*}{ Tool } & \multirow[b]{2}{*}{ Remarks } \\
\hline & & & (mbsf) & (mbsl) & & & & & & \\
\hline DVTP-P1 & U1320A & 1320a24 & 203.4 & 1673.4 & LF & 42 & III & 9 Jun & $9367 ; 88587 ; 0226-3$ & Hydraulic leak; tool vibrating during decay \\
\hline DVTP-P2 & U1320A & 1320a33 & 289.9 & 1759.9 & LF & 13 & III & 9 Jun & $9367 ; 88587 ; 0226-3$ & Hydraulic leak; tool vibrating during decay \\
\hline DVTP-P3 & U1324B & $1324 \mathrm{~b} 27$ & 229.1 & 1285.9 & & 50 & III & 22 Jun & $9367 ; 88587 ; 0226-3$ & Hydraulic leak; tool vibrating during decay \\
\hline DVTP-P4 & U1324B & $1324 \mathrm{~b} 45$ & 362.4 & 1419.2 & No match & 47 & III & 23 Jun & $9367 ; 88587 ; 0226-3$ & Hydraulic leak; good T \\
\hline DVTP-P5 & U1324B & & 387.9 & 1444.7 & NA & 10 & III & 23 Jun & & Failed; no data recorded \\
\hline DVTP-P6 & U1324B & 1324b59 & 464.3 & 1521.1 & No match & 34 & IIB & 24 Jun & $9368 ; 88579 ; 0226-2$ & Pullout/void; good T \\
\hline DVTP-P7 & U1324B & 1324b62 & 493.1 & 1549.9 & No match & 31 & III & 24 Jun & $9368 ; 88579 ; 0226-2$ & Dilatant soil?, good T \\
\hline DVTP-P8 & U1324B & 1324b64 & 521.9 & 1578.7 & $\mathrm{HF}$ & 41 & III & 24 Jun & $9368 ; 88579 ; 0226-2$ & Weird pressure; tool movements during decay \\
\hline DVTP-P9 & U1324B & & 541.1 & 1597.9 & & 30 & III & 25 Jun & & Programing error; no data recorded \\
\hline DVTP-P10 & U1324B & $1324 \mathrm{~b} 68$ & 560.4 & 1617.2 & $\mathrm{HF}$ & 32 & IIA & 25 Jun & $9367 ; 88587 ; 0226-3$ & Good T; unusual decay curve \\
\hline DVTP-P11 & U1324B & $1324 \mathrm{~b} 72$ & 589.2 & 1646.0 & $\mathrm{HF}$ & 45 & III & 25 Jun & $9367 ; 88587 ; 0226-3$ & Unreliable data \\
\hline DVTP-P12 & U1324B & $1324 \mathrm{~b} 74$ & 608.2 & 1665.0 & $\mathrm{HF}$ & 61 & IIA & 25 Jun & $9367 ; 88587 ; 0226-3$ & Pullout/void; tool vibrating during decay \\
\hline DVTP-P13 & U1324C & 1324c05 & 250 & 1305.7 & $\mathrm{HF}$ & 90 & I & 27 Jun & $9367 ; 88587 ; 0226-3$ & Tool vibrating during decay \\
\hline DVTP-P14 & U1324C & $1324 \mathrm{c} 07$ & 405 & 1460.7 & $\mathrm{HF}$ & 94 & III & 27 Jun & $9367 ; 88587 ; 0226-3$ & Pullout/void; communication with borehole \\
\hline DVTP-P15 & U1324C & $1324 \mathrm{c} 08$ & 505 & 1560.7 & $\mathrm{HF}$ & 93 & IIB & 28 Jun & $9367 ; 88587 ; 0226-3$ & $\begin{array}{l}\text { Pullout/void; commination with borehole?; further tool } \\
\text { insertion during decay }\end{array}$ \\
\hline DVTP-P16 & U1322B & $1322 \mathrm{~b} 19$ & 166.7 & 1486.2 & $\mathrm{HF}$ & 92 & III & 29 Jun & $9367 ; 88587 ; 0226-3$ & Pullout/void; commination with borehole \\
\hline DVTP-P17 & U1322C & 1322c02 & 100 & 1418.9 & LF & 91 & IIA & 1 Jul & $9368 ; 88579 ; 0226-2$ & Pullout/void; good T \\
\hline DVTP-P18 & U1322C & $1322 \mathrm{c} 03$ & 220 & 1538.9 & $\mathrm{HF}$ & 62 & IIB & $1 \mathrm{Jul}$ & $9368 ; 88579 ; 0226-2$ & Pullout/void; good T \\
\hline DVTP-P19 & U1322C & 1322c04 & 238 & 1556.9 & $\mathrm{HF}$ & 93 & IIA & $1 \mathrm{Jul}$ & $9368 ; 88579 ; 0226-2$ & Pullout/void; good T \\
\hline DVTP-P20 & U1322D & $1322 \mathrm{~d} 04$ & 175 & 1493.9 & $\mathrm{HF}$ & 60 & I & $2 \mathrm{Jul}$ & $9368 ; 88579 ; 0226-2$ & Type pressure/temperature decay \\
\hline T2P_1 & U1319A & t2p_1 & & & & & & 7 Jun & Sn4; S50-73; Z59-72; 0509-3; straight & Pressure test in water column \\
\hline T2P_2 & U1319A & t2p_2 & 80.5 & 1510.1 & LF & 35 & Tip: I; Shaft: I & 7 Jun & Sn4; S50-73; Z59-72; 0509-3; straight & $\begin{array}{l}\text { Tip broken; lost thermistor 3; insignificant pressure/temperature } \\
\text { response caused by pumping }\end{array}$ \\
\hline T2P_3 & U1320A & t2p_3 & 126.3 & 1596.3 & LF & 52 & Tip: IIA; Shaft: III & 8 Jun & Sn2; S50-75; S50-74; 0509-2; taper & $\begin{array}{l}\text { Tip bent; shaft had no response; insignificant pressure/ } \\
\text { temperature response caused by pumping }\end{array}$ \\
\hline $\mathrm{T} 2 \mathrm{P}_{-} 4$ & U1320A & t2p_4 & 213 & 1683.0 & LF & 25 & Tip: I; Shaft: III & 9 Jun & Sn4; S50-73; Z59-72; 0509-6; straight & $\begin{array}{l}\text { installed by its own weight; slight pressure and temperature } \\
\text { increase caused by pumping }\end{array}$ \\
\hline T2P_5 & U1324B & t2p_5 & 51.3 & 1108.1 & LF & 34 & Tip: IIA; Shaft: IIA & 21 Jun & Sn2; S50-75; Y67-16; 0509-2; straight & $\begin{array}{l}\text { Tip broken; lost thermistor } 2 \text {; slight pressure increase due to } \\
\text { pumping }\end{array}$ \\
\hline T2P_6 & U1324B & t2p_6 & 89.3 & 1146.1 & LF & 25 & Tip: III; Shaft: I & 21 Jun & Sn4; S50-73; Z59-72; 0509-6; taper & Further insertion caused by pumping; internal leak at tip \\
\hline T2P_7 & U1324B & t2p_7 & 117.8 & 1174.6 & LF & 31 & Tip: III; Shaft: I & 21 Jun & Sn4; S50-73; Z59-72; 0509-6; taper & Further insertion caused by pumping; internal leak at tip \\
\hline T2P_8 & U1324B & t2p_8 & 136.3 & 1193.1 & LF & 30 & Tip: III; Shaft: IIA & 22 Jun & Sn4; S50-73; Z59-72; 0509-6; taper & Shaft was not stable; internal leak at tip \\
\hline T2P_9 & U1324B & t2p_9 & 368 & 1424.8 & LF & 40 & Tip: III; Shaft: III & 23 Jun & Sn2; S50-75; S50-74; 0509-1; taper & Communication with borehole fluids \\
\hline T2P_10 & U1324B & $\mathrm{t} 2 \mathrm{p}_{-} 10$ & 394.5 & 1451.3 & & 30 & Tip: III; Shaft: III & 23 Jun & Sn2; S50-75; S50-74; 0509-1; taper & Lost communication with sensors \\
\hline T2P_11 & U1324B & $\mathrm{t} 2 \mathrm{p}_{-} 11$ & 593.2 & 1650.0 & Bad data & 15 & Tip: III; Shaft: III & 25 Jun & Sn4; S50-73; S50-74; 0509-6; taper & Tool test; weird T \\
\hline T2P_12 & U1324C & $\mathrm{t} 2 \mathrm{p} \_12$ & 50 & 1105.7 & LF & 60 & Tip: IIA; Shaft: IIA & 26 Jun & Sn4; S50-73; S50-74; 0509-6; taper & Slight pressure increase caused by pumping \\
\hline T2P_13 & U1324C & $\mathrm{t} 2 \mathrm{p}_{-} 13$ & 100 & 1155.7 & LF & 60 & Tip: IIA; Shaft: I & 26 Jun & Sn4; S50-73; S50-74; 0509-6; taper & Slight pressure pulses during decay \\
\hline T2P_14 & U1324C & $\mathrm{t} 2 \mathrm{p} \_14$ & 150 & 1205.7 & LF & 60 & Tip: IIB; Shaft: IIA & 26 Jun & Sn4; S50-73; S50-74; 0509-6; taper & Pressure perturbations during decay \\
\hline T2P_15 & U1324C & t2p_15 & 200 & 1255.7 & LF & 60 & Tip: IIA; Shaft: I & 27 Jun & Sn4; S50-73; S50-74; 0509-6; taper & Shaft has typical decay \\
\hline T2P_16 & U1324C & $\mathrm{t} 2 \mathrm{p}_{-} 16$ & 300 & 1355.7 & $\mathrm{HF}$ & 90 & Tip: I; Shaft: I & 27 Jun & Sn2; Z59-72; S50-75; 0509-1; taper & Typical decay on both tip and shaft \\
\hline T2P_17 & U1322B & $\mathrm{t} 2 \mathrm{p}_{-} 17$ & 42 & 1361.5 & $\mathrm{HF}$ & 60 & Tip: III; Shaft: III & 28 Jun & Sn2; S50-74; S50-73; 0509-1; taper & Communication with borehole fluid \\
\hline T2P_18 & & & & & & & & 29 Jun & & Bench test \\
\hline T2P_19 & U1322B & t2p_19 & 134.3 & 1453.8 & $\mathrm{HF}$ & 30 & Tip: IIB; Shaft: IIB & 29 Jun & Sn2; S50-74; S50-73; 0509-1; taper & Nearly constant pressure during decay \\
\hline T2P_20 & U1322B & t2p_20 & 157.8 & 1477.3 & $\mathrm{HF}$ & 60 & Tip: IIB; Shaft: IIB & 29 Jun & Sn2; S50-75; S50-73; 0509-1; taper & Nearly constant shaft pressure during decay \\
\hline T2P_21 & U1322C & t2p_21 & 50 & 1368.9 & & 60 & Tip: III; Shaft: III & 30 Jun & Sn4; S50-72; S50-75; 0509-4; taper & Memory card was ajar; no data recorded \\
\hline T2P_22 & U1322C & t2p_22 & 75 & 1393.9 & & 60 & Tip: III; Shaft: III & 30 Jun & Sn2; S50-74; S50-73; 0509-1; taper & Flooded the electronics; no data recorded \\
\hline T2P_23 & U1322C & t2p_23 & 150 & 1468.9 & $\mathrm{HF}$ & 60 & Tip: IIB; Shaft: IIA & 1 Jul & Sn4; S50-72; S50-75; 0509-4; taper & TruView data are only available for decay phase \\
\hline T2P_24 & U1322C & t2p_24 & 200 & 1518.9 & $\mathrm{HF}$ & 60 & Tip: I; Shaft: I & $1 \mathrm{Jul}$ & Sn4; S50-72; S50-75; 0509-4; taper & Typical decay on both tip and shaft \\
\hline T2P_25 & U1322D & $\mathrm{t} 2 \mathrm{p} \_25$ & 40 & 1358.9 & N/A & 60 & Tip: III; Shaft: III & $2 \mathrm{Jul}$ & Sn4; S50-72; S50-75; 0509-4; taper & Communication with borehole fluid \\
\hline
\end{tabular}


Table T1 (continued).

\begin{tabular}{|c|c|c|c|c|c|c|c|c|c|c|}
\hline \multirow{2}{*}{$\begin{array}{l}\text { Deployment } \\
\text { number }\end{array}$} & \multirow[b]{2}{*}{ Hole } & \multirow{2}{*}{$\begin{array}{c}\text { File } \\
\text { name }\end{array}$} & \multicolumn{2}{|c|}{ Depth } & \multirow{2}{*}{$\begin{array}{c}\text { TruView } \\
\text { data }\end{array}$} & \multirow{2}{*}{$\begin{array}{c}\text { Decay } \\
\text { time } \\
(\mathrm{min})\end{array}$} & \multirow[b]{2}{*}{ Type } & \multirow{2}{*}{$\begin{array}{l}\text { Date } \\
(2005)\end{array}$} & \multirow[b]{2}{*}{ Tool } & \multirow[b]{2}{*}{ Remarks } \\
\hline & & & (mbsf) & (mbsl) & & & & & & \\
\hline T2P_26 & U1322D & t2p_26 & 70 & 1388.9 & LF & 45 & Tip: III; Shaft: III & $2 \mathrm{Jul}$ & Sn4; S50-72; S50-75; 0509-4; taper & Communication with borehole fluid \\
\hline T2P_27 & U1322D & t2p_27 & 100 & 1418.9 & $\mathrm{HF}$ & 45 & Tip: IIB; Shaft: IIA & $2 \mathrm{Jul}$ & Sn4; S50-72; S50-75; 0509-4; taper & Pullout/void \\
\hline T2P_28 & U1322D & t2p_28 & 134 & 1452.9 & $\mathrm{HF}$ & 45 & Tip: III; Shaft: III & $2 \mathrm{Jul}$ & Sn4; S50-72; S50-75; 0509-4; taper & Communication with borehole fluid; broken tip; bent drive tube \\
\hline
\end{tabular}

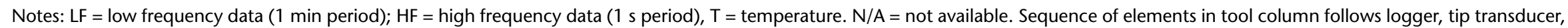
shaft transducer, thermistor, and geometry. Shaft transducer and geometry are not applicable for DVTPP. 
Table T2. In situ temperature and pressure results interpreted from the DVTPP and T2P deployments during IODP Expedition 308. (See table notes.)

\begin{tabular}{|c|c|c|c|c|c|c|c|c|c|c|c|}
\hline \multirow{2}{*}{$\begin{array}{c}\text { Deployment } \\
\text { number }\end{array}$} & \multirow[b]{2}{*}{ Hole } & \multicolumn{2}{|c|}{$\mathrm{BOH}$} & \multirow{2}{*}{$\begin{array}{c}u_{h} \\
(\mathrm{MPa})\end{array}$} & \multirow{2}{*}{$\begin{array}{c}\sigma_{\mathrm{v}} \\
(\mathrm{MPa})\end{array}$} & \multirow{2}{*}{$\begin{array}{l}\text { Decay time } \\
\quad \text { (min) }\end{array}$} & \multirow{2}{*}{$\begin{array}{c}\mu_{\text {end }} \\
(\mathrm{MPa})\end{array}$} & \multirow{2}{*}{$\begin{array}{c}\mu_{0}-1 / t \\
(\mathrm{MPa})\end{array}$} & \multirow{2}{*}{$\begin{array}{c}\mu_{0}-1 / \sqrt{t} \\
(\mathrm{MPa})\end{array}$} & \multicolumn{2}{|c|}{ Temperature $\left({ }^{\circ} \mathrm{C}\right)$} \\
\hline & & (mbsf) & (mbsl) & & & & & & & $T_{\text {end }}$ & $T_{1 / t}$ \\
\hline DVTP-P1 & U1320A & 203.4 & 1673.4 & 16.81 & 18.43 & 42 & & & & 9.22 & 9.10 \\
\hline DVTP-P2 & U1320A & 289.9 & 1759.9 & 17.68 & 20.09 & 13 & & & & 11.08 & 10.90 \\
\hline DVTP-P3 & U1324B & 229.1 & 1285.9 & 12.92 & 14.72 & 50 & & & & 9.49 & 9.47 \\
\hline DVTP-P4 & U1324B & 362.4 & 1419.2 & 14.26 & 17.26 & 47 & & & & 11.68 & 11.63 \\
\hline DVTP-P6 & U1324B & 464.3 & 1521.1 & 15.28 & 19.27 & 34 & 14.80 & 15.07 & 15.69 & 12.96 & 12.82 \\
\hline DVTP-P7 & U1324B & 493.1 & 1549.9 & 15.57 & 19.83 & 31 & & & & 13.40 & 13.25 \\
\hline DVTP-P8 & U1324B & 521.9 & 1578.7 & 15.86 & 20.39 & 41 & & & & 13.81 & 13.67 \\
\hline DVTP-P10 & U1324B & 560.4 & 1617.2 & 16.25 & 21.15 & 32 & 19.97 & 18.41 & 16.58 & 14.54 & 14.42 \\
\hline DVTP-P12 & U1324B & 608.2 & 1665.0 & 16.73 & 22.11 & 61 & 18.80 & 18.39 & 17.69 & 16.09 & 15.70 \\
\hline DVTP-P13 & U1324C & 250 & 1305.7 & 13.12 & 15.11 & 90 & 14.61 & 14.22 & 13.78 & 10.00 & 9.79 \\
\hline DVTP-P15 & U1324C & 505 & 1560.7 & 15.68 & 20.06 & 93 & 16.84 & 16.74 & 16.74 & 12.31 & 13.50 \\
\hline DVTP-P17 & U1322C & 100 & 1418.9 & 14.25 & 14.95 & 91 & 14.64 & 14.58 & 14.52 & 7.04 & 6.99 \\
\hline DVTP-P18 & U1322C & 220 & 1538.9 & 15.46 & 17.20 & 62 & 16.28 & 16.35 & 16.45 & 9.84 & 9.75 \\
\hline DVTP-P19 & U1322C & 238 & 1556.9 & 15.64 & 17.55 & 93 & 16.47 & 16.23 & 15.97 & 10.03 & 10.03 \\
\hline DVTP-P20 & U1322D & 175 & 1493.9 & 15.01 & 16.35 & 60 & 16.28 & 16.16 & 16.01 & 8.45 & 8.43 \\
\hline T2P_2 & U1319A & 80.5 & 1510.1 & 15.17 & 15.71 & 35 & $15.71 ; 16.35$ & $15.63 ; 16.25$ & $15.54 ; 16.13$ & 7.23 & \\
\hline T2P_3 & U1320A & 126.3 & 1596.3 & 16.04 & 17.04 & 52 & 16.27 & 16.23 & 16.17 & 6.99 & \\
\hline T2P_4 & U1320A & 213 & 1683.0 & 16.91 & 18.61 & 25 & & & & 8.99 & \\
\hline T2P_5 & U1324B & 51.3 & 1108.1 & 11.13 & 11.44 & 34 & $11.37 ; 11.65$ & $11.37 ; 11.61$ & $11.36 ; 11.54$ & 5.78 & \\
\hline T2P_6 & U1324B & 89.3 & 1146.1 & 11.51 & 12.11 & 25 & 12.09 & 12.00 & 11.88 & 6.31 & \\
\hline T2P_7 & U1324B & 117.8 & 1174.6 & 11.80 & 12.63 & 31 & 12.90 & 12.68 & 12.42 & 7.00 & \\
\hline T2P_8 & U1324B & 136.3 & 1193.1 & 11.99 & 12.98 & 30 & 13.23 & 12.96 & 12.67 & 7.35 & \\
\hline T2P_12 & U1324C & 50 & 1105.7 & 11.11 & 11.42 & 60 & $11.21 ; 11.56$ & $11.20 ; 11.44$ & $11.18 ; 11.31$ & 5.66 & \\
\hline T2P_13 & U1324C & 100 & 1155.7 & 11.61 & 12.30 & 60 & $11.93 ; 12.39$ & $11.92 ; 12.21$ & $11.91 ; 12.01$ & 6.65 & \\
\hline T2P_14 & U1324C & 150 & 1205.7 & 12.11 & 13.24 & 60 & $12.69 ; 13.10$ & $12.67 ; 12.97$ & $12.65 ; 12.82$ & 7.57 & \\
\hline T2P_15 & U1324C & 200 & 1255.7 & 12.61 & 14.18 & 60 & $14.09 ; 14.44$ & $13.91 ; 14.12$ & $13.72 ; 13.77$ & 8.58 & \\
\hline T2P_16 & U1324C & 300 & 1355.7 & 13.62 & 16.06 & 90 & $14.42 ; 15.20$ & $14.37 ; 14.58$ & $14.31 ; 13.87$ & 10.29 & \\
\hline T2P_19 & U1322B & 134.3 & 1453.8 & 14.60 & 15.60 & 30 & $15.08 ; 15.22$ & $15.02 ; 15.19$ & $14.95 ; 15.13$ & 7.89 & \\
\hline T2P_20 & U1322B & 157.8 & 1477.3 & 14.84 & 16.04 & 60 & $15.41 ; 15.60$ & $15.47 ; 15.60$ & $15.55 ; 15.59$ & 8.47 & \\
\hline T2P_23 & U1322C & 150 & 1468.9 & 14.76 & 15.89 & 60 & $15.29 ; 15.99$ & $15.29 ; 15.78$ & $15.30 ; 15.55$ & 8.26 & \\
\hline T2P_24 & U1322C & 200 & 1518.9 & 15.26 & 16.83 & 60 & $16.34 ; 17.16$ & $16.25 ; 16.86$ & $16.15 ; 16.54$ & 9.28 & \\
\hline T2P_27 & U1322D & 100 & 1418.9 & 14.25 & 14.95 & 45 & $14.69 ; 15.11$ & $14.70 ; 14.99$ & $14.72 ; 14.87$ & 7.11 & \\
\hline
\end{tabular}

Notes: $\mathrm{BOH}=$ bottom of hole. Only deployments used to interpret the in situ conditions are included in this table. The temperature/dual pressure (T2P) probe has two pressure ports. The T2P temperature reached equilibrium with the formation temperature at the end of the deployment; therefore, no extrapolation was applied. See Table T3 for heading definitions.

Table T3. Nomenclature.

\begin{tabular}{lll}
\hline Symbol & \multicolumn{1}{c}{ Definition } & \multicolumn{1}{c}{ Unit } \\
\hline$H_{\mathrm{w}}$ & Water depth at hole location & $\mathrm{L}$ \\
$P$ & Fluid pressure & $\mathrm{M} / \mathrm{L} / \mathrm{T}^{2}$ \\
$T$ & Temperature & $\theta$ \\
$t$ & Time & $\mathrm{T}$ \\
$\mathrm{g}$ & Acceleration of gravity & $\mathrm{M} / \mathrm{T}^{2}$ \\
$\mu_{0}$ & In situ pressure & $\mathrm{M} / \mathrm{L} / \mathrm{T}^{2}$ \\
$\mu_{\mathrm{h}}$ & Hydrostatic pressure & $\mathrm{M} / \mathrm{L} / \mathrm{T}^{2}$ \\
$\mu_{\text {end }}$ & Final pressure & $\mathrm{M} / \mathrm{L} / \mathrm{T}^{2}$ \\
$z$ & Target depth & $\mathrm{L}$ \\
$\lambda^{*}$ & Overpressure ratio & \\
$\rho_{\mathrm{c}}$ & Density of fluid with drilling cuttings & $\mathrm{M} / \mathrm{L}^{3}$ \\
$\rho_{\mathrm{m}}$ & Density of drilling mud & $\mathrm{M} / \mathrm{L}^{3}$ \\
$\rho_{\mathrm{w}}$ & Density of seawater & $\mathrm{M} / \mathrm{L}^{3}$ \\
$\sigma_{\mathrm{v}}$ & Overburden stress & $\mathrm{M} / \mathrm{L} / \mathrm{T}^{2}$ \\
\hline
\end{tabular}




\section{Appendix A}

\section{Davis-Villinger Temperature-Pressure Probe}

In Appendix A, we present the DVTPP deployments during Expedition 308, which includes five sections: (1) instruments that were used; (2) temperature calibration; (3) pressure calibration; (4) example DVTPP deployment showing the detailed deployment procedure; and (5) detailed description of each DVTPP deployment. Figures showing pressure, temperature, and TrueView data for each DVTPP deployment are in the "APP_A" folder in "Supplementary material."

\section{Instruments}

During Expedition 308, two data logger/pressure transducer/thermistor combinations were used: (1) logger 9368-PXDCR 88579-thermistor 0226-2 (DVTPP2) and (2) logger 9367-PXDCR 88587-thermistor 0226-3 (DVTPP3). In the "DOWNHOLE" folder in "Supplementary material," PXDCR 79481 and thermistor 0226-1 were listed together with logger 9367. However, this is not correct.

\section{Temperature calibration}

Temperature calibrations were carried out on the data logger and the thermistor separately. The data logger response to resistance was determined using a highly stable resistance box that simulates the resistance variation of the thermistor over its full temperature range. The calibration coefficients of the data logger were provided by the U.S. Implementing Organization (USIO) (Table AT1A). Table AT1B presents the commercial calibration of the thermistors. The Steinhart-Hart relationship is used to describe the temperature as a function of the thermistor resistance (Table AT1A) (Davis et al., 1997).

During Expedition 308, the DVTPP temperature data were not always reduced correctly. For example, the DVTPP3 temperature data was calibrated using the calibration coefficients of thermistor 0226-1 (see the "DOWNHOLE" folder in "Supplementary material"). However, thermistor 0226-1 was not used in either of the DVTPP tools that were deployed during Expedition 308. This problem was also reported during IODP Expedition 311 (A.M. Tréhu, pers. comm., 2007). In a similar fashion for DVTPP2, the temperature calibrations of several deployments were done using coefficients of thermistor 0226-1 or 0226-3 instead of 0226-2 (see the "DOWNHOLE" folder in "Supplementary material"). In this report, we recalculated the temperature for all deployments using the correct calibration coefficients provided by the USIO (Table AT1).

\section{Pressure calibration}

The calibration factors for all pressure transducers are illustrated in Table AT2. The calibration factors of the pressure transducers are stored in the central processing unit of the pressure interface module mounted to the DVTPP logger. Two frequency (or period) output signals are sent from the pressure transducer. Pressure is measured with a force-sensitive quartz crystal whose output period changes with applied load. A second period output comes from a quartz crystal temperature sensor used for temperature compensation. The last calibration of the two transducers was made in 2002 by the manufacturer (Table AT2).

In December 2006, the USIO performed a calibration verification of the DVTPP pressure transducers using a deadweight tester that was recently calibrated by the manufacturer. DVTPP2 and DVTPP3 recorded pressures 7 and 4 psi greater, respectively, than that measured by the deadweight tester. In this report, we subtracted the average atmosphere pressure recorded by the DVTPP from the pressure data. After the correction, the calibration offsets are excluded and the DVTPP pressure is comparable to the hydrostatic pressure calculated from an assumed seawater density of $1.024 \mathrm{~g} / \mathrm{cm}^{3}$ in which the atmosphere pressure is not accounted.

\section{DVTPP deployment procedure}

Every DVTPP deployment is slightly different. We present DVTPP Deployment 20 to illustrate our approach to interpreting the deployment history. This deployment was at 175 mbsf in Hole U1322D. The operational sequence for this deployment is illustrated in Table AT3, and a graphical representation of the pressure, temperature, coreline depth, block position, accelerometer, pump strokes, coreline tension, and hookload are illustrated in FIGUREA1_1322D04.XLS in the "APP_A" folder in "Supplementary material." For reasons that we do not understand, some of the bit depth data shifted during deployment. Instead, we use the traveling block position to constrain movements of the drill bit during tool deployment whenever it is available. The traveling block is attached to the top end of the drill string above the rig floor. Its position was recorded in meters above rig floor.

Prior to deployment, the BHA was located $5.5 \mathrm{~m}$ above the bottom of the hole (BOH). The DVTPP was connected to the CDS and lowered into the borehole with the wireline (Event 1). The DVTPP was stopped at the seafloor for $5 \mathrm{~min}$ to record the fluid pressure and temperature in the pipe (Event 2). Fluid circulation was stopped during the tool stop to remove the effect of pump pressure on the measured pressure. 
The pump flux is proportional to the pump stroke rate (1.654 gal/stroke) (Graber et al., 2002).

The CDS was then lowered by wireline (Event 3). At this time, the CDS was fully extended and hanging inside the drill pipe. The BHA was moved downward to $7 \mathrm{~m}$ above $\mathrm{BOH}$ (Event 4 ). As the CDS approached the BHA, it was decelerated and slowly lowered to latch into the BHA. This can be identified by a sharp decrease in coreline tension (Event 5). For this deployment, when fully extended the CDS was 21.84 $\mathrm{m}$ including the DVTPP probe. When the CDS was fully retracted, the tip of the DVTPP extended $1.1 \mathrm{~m}$ below the BHA. This length can vary depending on how many spacers $(92 \mathrm{~cm}$ long) are connected to the DVTPP. The CDS was retracted $\sim 2 \mathrm{~m}$ when latched in (Event 5).

Next, the BHA was lowered to further retract the CDS stoke (Event 6). The probe was pushed into the formation. This induced increases in pressure and temperature after the CDS was fully retracted. The operator stopped the insertion when the hookload dropped by $\sim 5,000 \mathrm{lb}$ (Event 7), indicating that the $\mathrm{BHA}$ reached $\mathrm{BOH}$ or that the formation is too firm for further penetration. In this case, the probe was pushed $\sim 1.1 \mathrm{~m}$ into the formation. Subsequently, the BHA was raised $2.4 \mathrm{~m}$ and the CDS was partially extended to decouple the DVTPP from the BHA (Event 8).

In this deployment, the tool was left in place for 60 min. Tool acceleration was recorded during the deployment, which is a measure of tool movement during the dissipation phase. The tool was then recovered by wireline (Event 9) and stopped at the mudline for $5 \mathrm{~min}$ to register the fluid pressure in the pipe (Event 10).

\section{DVTPP deployments during Expedition 308}

\section{Deployment 1: Hole U1320A, 203.4 mbsf}

Table AT4 and FIGUREA2_1320A24.XLS in the "APP_A" folder in "Supplementary material" present the sequence of operations and the tool response to particular events for DVTPP Deployment 1. Fluid circulation was kept on for the entire deployment. The tool was stopped at the seafloor for $10 \mathrm{~min}$ to record the fluid pressure in the pipe. When the probe was pushed into the formation, the temperature and pressure increased. After the penetration pressure pulse, the pressure decreased rapidly and erratically. The last pressure reading was $1 \mathrm{MPa}$ less than the hydrostatic pressure.

We interpreted that this was caused by an internal hydraulic leak in the DVTPP; when pressure reached a high value, fluid leaked into the pressure housing, causing a rapid decrease. The pressure then slowly increased and leakage once again occurred. Because of the internal leak, no in situ pressure can be ascertained. Unfortunately, this internal leak was not identified and fixed until DVTPP Deployment 4. The temperature record appears reasonable. The last temperature reading was $10.2^{\circ} \mathrm{C}$. However, the accelerometer recorded slight tool movement throughout the dissipation phase. The tool movements resulted in a very slight oscillation (magnitude $<0.01^{\circ} \mathrm{C}$, period $\approx 50 \mathrm{~s}$ ) in the temperature record. This suggests minor coupling (through the CDS) with the BHA. The frictional heat caused by tool movement may have affected the temperature measurement.

\section{Deployment 2: Hole U1320A, 289.9 mbsf}

Table AT5 and FIGUREA3_1320A33.XLS in the "APP_A" folder in "Supplementary material" present the sequence of operations and the tool response to particular events for DVTPP Deployment 1. As the probe was pushed into the formation, the temperature and pressure increased. The pressure then decreased rapidly to less than the hydrostatic pressure. Once again, an internal leak is interpreted to be present; no in situ pressure can be inferred from Deployment 2 . The temperature record was reasonable, and the last temperature reading was $11.08^{\circ} \mathrm{C}$. The accelerometer recorded tool movements throughout the dissipation phase. The frictional heat caused by tool movement may have affected the temperature measurement.

\section{Deployment 3: Hole U1324B, 229.1 mbsf}

Table AT6 and FIGUREA4_1324B27.XLS in the "APP_A" folder in "Supplementary material" present the sequence of operations and the tool response to particular events for DVTPP Deployment 3. The TruView data are missing for this deployment. Key deployment events are derived from the shipboard DVTPP Downhole Tool Data Sheet (see the "DOWNHOLE" folder in "Supplementary material") and the pressure and temperature data.

When the probe was pushed into the formation, the temperature and pressure increased. After the penetration pressure pulse, the pressure decreased rapidly and erratically. Because of the internal leak, no in situ pressure could be inferred from Deployment 3. The temperature record looks reasonable, and the last temperature reading was $9.5^{\circ} \mathrm{C}$. The accelerometer recorded tool movements throughout the dissipation phase. The tool movements resulted in a slight oscillation (magnitude $\approx 0.05^{\circ} \mathrm{C}$, period $\approx 1 \mathrm{~min}$ ) in the temperature record. This most likely was due to some coupling between the BHA and the tool. The frictional heat caused by tool movement may have affected the temperature measurement. 
Deployment 4: Hole U1324B, 362.4 mbsf

Table AT7 and FIGUREA5_1324B45.XLS in the "APP_A" folder in "Supplementary material" present the sequence of operations and the tool response to particular events for DVTPP Deployment 4 . The TruView data do not match this deployment. Key deployment events are derived from the shipboard DVTPP Downhole Tool Data Sheet (see the "DOWNHOLE" folder in "Supplementary material") and the pressure and temperature data.

As the pressure decay started, the pressure decreased rapidly and erratically. This was the fourth consecutive deployment where erratic pressures were recorded. After this deployment the tool was inspected and an internal hydraulic leak was found and fixed. No in situ pressure could be inferred from Deployment 4 because of the leak. The temperature record was reasonable, and the last reading was $11.68^{\circ} \mathrm{C}$. The temperature record had a very slight oscillation (magnitude $\approx 0.01^{\circ} \mathrm{C}$, period $\approx 1 \mathrm{~min}$ ) during the dissipation phase, whereas the accelerometer did not record significant tool acceleration. This indicates some minor coupling between the BHA and the tool.

\section{Deployment 5: Hole U1324B, 387.9 mbsf}

No data were recorded for this deployment.

\section{Deployment 6: Hole U1324B, 464.3 mbsf}

Table AT8 and FIGUREA6_1324B59.XLS in the "APP_A" folder in "Supplementary material" present the sequence of operations and the tool response to particular events for DVTPP Deployment 6. The TruView data do not match this deployment. Key deployment events are derived from the shipboard DVTPP Downhole Tool Data Sheet (see the "DOWNHOLE" folder in "Supplementary material") and the pressure and temperature data.

As the probe was pushed into the formation, the temperature and pressure increased (Table AT8). When the BHA was lifted to decouple the BHA through the CDS, the pressure decreased dramatically to subhydrostatic pressure. A pressure rebound then occurred. We interpret that the tool was pulled up with the BHA, creating a void around the probe tip. As the void equilibrated with the formation, the pressure increased to $14.86 \mathrm{MPa}$ at the end of the deployment. This deployment recorded a good temperature decay curve. The last temperature reading was $12.96^{\circ} \mathrm{C}$.

\section{Deployment 7: Hole U1324B, 493.1 mbsf}

Table AT9 and FIGUREA7_1324B62.XLS in the "APP_A" folder in "Supplementary material" present the sequence of operations and the tool response to particular events for DVTPP Deployment 7. The TruView data do not match this deployment. Key deployment events are derived from the onboard DVTPP Downhole Tool Data Sheet (see the "DOWNHOLE" folder in "Supplementary material") and the pressure and temperature profiles.

As the probe was pushed into the formation, the temperature and pressure increased (Table AT9). After penetration, the pressure decreased to a value significantly below hydrostatic pressure and then slowly rebounded to a final value of $12.72 \mathrm{MPa}$. The pressure data may be explained by either a slow tool pullout after penetration or penetration in a dilatant sediment. Core photos show that the sediment at this location is clayey silt to silt. Probe penetration could generate an annular dilation zone around the probe, which could have significant negative excess pore pressure. The drop to subhydrostatic pressure may reflect this negative excess pore pressure migrating to the pressure port. The temperature record looks very good, and the last temperature reading was $13.4^{\circ} \mathrm{C}$.

\section{Deployment 8: Hole U1324B, 521.9 mbsf}

Table AT10 and FIGUREA8_1324B64.XLS in the "APP_A" folder in "Supplementary material" present the sequence of operations and the tool response to particular events for DVTPP Deployment 8. The measured pore pressure was less than the hydrostatic pressure throughout the deployment, and there was no record of penetration. As a result, during the next DVTPP deployment, the DVTPP3 was deployed and the DVTPP2 was rebuilt.

The temperature record was reasonable. The last temperature reading was $13.84^{\circ} \mathrm{C}$. However, the DVTPP Downhole Tool Data Sheet (see the "DOWNHOLE" folder in "Supplementary material") documented a tool pullout operation $5 \mathrm{~min}$ after the end of the penetration. At this time, the BHA moved upward $4 \mathrm{~m}$ and the hookload increased. The BHA then moved upward $2 \mathrm{~m}$ and lowered and raised again. All of this occurred during the dissipation phase. The raising and lowering of the BHA were recorded by increases and decreases in the hookload and the accelerometer record. The thermistor did not record any significant temperature change during those operations. A second pullout occurred $41 \mathrm{~min}$ after the penetration. These observations suggest that the first "pullout" and the following bit movements were within the retraction/extension limit of the CDS and thus did not cause significant tool movement.

\section{Deployment 9: Hole U1324B, 541.1 mbsf}

A programming error occurred during this deployment and no data were recorded. 
Deployment 10: Hole U1324B, 560.4 mbsf

Table AT11 and FIGUREA9_1324B68.XLS in the "APP_A" folder in "Supplementary material" present the sequence of operations and the tool response to particular events for DVTPP Deployment 8. Pressure and temperature both increased sharply during penetration. When the BHA was lifted to decouple the BHA, the pressure decreased rapidly by $\sim 1 \mathrm{MPa}$ and then decayed to a value of $20 \mathrm{MPa}$ while the tool was in the formation. The pressure decayed linearly with time, which was unusual. Additionally, the pressure did not decrease to atmospheric pressure when the DVTPP was raised to the rig floor. In situ pressure may not be inferred from this deployment. The temperature decreased to $15.69^{\circ} \mathrm{C}$ prior to pullout.

\section{Deployment 11: Hole U1324B, 589.2 mbsf}

Table AT12 and FIGUREA10_1324B72.XLS in the "APP_A" folder in "Supplementary material" present the sequence of operations and the tool response to particular events for DVTPP Deployment 11. The temperature and pressure sensors both recorded unreliable data during this deployment.

\section{Deployment 12: U1324B, 608.2 mbsf}

Deployment 12 was completed at the base of the hole. Table AT13 and FIGUREA11_1324B74.XLS in the "APP_A" folder in "Supplementary material"present the sequence of operations and the tool response to particular events for this deployment. The pressure increased during penetration and then quickly declined, followed by a rapid recovery. The bit movement and acceleration record suggest that the quick pressure drop was related to the decoupling of the tool from the drill string after the insertion, and the rapid recovery was due to reset of the tool on its own weight. The pressure then followed a dissipation profile to a final pressure of $18.9 \mathrm{MPa}$. The temperature record continuously decayed to a low value of $17.2^{\circ} \mathrm{C}$ and then slightly increased to $17.34^{\circ} \mathrm{C}$. The last temperature reading was $17.15^{\circ} \mathrm{C}$. The accelerometer recorded tool movements throughout the dissipation phase. We interpret a coupling between the BHA and the tool. The oscillating pressure and the odd temperature record were caused by tool movements.

\section{Deployment 13: Hole U1324C, 250 mbsf}

Table AT14 and FIGUREA12_1324C05.XLS in the "APP_A" folder in "Supplementary material" present the sequence of operations and the tool response to particular events for DVTPP Deployment 13. Similar to Deployment 12, this deployment also recorded tool movement during the dissipation phase. No sharp pressure drop was recorded when the drill bit was raised after insertion. The temperature record increased slightly during the dissipation phase, and the last temperature reading was $11.01^{\circ} \mathrm{C}$. This reading may not reflect the formation temperature due to the influence of the tool movement. The pressure also slightly increased during dissipation and then subsided to an end value of $14.7 \mathrm{MPa}$. This pressure increase may affect the estimate of the formation pressure.

\section{Deployment 14: Hole U1324C, 405 mbsf}

Table AT15 and FIGUREA13_1324C07.XLS in the "APP_A" folder in "Supplementary material" present the sequence of operations and the tool response to particular events for DVTPP Deployment 14. The tool insertion generated a relatively small pressure pulse for this depth. The pressure dropped rapidly when the drill bit was lifted. The pressure then rebounded to a final value of $15.82 \mathrm{MPa}$, which was very close to the recorded pressure at $\mathrm{BOH}$ prior to the penetration. The temperature increased when the drill bit was lifted and then decreased rapidly to a value close to the borehole fluid temperature. Near the end of the deployment, the temperature increased to a final value of $11.38^{\circ} \mathrm{C}$. The temperature increase was most likely due to tool movement, which can be identified on the acceleration data. We interpret that tool dislodgement weakened the seal around the probe and created communication with the borehole fluid. The sensors recorded the pressure and temperature of the borehole fluids instead of in situ conditions.

\section{Deployment 15: Hole U1324C, 505 mbsf}

Table AT16 and FIGUREA14_1324C08.XLS in the "APP_A" folder in "Supplementary material" present the sequence of operations and the tool response to particular events for DVTPP Deployment 15. Similar to Deployment 14, the tool insertion generated a relatively small pressure pulse for this depth. The pressure decreased rapidly when the drill bit was lifted. The pressure then rebounded to a nearly constant value. The temperature only slightly decreased after penetration and then increased to a high value (higher than its penetration temperature) at the end of the deployment. We interpreted that the tool surface temperature was lower than the formation temperature during penetration. The tool temperature had to increase to equilibrate with the formation. The end temperature was $13.5^{\circ} \mathrm{C}$.

\section{Deployment 16: Hole U1322B, 166.7 mbsf}

Table AT17 and FIGUREA15_1322B19.XLS in the "APP_A" folder in "Supplementary material" pres- 
ent the sequence of operations and the tool response to particular events for DVTPP Deployment 16. The temperature and pressure increased when the CDS latched in position. This suggests that the tip went into the formation slightly while the CDS was latching in. When the drill bit was lowered to insert the tool, it recorded a second temperature and pressure increase. Pressure decreased rapidly when the drill bit was lifted. The pressure then quickly rebounded to a near-constant value that was very close to the recorded pressure at $\mathrm{BOH}$ prior to penetration. There may have been communication with the borehole fluid. The temperature dropped rapidly and then slowly increased to $9.06^{\circ} \mathrm{C}$. The end temperature of $9.06^{\circ} \mathrm{C}$ was not representative of in situ conditions.

\section{Deployment 17: Hole U1322C, 100 mbsf}

Table AT18 and FIGUREA16_1322C02.XLS in the "APP_A" folder in "Supplementary material" present the sequence of operations and the tool response to particular events for DVTPP Deployment 17. The bit depth dramatically shifted during this deployment, and the block position data are not available. The pressure decreased rapidly after the insertion spike and then slowly dissipated to a final value of $14.73 \mathrm{MPa}$. This dissipation curve may be extrapolated to estimate in situ pressure. The temperature record had good insertion spike and continuous decay curve. The last temperature reading was $7.04^{\circ} \mathrm{C}$.

\section{Deployment 18: Hole U1322C, 220 mbsf}

Table AT19 and FIGUREA17_1322C03.XLS in the "APP_A" folder in "Supplementary material" present the sequence of operations and the tool response to particular events for DVTPP Deployment 18. The pressure increased during penetration and then decreased abruptly when the drill bit was lifted. The pressure then rebounded slowly to a final value of 16.36 MPa. Modeling of the rebound curve may constrain the in situ pressure. The temperature record had good insertion spike and continuous decay curve. The temperature decayed to $9.11^{\circ} \mathrm{C}$ at the end of deployment.

\section{Deployment 19: Hole U1322C, 238 mbsf}

Table AT20 and FIGUREA18_1322C04.XLS in the "APP_A" folder in "Supplementary material" present the sequence of operations and the tool response to particular events for DVTPP Deployment 19. The pressure increased during penetration and decreased abruptly when the bit was picked up off $\mathrm{BOH}$. Pressure then slowly dissipated to a final value of 16.55 $\mathrm{MPa}$. Extrapolation of the pressure record may provide an estimate of the in situ pressure. The temperature record had good insertion spike and continuous decay curve. The temperature decayed to $10.03^{\circ} \mathrm{C}$ at the end of deployment.

\section{Deployment 20: Hole U1322D, 175 mbsf}

Table AT3 and FIGUREA1_1322D04.XLS in the "APP_A" folder in "Supplementary material" present the sequence of operations and the tool response to particular events for DVTPP Deployment 20. Both pressure and temperature profiles had good insertion spikes and continuous decay curves. The pressure dissipated to $16.37 \mathrm{MPa}$ and the temperature dissipated to $8.68^{\circ} \mathrm{C}$ at the end of the deployment. Extrapolation of the pressure record will provide estimate of the in situ condition.

\section{Appendix B \\ Temperature/dual pressure probe}

This appendix presents the T2P deployments made during Expedition 308 in four parts: (1) instruments used; (2) temperature calibration; (3) pressure calibration; and (4) detailed description of each T2P deployment. Figures showing pressure, temperature, and TrueView data for each T2P deployment are in the "APP_B" folder in "Supplementary material."

\section{Instruments}

During Expedition 308, two types of penetrometer tips (Fig. F4), two data loggers, six pressure transducers, and five thermistors were used in combination to form the T2P probes that measured the formation pressure and temperature (Table T1).

\section{Temperature calibration}

Temperature calibrations were carried out on the data logger and thermistor separately. The data logger response to resistance was determined using a highly stable resistance box that simulates the resistance variation of the thermistor over its full temperature range. The calibration coefficients of the data logger were provided by the USIO prior to the expedition (Table AT21A). Table AT21B presents the commercial calibration of the thermistors prior to the cruise. Accuracy of the presented data is $\pm 0.05^{\circ} \mathrm{C}$ between $-40^{\circ}$ and $125^{\circ} \mathrm{C}$. The Steinhart-Hart relationship is used to describe the temperature as a function of the thermistor resistance (Table AT21A) (Davis et al., 1997).

\section{Pressure calibration}

The T2P measures pore pressure with steel pressure transducers. The force on the sensing element due to the pressure results in a deformation of the sensing element and a change in the output signal. 


\section{Onboard calibration}

Five out of six pressure transducers were calibrated using a witness pressure transducer provided by the USIO and a high-pressure oil pump in the downhole tools laboratory on the drillship prior to deployment. We ran the pump pressure from atmospheric pressure to 5000 psi and then stepped down to atmospheric pressure. The hysteresis was insignificant (Fig. AF1). The calibration curve is a straight line that can be characterized by its slope and its intersection on the $y$-axis (Fig. AF1; Table AT22).

\section{Problems in the pressure calibration}

All transducers were flooded with seawater whenever the tip of the T2P was broken. The seawater that leaked into the transducer weakened the insulation of the circuit inside the transducer, and the transducers became unstable, rendering the original pressure calibrations invalid.

To remove the moisture and stabilize the pressure transducers on the drill ship, the transducers were oven-dried at up to $60^{\circ} \mathrm{C}$ for up to $24 \mathrm{~h}$ before reuse. After oven drying, the slope of the calibration curve showed no significant change, but the intersection on the $y$-axis was subject to change (Table AT22). We did not recalibrate the transducers each time after being flooded. Therefore, we needed a systematic approach to correct any potential errors related to the change of the intersection as a result of oven drying.

Furthermore, analysis of pressure data calibrated according to the onboard calibrations showed that certain transducers were very sensitive to operating temperature. As an example, for onboard pressure calibration of T2P Deployment 1 (a tool test in water column) (see FIGUREB7_T2P_DEPLOY1.XLS in the "APP_B" folder in "Supplementary material") the measurements were made at temperatures from $4^{\circ}$ to $27^{\circ} \mathrm{C}$. The tip pressure reading was in good agreement with the hydrostatic pressure calculated by assuming an average fluid density of $1.024 \mathrm{~g} / \mathrm{cm}^{3}$. The shaft pressure reading matched the tip pressure closely at $\sim 20^{\circ} \mathrm{C}$, the temperature at which the transducers were calibrated. However, at significantly colder temperature, there was discrepancy between the tip and shaft pressures. The discrepancy varied with water temperature, up to $0.6 \mathrm{MPa}$ at $\sim 5^{\circ} \mathrm{C}$. In this example, the shaft pressure transducer was much more sensitive to temperature than the tip transducer.

The "compensated temperature range" of the T2P pressure transducers is from $25^{\circ}$ to $235^{\circ} \mathrm{C}$. Out of this range, the slope $(S)$ and intersection (I) of the calibration curve are subject to change because of variation in temperature (Fig. AF2). The onboard calibrations were done at the room temperature of the downhole tools laboratory on the vessel. These calibrations are not sufficient to describe the behavior of the transducers over the operating temperature range of the tool. Therefore, the temperature influence on the calibration curve must be tested to achieve accurate pressure calibration.

\section{Postcruise calibration}

Two pressure transducers were lost during postcruise shipment between laboratories. We checked the performance of the four available transducers before the recalibration. They were not stable and performed differently on different channels and data loggers. This was similar to the behavior observed immediately after transducers were flooded on the ship. We interpret this as being caused by the salt left in the transducers when they were flooded during deployments.

To correct for this problem, the transducers were baked at $55^{\circ} \mathrm{C}$ in an oven prior to recalibration to stabilize the transducers. Three of the four available transducers were very stable after oven drying.

In March 2007, we recalibrated the T2P pressure transducers using the same deadweight tester that was used to verify the calibrations of the DVTPP pressure transducers (see "Appendix A"). Calibrations were conducted at controlled temperatures to explore the influence of temperature on the slope and intersection of the calibration curve.

We ran the deadweight tester pressure from atmospheric pressure to 4015 psi and then stepped down to atmospheric pressure. The hysteresis was insignificant and the calibration curves were straight lines (Fig. AF3). No significant difference was observed between loggers Sn 2 and Sn 4 or between the tip pressure channel and the shaft pressure channel.

The results show that the slope and intersection of the calibration curve are linear functions of temperature (Figs. AF4, AF5, AF6). These relationships allow us to confidently interpret the calibration coefficients (slope and intersection of the calibration curve) for any given temperature within the range.

\section{Recalibration of the T2P pressure data}

We present the T2P deployment in the water column (T2P 1) to illustrate how we recalibrated the T2P pressure data using the postcruise calibrations (see FIGUREB7_T2P_DEPLOY1.XLS in the "APP_B" folder in "Supplementary material"). The two pressure transducers (S50-73 at the tip and Z59-72 at the shaft) were recalibrated under controlled temperatures. We used the temperature measured at the T2P tip thermistor to determine the calibration coeffi- 
cients from the trendlines in Figures AF4 and AF5. We then applied the calibration coefficients to calculate the pressure from the transducer reading.

Neither of the calculated tip and shaft pressures match the hydrostatic pressures at the tool stops. We interpret this is caused by changes of the intersection due to oven drying (Table AT22). The offset from hydrostatic pressure is a constant value regardless of the operating temperature for both transducers. This suggests that the change in the intersection caused by the effects of oven drying is constant for any given deployment (e.g., a constant vertical shift of the $I-T$ relationship presented in Figs. AF4B, AF5B, and AF6B).

The offset was corrected by matching the tip and shaft pressure records to the hydrostatic pressure at tool stops. After this correction, the tip pressure matches the shaft pressure very well. The hydrostatic pressures at tool stops are calculated from an assumed seawater density of $1.024 \mathrm{~g} / \mathrm{cm}^{3}$ in which the atmosphere pressure is not accounted.

For the three pressure transducers not recalibrated under controlled temperatures, we applied the calibration coefficients obtained from the onboard calibration tests (Table AT22). We then compared these to the pressure data of one of the recalibrated transducers (S50-73, S50-75, and Z59-72). We took the difference between the tip and the shaft pressures as a function of the temperature measured at the probe tip. The temperature influence and the shift of the intersection (a constant value) were then compensated by applying this function (see FIGUREB15_T2P_DEPLOY8.XLS and FIGUREB22_T2P_DEPLOY16.XLS in the "APP_B" folder in "Supplementary material").

\section{T2P deployment procedure}

The deployment procedure of the T2P is similar to that of the DVTPP (see "Appendix A"). We integrate TruView data, the shipboard T2P Deployment Log Sheet (see the "DOWNHOLE" folder in "Supplementary material"), and pressure and temperature records to define operation events and understand field measurements.

\section{T2P deployments during Expedition 308}

\section{Deployment 1: Hole 1319A, tool test in water column}

Deployment 1, completed in the water column prior to drilling, was the first sea deployment of the T2P probe. The deployment was intended to pressure test the T2P probe, to check the pressure transducer calibrations, and to confirm that the T2P probe could successfully pass through the lockable flapper valve (LFV) of the BHA.
The time-event log for T2P Deployment 1 is illustrated in Table AT23, and a graphical representation of the pressure and temperature records is illustrated in FIGUREB7_T2P_DEPLOY1.XLS in the "APP_B" folder in "Supplementary material." The T2P was lowered until the tip was 511 meters below sea level (mbsl), where a hydrostatic reference was recorded for $2 \mathrm{~min}$. The tool was then lowered until the tip was at 1011 mbsl for another 2 min reference. The T2P probe was then lowered through the LFV. The T2P probe tip reached a maximum depth of 1387.5 mbsl (42.1 $\mathrm{m}$ above seafloor), where a $7 \mathrm{~min}$ reference was recorded. References were also taken during retrieval of the T2P probe when the tip was at 1010 mbsl and at 511 mbsl. No drilling fluid was circulated during the deployment.

The tool test was successful. The tool recorded pressure and temperature for the entire deployment and successfully passed through the LFV. The temperature record showed a downhole decrease in temperature to $4.58^{\circ} \mathrm{C}$ at $1387.5 \mathrm{mbsl}$.

\section{Deployment 2: Hole U1319A, 80.5 mbsf}

Table AT24 and FIGUREB9_T2P_DEPLOY2.XLS in the "APP_B" folder in "Supplementary material" present the sequence of the operations and the tool response to particular events for T2P Deployment 2. Traveling block position data are not available for this deployment. The bit depth data dramatically shifted during this deployment. Drilling fluid circulation was stopped when taking the hydrostatic reference, when pushing the probe into the sediment, and for the first $12 \mathrm{~min}$ the T2P probe was in the sediment. Fluid circulation resumed $12 \mathrm{~min}$ after the penetration at 14 strokes per minute (spm). Corresponding to the onset of fluid circulation, both the tip and shaft pressures increased very slightly $(<0.01$ $\mathrm{MPa})$.

The temperature and pressure records increased when the CDS was latching into position (Table AT24). This response suggests the tool entered the formation while positioning the CDS to the retracted position. When the drill bit was lowered to insert the tool, it recorded a second temperature and pressure increase. Pressure and temperature records varied during the penetration process. We believe these variations were due to variations of the soil properties. After $35 \mathrm{~min}$ in the formation, pressure at the tip was $15.71 \mathrm{MPa}$, whereas the shaft recorded pressure of $16.35 \mathrm{MPa}$. Extrapolation of the pressure records may provide an estimate of the in situ pressure. The temperature record provided an in situ formation temperature of $7.23^{\circ} \mathrm{C}$ at the end of the deployment. 
When the T2P probe was recovered on the rig floor, the shroud was not covering the tip. The tip of the tool was damaged and the themistor was missing. The drive tube was bent slightly. We interpret that the shroud never reseated over the tip during retrieval of the tool. Damage of the tip was interpreted to result from bending of the tip during penetration followed by a straightening of the tip when the T2P probe was pulled through the LFV in the BHA. Most likely, the T2P probe and drive tube were damaged because the T2P probe did not enter the sediment vertically. To achieve vertical penetration, future deployments occurred with the drill bit $<2 \mathrm{~m}$ off $\mathrm{BOH}$ instead of $12 \mathrm{~m}$.

\section{Deployment 3: Hole U1320A, 126.3 mbsf}

Table AT25 and FIGUREB10_T2P_DEPLOY3.XLS in the "APP_B" folder in "Supplementary material" present the sequence of the operations and the tool response to particular events for T2P Deployment 3. In contrast to Deployment 2, Deployment 3 used the tapered needle probe and was initiated with the drill bit $\sim 1 \mathrm{~m}$ off $\mathrm{BOH}$. These modifications were done to decrease the chance for bending or breaking the needle probe. The quality of the bit depth data is poor. The absolute bit depth value is not reliable. To explore the bit movement during the deployment, the bit depth data have to be used together with Table AT25.

The T2P probe recorded temperature and pressure at the tip, whereas the shaft transducer did not record any data during the deployment. The temperature and pressure records increased while positioning the CDS to retracted position. When the drill bit was lowered to insert the tool, it recorded a second temperature and pressure increase. The tip pressure decreased abruptly when the drill bit was lifted. The fluid circulation resumed at $10 \mathrm{spm} 5 \mathrm{~min}$ after penetration. No significant pressure and temperature responses were observed as a result of the onset of fluid circulation. Pressure dissipation was recorded at the tip until the probe was pulled out of the formation. The last recorded pressure was $16.27 \mathrm{MPa}$. Extrapolation of the pressure records will provide an estimate of the in situ pressure. The temperature decay was continuous and provided an in situ formation temperature of $6.99^{\circ} \mathrm{C}$.

\section{Deployment 4: Hole U1320A, 213.0 mbsf}

Table AT26 and FIGUREB11_T2P_DEPLOY4.XLS in the "APP_B" folder in "Supplementary material" present the sequence of the operations and the tool response to particular events for T2P Deployment 4. Deployment 4 used the straight needle probe. Operational procedures were similar to Deployment 3 except we did not use the drill string to push the T2P into the formation. Instead, we used the weight of the tool to push the tool into the formation. The tip pressure and temperature recorded spikes during penetration by the tool weight, whereas the shaft pressure did not record any penetration response. This indicates that the shaft pressure port did not go into the formation throughout the deployment. Fluid circulation resumed 6 min after the insertion spike, causing slight increases in both pressure and temperature. The final tip pressure was $17.19 \mathrm{MPa}$, the same as the shaft pressure. This suggests that the borehole fluid communicated with the tip pressure because of the short penetration distance $(<0.25 \mathrm{~m})$. The temperature reached an equilibrium value of $8.99^{\circ} \mathrm{C}$. The temperature measurement may be subject to the influence of the borehole fluid.

\section{Deployment 5: Hole U1324B, 51.3 mbsf}

Table AT27 and FIGUREB12_T2P_DEPLOY5.XLS in the "APP_B" folder in "Supplementary material" present the sequence of the operations and the tool response to particular events for T2P Deployment 5. The bit depth data shift dramatically, whereas the bit movement directions match the bit movements recorded in the T2P log sheet. To explore the bit position during the deployment, the bit depth data should be used together with Table AT27.

The BHA was positioned $0.5 \mathrm{~m}$ off $\mathrm{BOH}$ before the CDS latch-in. The temperature and pressure records increased while positioning the CDS to the retracted position. According to the tool dimensions, the T2P tip went into the formation by $\sim 0.6 \mathrm{~m}$ at the latch-in position. The drill bit was lowered to $0.25 \mathrm{~m}$ off $\mathrm{BOH}$ at the end of penetration. The tool only recorded slight temperature and pressure increases due to the $0.25 \mathrm{~m}$ further insertion. The fluid circulation resumed $10 \mathrm{~min}$ after the penetration at $9 \mathrm{spm}$. Corresponding to the onset of fluid circulation, both the tip and shaft sensors recorded a slight pressure increase $(<0.05 \mathrm{MPa})$. The tip and shaft pressures were generally constant during the dissipation phase. The tip had a final pressure of $11.37 \mathrm{MPa}$, and the shaft had a final pressure of $11.65 \mathrm{MPa}$. The temperature record continuously decayed to an equilibrium temperature of $5.78^{\circ} \mathrm{C}$.

Upon pulling the tool out of the formation, all sensor readings were lost. At the rig floor, it was noted that the tip was bent and the thermistor and bottom porous stone were missing from the tool. We believed the tool may have been bent during penetration and then broken during the pullout when all sensor readings were lost. The pressure and temperature measurements should be viewed cautiously because of the damage incurred during the deployment. 


\section{Deployment 6: Hole U1324B, 89.3 mbsf}

Table AT28 and FIGUREB13_T2P_DEPLOY6.XLS in the "APP_B" folder in "Supplementary material" present the sequence of the operations and the tool response to particular events for T2P Deployment 6. The pressure and temperature records showed three spikes. The first spike occurred when the tool landed in the BHA, the second pulse occurred when the tool was pushed into the formation, and the third pulse occurred when circulation began while the tool was in the sediment. The shaft pressure reading continuously dissipated to its end value of $12.09 \mathrm{MPa}$. The tip pressure was not smooth and went close to or below the hydrostatic pressure after each pulse. We interpreted that there was an internal hydraulic leak at the tip. The temperature record was reasonable after the first two pulses, whereas it showed a rapid decrease after the third pulse. The last temperature reading was $5.74^{\circ} \mathrm{C}$, which was even lower than the borehole fluid temperature $\left(5.98^{\circ} \mathrm{C}\right)$ that was recorded prior to the first spike. We use the temperature data after the second spike to constrain the in situ temperature.

\section{Deployment 7: Hole U1324B, 117.8 mbsf}

Table AT29 and FIGUREB14_T2P_DEPLOY7.XLS in the "APP_B" folder in "Supplementary material" present the sequence of the operations and the tool response to particular events for T2P Deployment 7. Similar to Deployment 6, the pressure and temperature records all showed responses to latching of the tool in the BHA, pushing into to the formation, and turning on circulation while in the formation. The internal leak at the tip pressure was not identified and repaired in Deployment 7 . The shaft pressure reading had a continuous dissipation curve to its end value of $12.84 \mathrm{MPa}$ after the third spike. The temperature record exhibited a type decay curve and provided an in situ temperature of $7.00^{\circ} \mathrm{C}$.

\section{Deployment 8: Hole U1324B, 136.3 mbsf}

Table AT30 and FIGUREB15_T2P_DEPLOY8.XLS in the "APP_B" folder in "Supplementary material" present the sequence of the operations and the tool response to particular events for T2P Deployment 8. The shaft pressure was not stable during this deployment, with multiple abrupt increases and decreases in pressure that were not associated with deployment events. The tip pressure and temperature records showed responses to latching of the tool in the BHA, pushing into to the formation, and backing-off the drill bit after penetration. The hydraulic leak at the tip pressure resulted in erratic dissipation curve. The temperature decay was smooth and provided an in situ temperature of $7.35^{\circ} \mathrm{C}$. The tool was disassem- bled and reassembled after this deployment because of the poor pressure readings on both transducers.

\section{Deployment 9: Hole U1324B, 368 mbsf}

Table AT31 and FIGUREB16_T2P_DEPLOY9.XLS in the "APP_B" folder in "Supplementary material" present the sequence of the operations and the tool response to particular events for T2P Deployment 9. This deployment recorded large pressure and temperature increases with the landing of the tool in the BHA. After a short period of decay, the tool was pulled out of the formation by pulling the wireline up. The pressure abruptly dropped to the borehole fluid pressure. The temperature increased abruptly first and then decreased to the borehole fluid temperature. The pressure and temperature had similar responses when pushing the tool into the formation. The abrupt pressure decrease was caused by backingoff the drill bit. The pressure and temperature records suggest that the tool was measuring the pressure and temperature of the borehole fluid. No in situ conditions can be ascertained from this deployment.

\section{Deployment 10: Hole U1324B, 394.5 mbsf}

The connection between the sensors and the data acquisition system had poor contact. This precluded collection of any data.

\section{Deployment 11: Hole U1324B, 593.2 mbsf}

Table AT32 and FIGUREB17_T2P_DEPLOY11.XLS in the "APP_B" folder in "Supplementary material" present the sequence of the operations and the tool response to particular events for T2P Deployment 11. All connections were cleaned and the tool was reassembled because of the communication problem during Deployment 10. Deployment 11 was a test of the sensors and data acquisition system and did not involve pushing the probe into the sediment. The coreline depth and hook load data were not reliable during this deployment. The tip pressure showed excellent agreement with the shaft pressure. Two pressure decreases occurred in the tip pressure. These may have been caused by the tip being partly embedded in the sediment, whereas the shaft had not penetrated the formation. Overall this deployment confirmed that the electronic failure had been fixed.

\section{Deployment 12: Hole U1324C, 50 mbsf}

Table AT33 and FIGUREB18_T2P_DEPLOY12.XLS in the "APP_B" folder in "Supplementary material" present the sequence of the operations and the tool response to particular events for T2P Deployment 12. The bit depth data had a dramatic shift and was not reliable. To explore the bit movement during the 
deployment, the bit depth data should be used together with Table AT33. The temperature and pressure records increased while positioning the CDS to the retracted position. When the drill bit was lowered to insert the tool, further temperature and pressure responses were recorded. Pressure and temperature records varied during the penetration process. These variations were due to variations of the sediment properties. The tip and shaft pressures decreased when the BHA was lifted; however, the magnitude of the decreases was small $(<0.1 \mathrm{MPa})$. At the same time, the thermistor recorded a rapid increase in temperature. Fluid circulation resumed $8 \mathrm{~min}$ after the penetration at $10 \mathrm{spm}$. Corresponding to the onset of fluid circulation, both the tip and shaft pressures slightly increased. Then all sensors recorded a gradual dissipation. The tip measurement had an end value of $11.21 \mathrm{MPa}$. The shaft measurement had an end value of $11.56 \mathrm{MPa}$. Extrapolation of the pressure records will provide an estimate of the in situ pressure. The temperature decayed to an equilibrium temperature of $5.66^{\circ} \mathrm{C}$.

\section{Deployment 13: Hole U1324C, 100 mbsf}

Table AT34 and FIGUREB19_T2P_DEPLOY13.XLS in the "APP_B" folder in "Supplementary material" present the sequence of the operations and the tool response to particular events for T2P Deployment 13. All sensors had significant increases associated with pushing the tool into the sediment. The tip and shaft pressures decreased when the BHA was lifted, whereas the magnitude of the decrease was much larger at the tip. As the same time, the thermistor recorded a small increase in temperature. All sensors recorded a gradual dissipation. The tip had an end value of $11.93 \mathrm{MPa}$, and the shaft had an end value of $12.39 \mathrm{MPa}$. Extrapolation of the pressure records will provide an estimate of the in situ pressure. The temperature decayed to an equilibrium temperature of $6.65^{\circ} \mathrm{C}$.

\section{Deployment 14: Hole U1324C, 150 mbsf}

Table AT35 and FIGUREB20_T2P_DEPLOY14.XLS in the "APP_B" folder in "Supplementary material" present the sequence of the operations and the tool response to particular events for T2P Deployment 14. Similar to Deployment 13, pressure and temperature increased with insertion into the formation, followed by dissipation curves. All sensors recorded two perturbations while in the formation that could not be associated with any deployment event. After the last perturbation, the shaft pressure continued along a normal dissipation curve, whereas the tip showed a larger pressure decrease followed by a pressure in- crease. The tip measurement had an end value of 12.69 MPa. The shaft measurement had an end value of $13.10 \mathrm{MPa}$. The pressure records likely can be used to evaluate the in situ pressure. The temperature $\left(7.57^{\circ} \mathrm{C}\right)$ appeared to be in equilibrium with the formation prior to pulling the tool out off $\mathrm{BOH}$.

\section{Deployment 15: Hole U1324C, 200 mbsf}

Table AT36 and FIGUREB21_T2P_DEPLOY15.XLS in the "APP_B" folder in "Supplementary material" present the sequence of the operations and the tool response to particular events for T2P Deployment 15. The temperature and pressure records increased while positioning the CDS to the retracted position. When the drill bit was lowered to insert the tool, it recorded further temperature and pressure responses. The tip and shaft pressures rapidly decreased when the BHA was backing-off the $\mathrm{BOH}$. At the same time, the thermistor recorded a rapid increase in temperature. The shaft then continued along a normal dissipation curve, whereas the tip showed a pressure rebound followed by a gradual dissipation. The tip measurement had an end value of $14.09 \mathrm{MPa}$. The shaft measurement had an end value of $14.44 \mathrm{MPa}$. The pressure records can be used to evaluate the in situ pressure. The temperature decayed to an equilibrium temperature of $8.58^{\circ} \mathrm{C}$.

All sensors lost communication with the data acquisition unit during retrieval of the tool from the formation. When the tool reached the rig floor, the tip was bent and the drive tube was loose. The loose drive tube most likely caused the failure to record data during the retrieval as the sensor cables were routed through the drive tube where they were connected with the data acquisition unit.

\section{Deployment 16: Hole U1324C, 300 mbsf}

Table AT37 and FIGUREB22_T2P_DEPLOY16.XLS in the "APP_B" folder in "Supplementary material" present the sequence of the operations and the tool response to particular events for T2P Deployment 16. The temperature and tip pressure records increased while positioning the CDS to the retracted position. When the drill bit was lowered to insert the tool, it recorded further temperature and pressure responses. Pressure and temperature records varied during the penetration process. These variations were due to variations of the soil properties and penetration rate. The pressure and temperature sensors recorded continuous dissipation curves. The end temperature of $10.29^{\circ} \mathrm{C}$ was equilibrated with the formation. The end shaft pressure was $15.2 \mathrm{MPa}$, and the end tip pressure was $14.42 \mathrm{MPa}$. Extrapolation of the pres- 
sure records will provide an estimate of the in situ pressure.

\section{Deployment 17: Hole U1322B, 42 mbsf}

Table AT38 and FIGUREB23_T2P_DEPLOY17.XLS in the "APP_B" folder in "Supplementary material" present the sequence of the operations and the tool response to particular events for T2P Deployment 17. When the drill bit was lowered to insert the tool, it recorded temperature and pressure responses. However, the pressure signals decreased significantly when backing-off the drill bit. The pressures were constant during the dissipation phase and were equal to the pressure recorded prior to the tool insertion. The temperature record showed a second spike when backing-off the drill bit and then decayed to a temperature that was close to the borehole fluid temperature. These observations suggest that the tool was communicating with the borehole fluid. Therefore, this deployment did not provide any constraint on in situ conditions.

\section{Deployment 19: Hole U1322B, 134.3 mbsf}

Table AT39 and FIGUREB24_T2P_DEPLOY19.XLS in the "APP_B" folder in "Supplementary material" present the sequence of the operations and the tool response to particular events for T2P Deployment 19. The temperature and pressure records increased while positioning the CDS to the retracted position. When the drill bit was lowered to insert the tool, it recorded further temperature and pressure responses. Pressure and temperature records varied during the penetration process. These variations were due to variations of the sediment properties. The tip and shaft pressures abruptly decreased when the BHA was backing-off the $\mathrm{BOH}$. At the same time, the thermistor recorded a rapid increase. After this perturbation, the tip and shaft pressure rapidly rebounded to nearly constant values. The end shaft pressure was $15.22 \mathrm{MPa}$, and the end tip pressure was $15.08 \mathrm{MPa}$. The temperature decayed to an equilibrium temperature of $7.89^{\circ} \mathrm{C}$.

\section{Deployment 20: Hole U1322B, 157.8 mbsf}

Table AT40 and FIGUREB25_T2P_DEPLOY20.XLS in the "APP_B" folder in "Supplementary material" present the sequence of the operations and the tool response to particular events for T2P Deployment 20. The temperature and pressure records increased during the first landing attempt with the bit $12 \mathrm{~m}$ off $\mathrm{BOH}$, then the tool was pulled back up to reland it with the bit $3 \mathrm{~m}$ off the BOH. Fluids were circulated during landing of the tool in the BHA. When the drill bit was lowered to insert the tool, it recorded further temperature and pressure responses. The tip and shaft pressures abruptly decreased when the BHA was backing-off the $\mathrm{BOH}$. At the same time, the thermistor recorded a rapid increase. After this perturbation, the tip pressure rapidly rebounded to a value and then slowly built up to an end pressure of 15.41 MPa. The shaft pressure rapidly rebounded to a nearly constant value of $15.60 \mathrm{MPa}$. The end pressures may provide a rough estimate of the in situ pressure. The temperature decayed to an equilibrium temperature of $8.47^{\circ} \mathrm{C}$.

\section{Deployment 21: Hole U1322C, 50 mbsf}

A data acquisition error resulted in only $3 \mathrm{~min}$ of recorded data. Inspection of the data acquisition unit after recovering the probe revealed that the memory card was dislodged and thus data could not be recorded. The memory card was replaced, and the quick release button for the card was removed. This modification made it harder for the memory card to be accidentally ejected.

\section{Deployment 22: Hole U1322C, 75 mbsf}

This deployment suffered from a hydraulic leak that flooded the electronics connecting the pressure transducers and the thermistor to the data acquisition unit. The flooding shorted all circuits; therefore, no pressure and temperature data were recorded. All electrical components were cleaned and dried after the deployment.

\section{Deployment 23: Hole U1322C, 150 mbsf}

Table AT41 and FIGUREB26_T2P_DEPLOY23.XLS in the "APP_B" folder in "Supplementary material" present the sequence of the operations and the tool response to particular events for T2P Deployment 23 . TruView data are only available for the dissipation phase. Temperature and pressure signals increased with landing of the tool in the BHA and again with penetration into the formation. The tip pressure decreased when the bit was pulled up and then slowly rebounded to a final pressure of $15.29 \mathrm{MPa}$. The shaft pressure decreased when the bit was lifted and then continuously decayed to an end pressure of $15.99 \mathrm{MPa}$. The temperature decayed to an equilibrium value of $8.26^{\circ} \mathrm{C}$.

\section{Deployment 24: Hole U1322C, 200 mbsf}

Table AT42 and FIGUREB27_T2P_DEPLOY24.XLS in the "APP_B" folder in "Supplementary material" present the sequence of the operations and the tool response to particular events for T2P Deployment 24 . The tip pressure and temperature records increased while positioning the CDS to the retracted position. A second increase recorded by all sensors occurred when the tool was pushed into the formation. Pres- 
sure and temperature records then smoothly dissipated while the tool was in the formation. The tip decayed to a final pressure of $16.34 \mathrm{MPa}$, and the shaft dissipated to a final pressure of $17.16 \mathrm{MPa}$. Extrapolation of the pressure records will provide good estimate of the in situ pressure. The temperature decayed to an equilibrium value of $9.28^{\circ} \mathrm{C}$.

\section{Deployment 25: Hole U1322D, 40 mbsf}

Table AT43 and FIGUREB28_T2P_DEPLOY25.XLS in the "APP_B" folder in "Supplementary material" present the sequence of the operations and the tool response to particular events for T2P Deployment 25. The TruView data are missing for this deployment. Key deployment events are derived from the shipboard T2P Log Sheet (see the "DOWNHOLE" folder in "Supplementary material"). Pressure and temperature pulses were recorded when the probe was pushed into the formation but the pressure dropped rapidly when the drill bit was lifted off the $\mathrm{BOH}$. The tip and shaft then increased to a nearly constant pressure of $13.78 \mathrm{MPa}$, which was equal to the fluid pressure at $\mathrm{BOH}$. The temperature decreased rapidly upon pulling up of the bit and then was nearly constant and close to the temperature of the borehole fluid. The pressure and temperature records suggest that the measurement was influenced by communication with the borehole fluid. Thus this deployment did not provide any constraint on in situ conditions.

\section{Deployment 26: Hole U1322D, 70 mbsf}

Table AT44 and FIGUREB29_T2P_DEPLOY26.XLS in the "APP_B" folder in "Supplementary material" present the sequence of the operations and the tool response to particular events for T2P Deployment 26. Similar to Deployment 25, the seal around the probe was weakened when the bit was lifted off the $\mathrm{BOH}$. The pressure and temperature measurements were subject to influence of the borehole fluid. This deployment did not provide any constraint on in situ conditions.

\section{Deployment 27: Hole U1322D, 100 mbsf}

Table AT45 and FIGUREB30_T2P_DEPLOY27.XLS in the "APP_B" folder in "Supplementary material" present the sequence of the operations and the tool response to particular events for T2P Deployment 27. The pressure and temperature records increased while positioning the CDS to the retracted position and pushing the tool into the formation. The tip and shaft pressures rapidly decreased while backing-off the bit. The tip pressure rebounded to a near-constant value of $14.69 \mathrm{MPa}$. The shaft pressure dissipated to a final value of $15.11 \mathrm{MPa}$. This dissipation curve can be extrapolated to evaluate the in situ pressure. Smooth temperature decay was measured. The final temperature of $7.11^{\circ} \mathrm{C}$ was equilibrated with the formation.

\section{Deployment 28: Hole U1322D, 134 mbsf}

Table AT46 and FIGUREB31_T2P_DEPLOY28.XLS in the "APP_B" folder in "Supplementary material" present the sequence of the operations and the tool response to particular events for T2P Deployment 28. The pressure and temperature records increased while positioning the CDS to the retracted position and pushing the tool into the formation. The tip and shaft pressures rapidly decreased while backing-off the bit. Pressures at the shaft and tip were near-constant during the dissipation phase. The temperature increased while backing-off the bit and then rapidly decayed to a final temperature of $7.31^{\circ} \mathrm{C}$. The pressure and temperature measurements were subject to influence of the borehole fluid. This deployment did not provide any constraint on in situ conditions.

All sensor data records were lost during recovery of the probe. At the rig floor, it was noted that the tip had broken and the drive tube had bent during the deployment. Damage to the probe likely occurred while pushing into the formation and then the tip was broken when pulling out of the formation.

\section{Appendix C}

\section{Fluid pressure within the drilling pipe}

To check tool performance and the pressure calibration, we made multiple $2-10 \mathrm{~min}$ tool stops to take the fluid pressure in the drill pipe prior to and after tool penetration. We stopped fluid circulation during tool stop to remove the effect of pump pressure on the measured pressure. Here, we present a discussion of the pressure state within the drill pipe based on the DVTPP pressure measurements.

Figure AF7 presents the fluid pressure taken at or above the seafloor. The measured fluid pressure is generally not equal to the calculated hydrostatic pressure. The tool pressure is either close to or higher than hydrostatic pressure for deployments with no drilling mud involved. However, the tool pressure can be either significantly higher or lower than hydrostatic pressure if drilling mud was used. In addition, the range of the offset value is larger than seen during deployments in water without mud. Thus, the tool-stop technique can not effectively check the pressure calibration.

Figure AF8 presents the fluid pressure taken at $\mathrm{BOH}$ prior to tool penetration. The fluid pressure at $\mathrm{BOH}$ is either close to or higher than the hydrostatic pres- 
sure for deployments with no drilling mud involved. The tool pressure is significantly higher than hydrostatic pressure if drilling mud was used. It shows a general trend where the pressure offset at the $\mathrm{BOH}$ increases with the depth of the borehole.

To understand the fluid pressure in the drill pipe, we present two ideal scenarios of the fluid conditions within the drill pipe and outside the drill pipe. The first scenario is one where no drilling mud was used and the seawater was not contaminated with drilling cuttings (Fig. AF9A). In this case, the fluid in the pipe is static and the pressure is equal to hydrostatic pressure everywhere. The second scenario is when drilling mud was used and the mud elevations inside and outside the pipe are at the seafloor. The fluid in the drill pipe is static and has hydrostatic pressure above the mud elevation (e.g., Stops 1 and 2 in Fig. AF9B). The fluid pressure below the mud elevation (e.g., Stop 3) is higher than hydrostatic pressure, follows the static pressure gradient of the drilling mud, and can be calculated using

$$
P=\rho_{\mathrm{w}} \mathrm{g} H_{\mathrm{w}}+\rho_{\mathrm{m}} \mathrm{g}\left(z-H_{\mathrm{w}}\right),
$$

where

$$
\begin{aligned}
& \mathrm{g}=\text { acceleration of gravity, } \\
& \rho_{\mathrm{w}}=\text { density of seawater, } \\
& \rho_{\mathrm{m}}=\text { density of drilling mud, } \\
& z=\text { the target depth, and } \\
& H_{\mathrm{w}}=\text { depth of water at the location of the hole. }
\end{aligned}
$$

For almost all deployments, the tool pressure during tool stop reached a steady pressure within 1 min (see "Appendix A," "Appendix B"). This suggests that fluid in the dill pipe was static during most of the time of the tool stop. It is reasonable to assume that the fluid pressure within the drill pipe was equal to the fluid pressure inside the annulus at $\mathrm{BOH}$.

Figure AF10 presents three possible scenarios that could be encountered at tool stops. The first scenario is one in that no drilling mud was used; the elevation of fluid with cuttings inside the pipe is lower than that outside the pipe. The fluid elevation in the drill pipe must be above sea level to reach the static condition. $\Delta H$ can be calculated by

$$
\Delta H=\frac{\left(\rho_{c}-\rho_{w}\right) H_{1}}{\rho_{w}} .
$$

Once $\Delta H$ is determined, the fluid pressure in the drill pipe can be calculated everywhere. The offset from hydrostatic pressure is constant above the interface of seawater and the fluid with cuttings (e.g., Stops 1 and 2). Below the interface, fluid pressure follows the pressure gradient of the fluid with drilling cuttings (Fig. AF10A).

The second scenario is one where drilling mud was used to stabilize the borehole, and the mud elevation within the pipe is lower than that outside the pipe. The fluid elevation in the drill pipe must be above sea level to equilibrate with the fluid pressure at BOH. $\Delta H$ can be calculated by

$$
\Delta H=\frac{\left(\rho_{c}-\rho_{w}\right) H_{1}+\left(\rho_{m}-\rho_{w}\right) H_{2}}{\rho_{w}} .
$$

The pressure within the pipe is higher than hydrostatic pressure everywhere. The offset from hydrostatic pressure is constant above the interface of seawater and the drilling mud (e.g., Stops 1 and 2). Below the interface, fluid pressure follows the pressure gradient of the drilling mud (Fig. AF10B).

The third scenario is one where drilling mud was used to stabilize the borehole and the mud elevation within the pipe is higher than the mud elevation outside the pipe. The fluid elevation in the drill pipe will be lower than sea level to equilibrate with the fluid pressure at $\mathrm{BOH} . \Delta H$ can be calculated by

$$
\Delta H=\frac{\left(\rho_{w}-\rho_{m}\right) H_{1}+\left(\rho_{c}-\rho_{m}\right) H_{2}}{\rho_{w}} .
$$

The pressure within the pipe could be either lower (e.g., Stops 1 and 2) or higher than hydrostatic pressure (e.g., Stop 3) depending on the location of the tool stop (Fig. AF10C). 
Figure AF1. Onboard pressure calibration of transducer Z59-72. The pump pressure was run to 4000 psi from atmospheric pressure (psia) and then stepped down to atmosphere pressure.

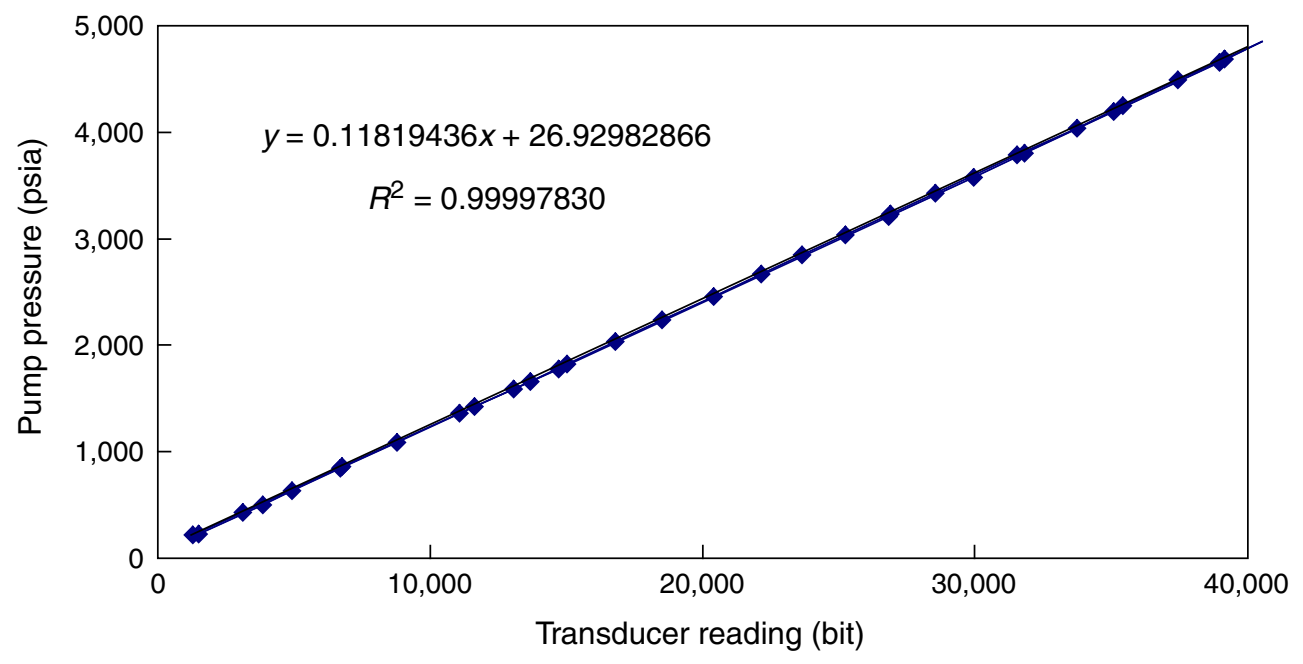


Figure AF2. Influence of temperature $(T)$ on T2P pressure transducers. The slope $(S)$ and intersection $(I)$ of the calibration curve can change with temperature.

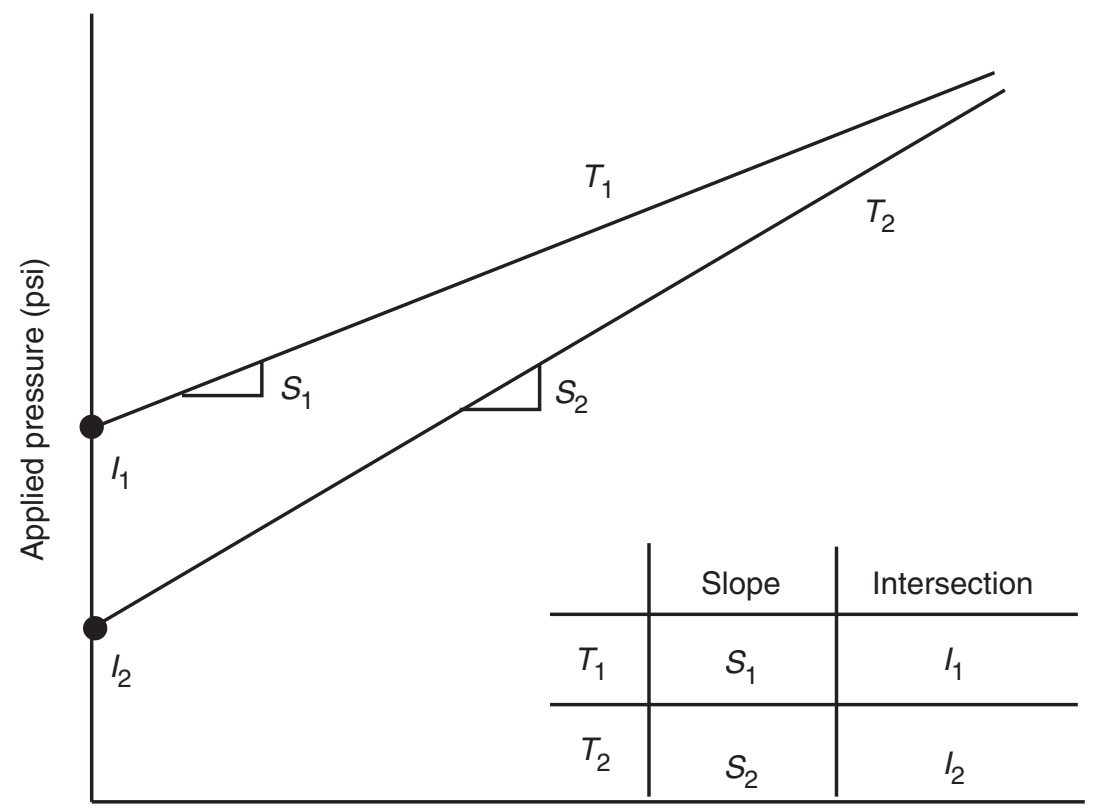

Transducer reading (bit) 
Figure AF3. Postcruise pressure calibration of transducer Z59-72. Calibration was done at $19.976^{\circ} \mathrm{C}$ in a temperature bath. Deadweight tester was run to 4015 psi from atmospheric pressure (psia) and then stepped down to atmosphere pressure.

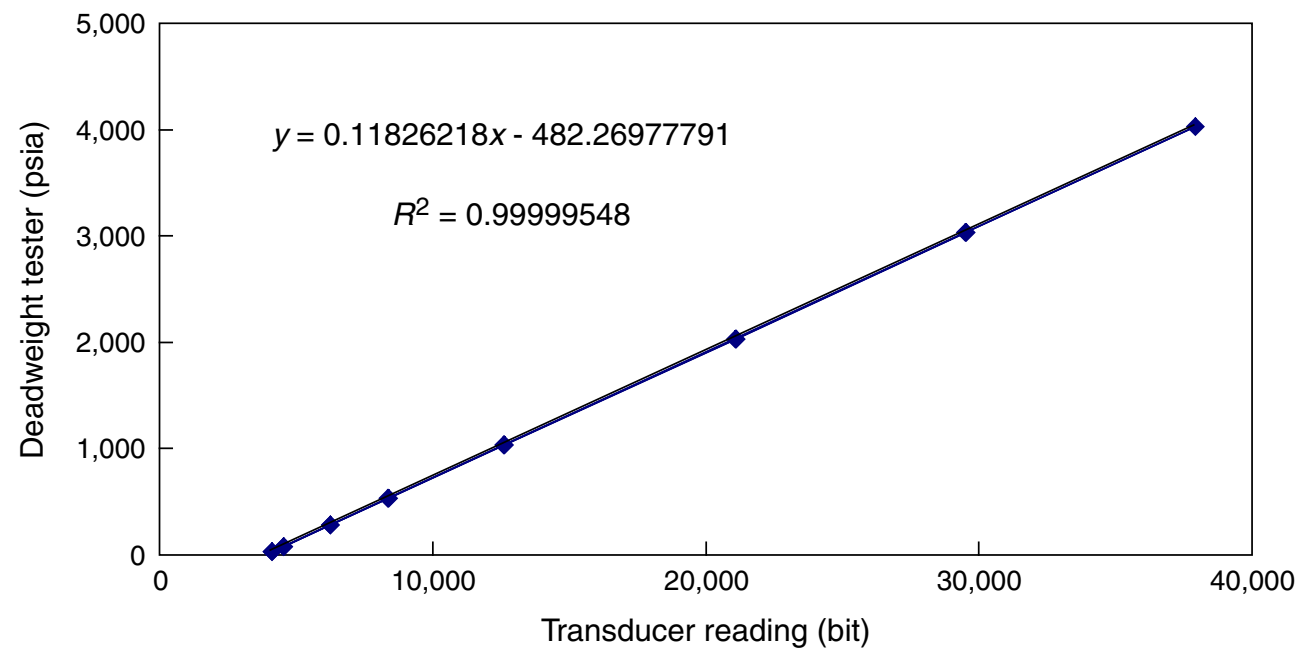


Figure AF4. Calibration coefficients of transducer S50-73 vs. temperature. A. Calibration curve slope vs. temperature. B. Intersection on $y$-axis of the calibration curve vs. temperature.
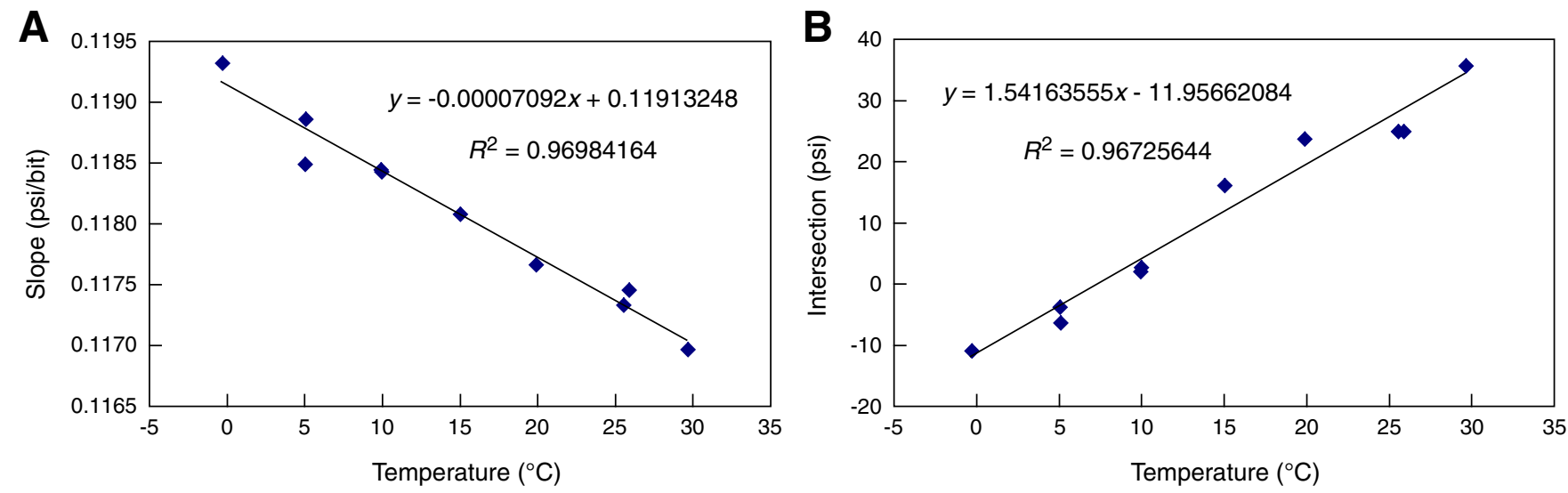
Figure AF5. Calibration coefficients of transducer Z59-72 vs. temperature. A. Calibration curve slope vs. temperature. B. Intersection on $y$-axis of the calibration curve vs. temperature.
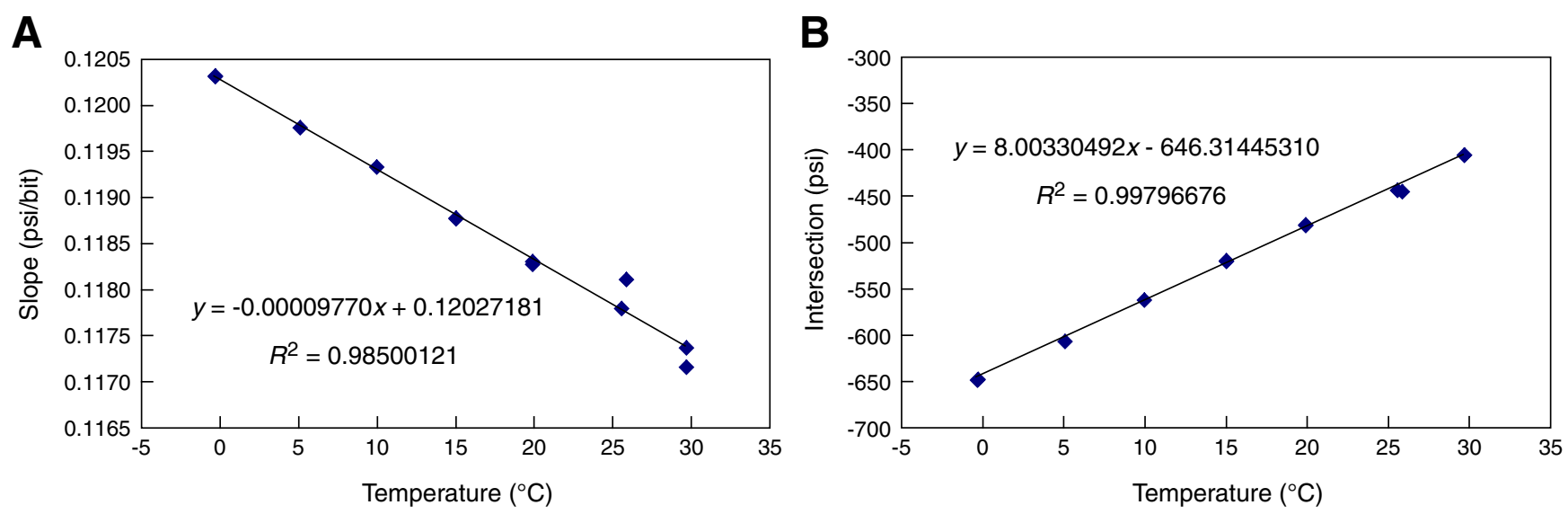
Figure AF6. Calibration coefficients of transducer S50-75 vs. temperature. A. Calibration curve slope vs. temperature. B. Intersection on $y$-axis of the calibration curve vs. temperature.
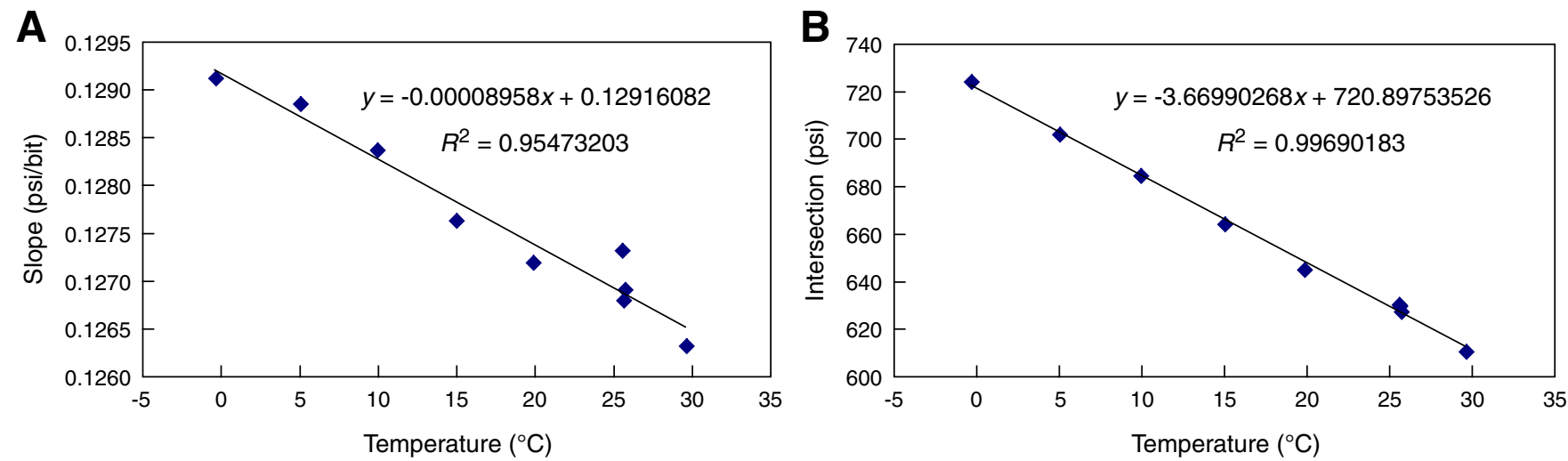
Figure AF7. Offset between tool pressure and hydrostatic pressure for tool stops at or above seafloor. Hydrostatic pressure was calculated assuming a seawater density of $1.024 \mathrm{~g} / \mathrm{cm}^{3}$. DVTPP $=$ Davis-Villinger Temperature-Pressure Probe.

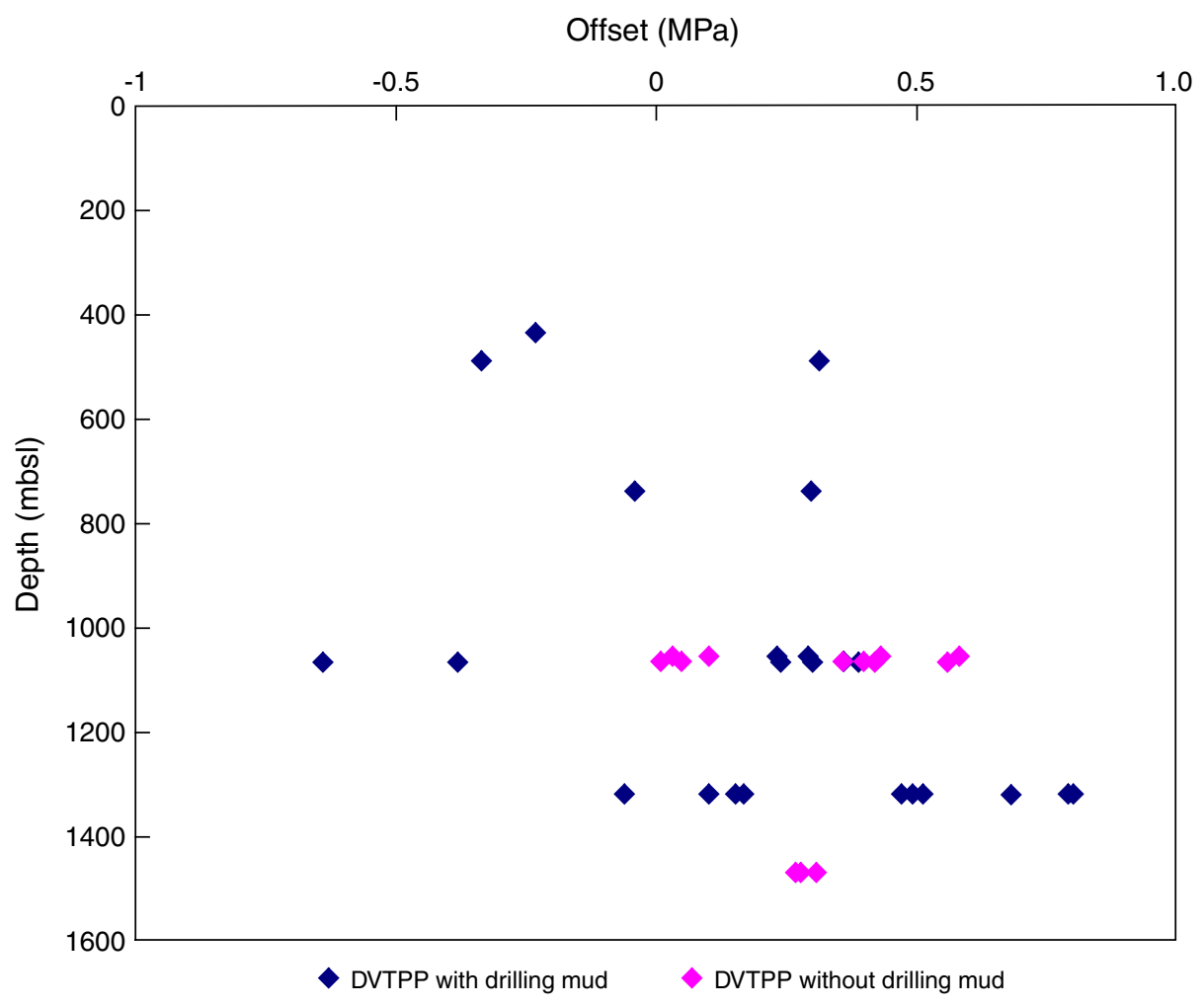


Figure AF8. Offset between tool pressure and hydrostatic pressure at the bottom of the hole. Hydrostatic pressure calculated assuming a seawater density of $1.024 \mathrm{~g} / \mathrm{cm}^{3}$. DVTPP $=$ Davis-Villinger Temperature-Pressure Probe.

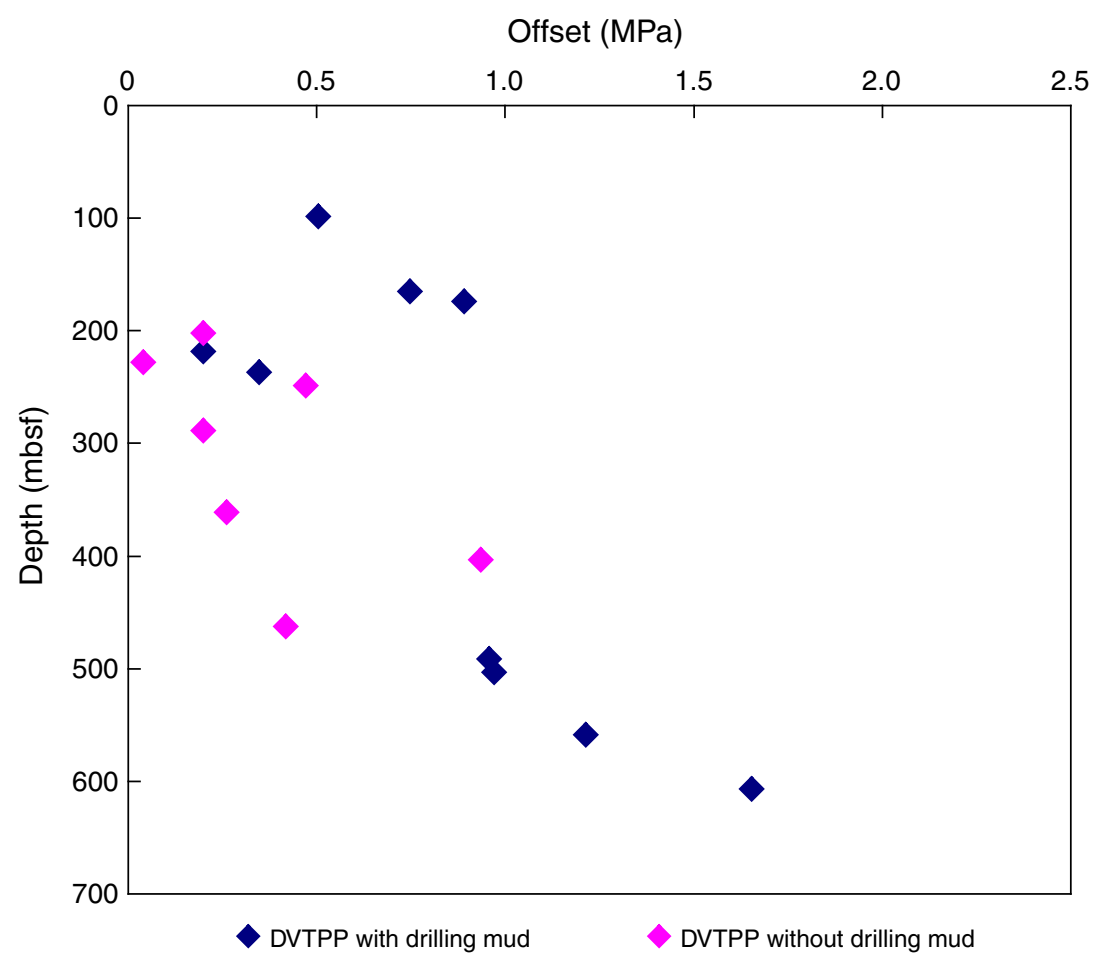


Figure AF9. Two ideal scenarios of fluid condition in drill pipe A. Predicted fluid pressure profile for cases in which no drilling mud was used and the seawater was not contaminated with the drilling cuttings. B. Predicted fluid pressure profile for cases in which drilling mud was used and the mud elevations inside and outside the pipe are at seafloor. Brown line $=$ predicted static pressure assuming the borehole was filled with a $10.5 \mathrm{ppg}$ drilling mud. $\rho_{\mathrm{w}}=$ density of seawater $\left(1.024 \mathrm{~g} / \mathrm{cm}^{3}\right), \rho_{\mathrm{m}}=$ density of drilling mud $\left(1.259 \mathrm{~g} / \mathrm{cm}^{3} ; 10.5 \mathrm{ppg}\right), H_{\mathrm{w}}=$ water depth at hole location, $H_{\mathrm{H}}=$ hole depth, $H_{\mathrm{s} 1}=$ water depth at Stop 1.

A

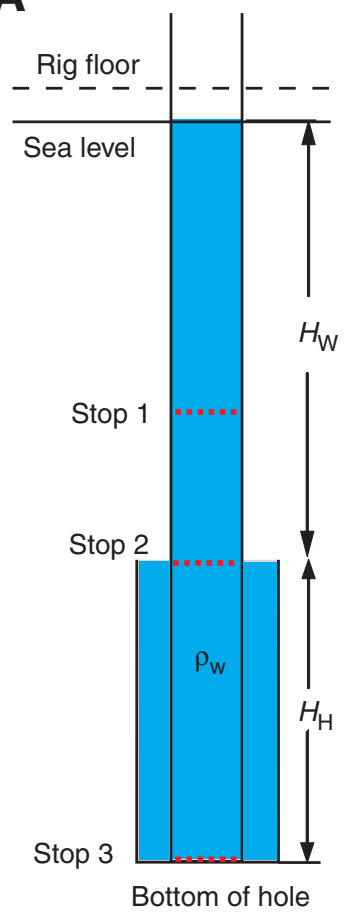

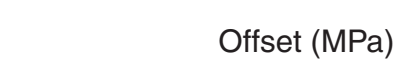

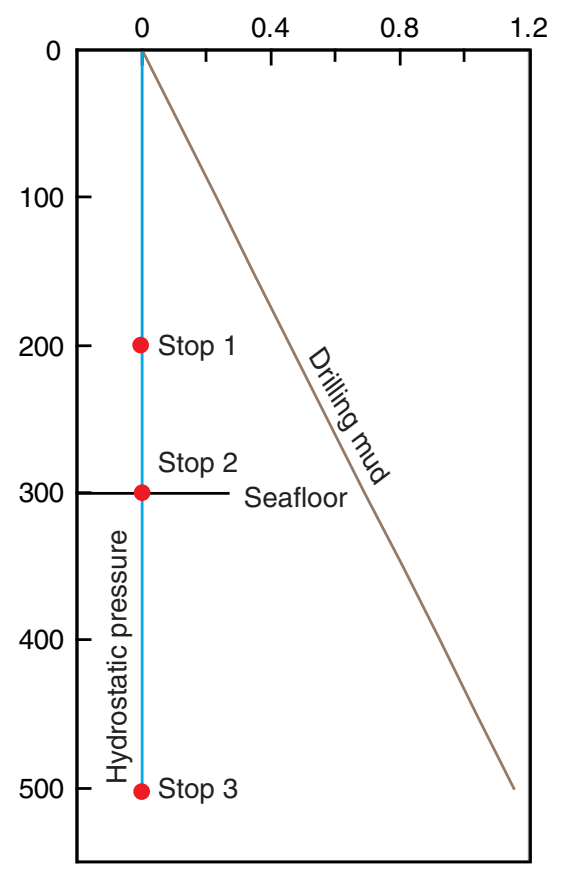

Seawater

B
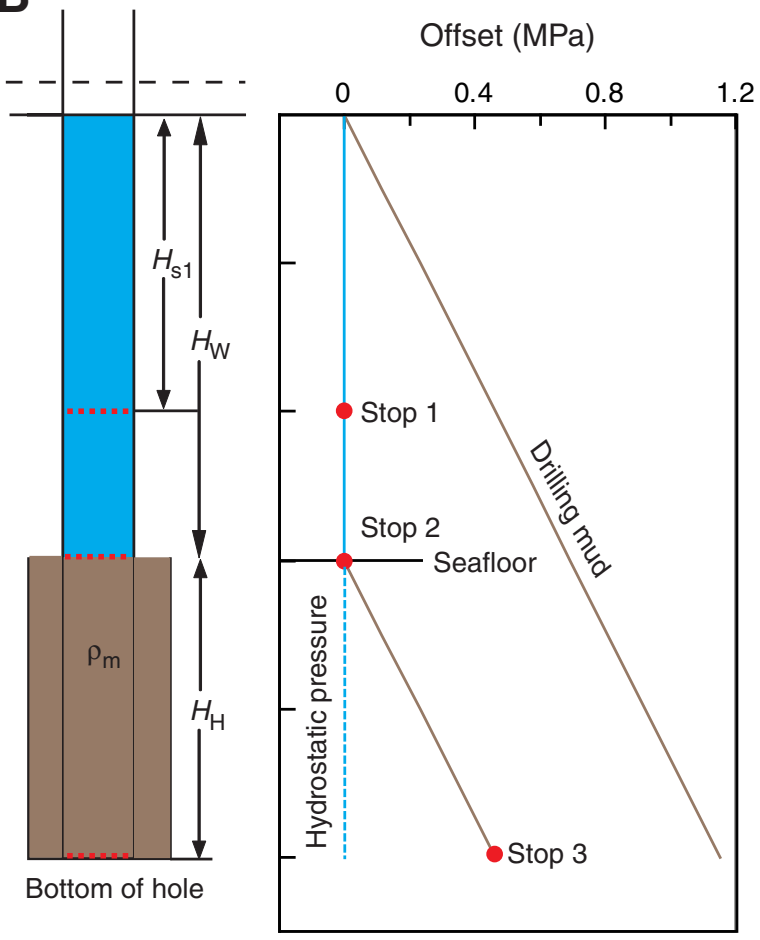

Drilling mud 
Figure AF10. Three possible scenarios that could be encountered at tool stops. The drill pipe above the rig floor was assumed to be sufficiently long, and three fluids with different density do not mix. A. Predicted fluid pressure profile for cases where no drilling mud was used and fluid in the borehole is contaminated with drilling cuttings. B. Predicted fluid pressure profile for cases where drilling mud was used to stabilize the borehole and mud elevation within the pipe is lower than the mud elevation outside the pipe. C. Predicted fluid pressure profile for cases where drilling mud was used to stabilize the borehole and mud elevation within the pipe is higher than the mud elevation outside the pipe. Brown line $=$ predicted static pressure by assuming the borehole was filled with a $10.5 \mathrm{ppg}$ drilling mud. $\rho_{\mathrm{w}}=$ density of seawater $\left(1.024 \mathrm{~g} / \mathrm{cm}^{3}\right), \rho_{\mathrm{m}}=$ density of drilling mud $\left(1.259 \mathrm{~g} / \mathrm{cm}^{3} ; 10.5 \mathrm{ppg}\right), \rho_{\mathrm{c}}=$ density of fluid with cuttings $\left(1.139 \mathrm{~g} / \mathrm{cm}^{3} ; 9.5 \mathrm{ppg}\right), H_{\mathrm{W}}=$ water depth at hole location, $H_{\mathrm{H}}=$ hole depth, $H_{\mathrm{s} 1}=$ water depth at Stop 1, $\Delta H=$ offset in hydrostatic pressure, $\mathrm{H}_{1}=$ hydrostatic pressure at Stop $1, H_{2}=$ hydrostatic pressure at Stop 2.

A

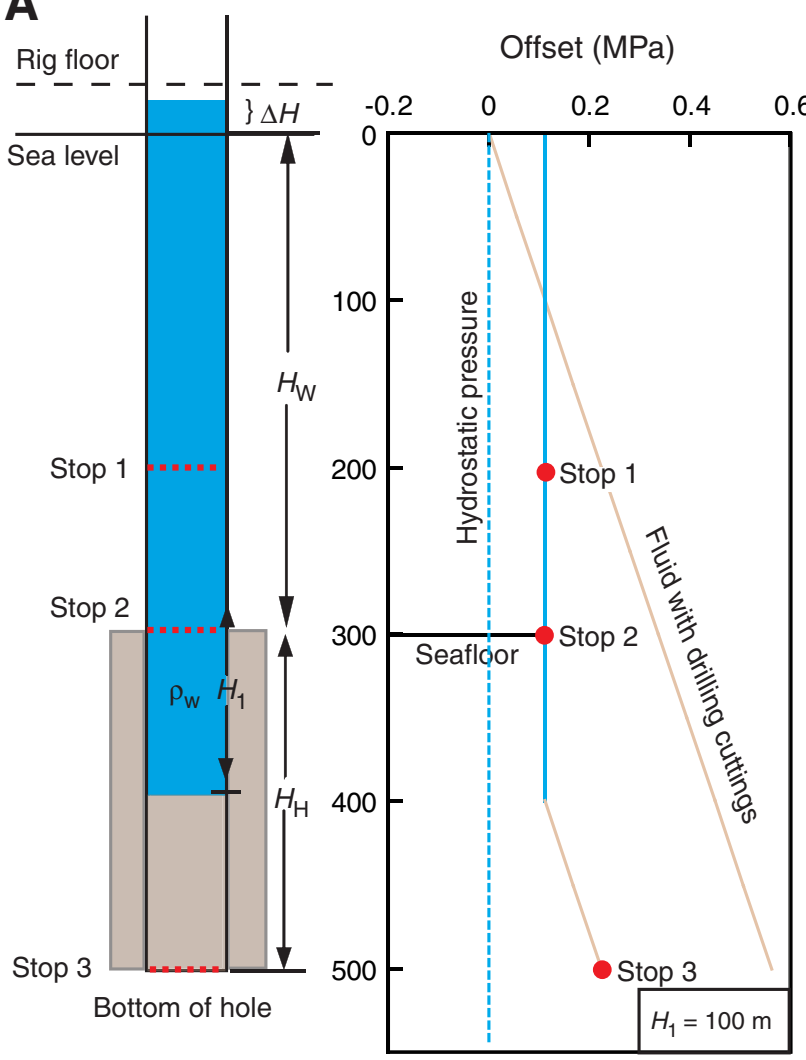

B

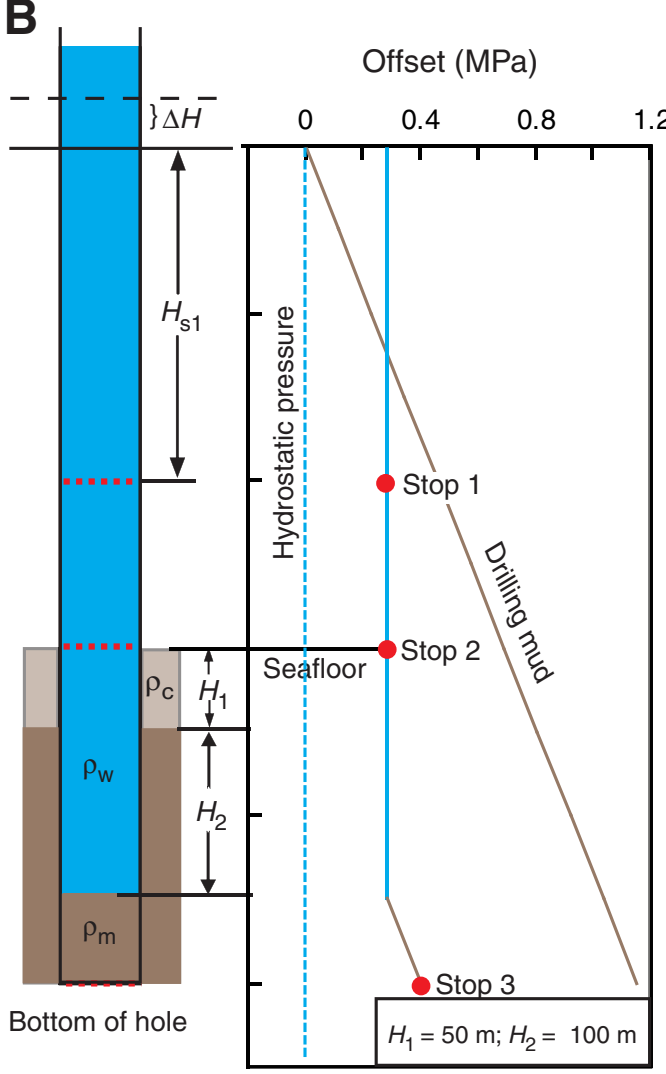

C

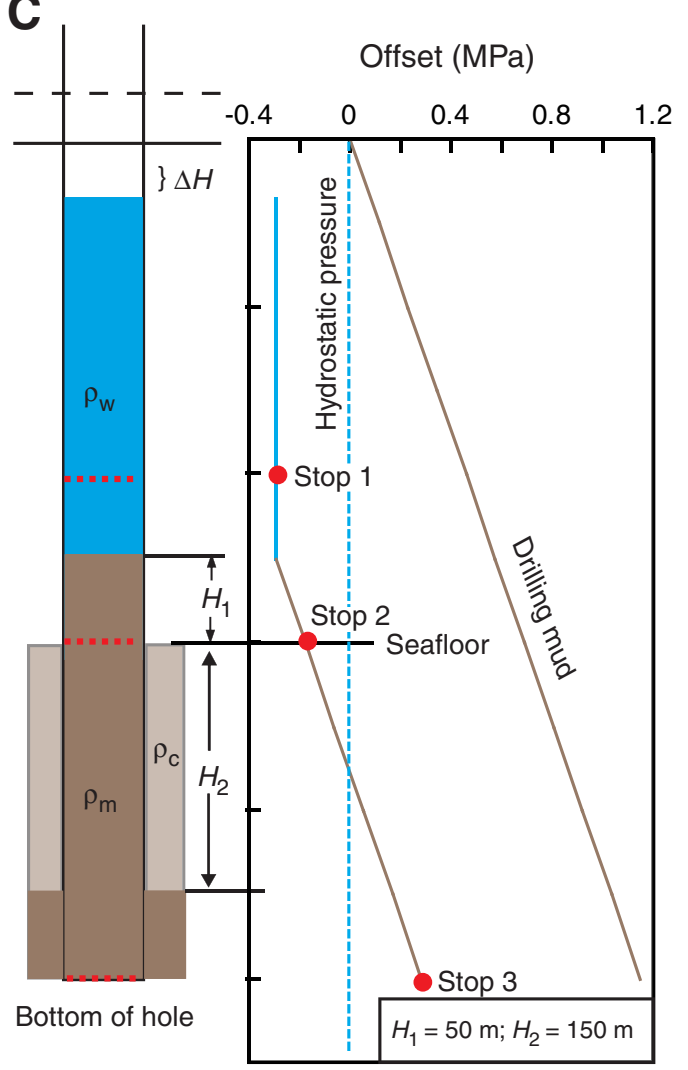


Table AT1. Temperature calibration of DVTPP. A. Calibration coefficients for data loggers and thermistors. Channel T1 is the logger channel used to measure the thermistor. $R_{\mathrm{t}}{ }^{\prime}=$ thermistor resistance in ohms. B. Actual thermistor calibration data.

Table AT1A. Calibration coefficients. (See table notes.)

\begin{tabular}{lll}
\hline $\begin{array}{l}\text { Calibration } \\
\text { coefficient }\end{array}$ & Logger 9367 & Logger 9368 \\
\hline$R_{1}$ & 251680.977 & 249507.092 \\
$k_{0}$ & 65564.0623 & 65534.6958 \\
$k_{1}$ & 65550.3036 & 65533.6013 \\
\hline
\end{tabular}

\begin{tabular}{lll}
\hline $\begin{array}{l}\text { Calibration } \\
\text { coefficient }\end{array}$ & Thermistor 0226-3 & Thermistor 0226-2 \\
\hline$A$ & $4.60148156 \mathrm{E}-04$ & $4.52826700 \mathrm{E}-04$ \\
$B$ & $2.10947147 \mathrm{E}-04$ & $2.11217111 \mathrm{E}-04$ \\
$C$ & $6.41209309 \mathrm{E}-08$ & $6.19876025 \mathrm{E}-08$ \\
\hline
\end{tabular}

Notes: For Channel T1 calibration, $R_{\mathrm{t}}{ }^{\prime}=R_{1} \times\left(k_{1}-x\right) /\left[k_{0}-\left(k_{1}-x\right)\right]$, where $x=T_{1}$ counts. For thermistor calibration (ohms to Kelvin [Steinhart and Hart]), $1 / t=A+B \times \operatorname{Ln}\left(R_{\mathrm{t}}^{\prime}\right)+C \times \operatorname{Ln}\left(R_{\mathrm{t}}^{\prime}\right)^{3}$, where ${ }^{\circ} \mathrm{C}=\mathrm{K}-273.15$.

Table AT1B. Temperature vs. resistance.

\begin{tabular}{ccccc}
\hline \multirow{2}{*}{$\begin{array}{c}\text { Serial } \\
\text { number }\end{array}$} & $0.000^{\circ} \mathrm{C}$ & $50.000^{\circ} \mathrm{C}$ & $100.000^{\circ} \mathrm{C}$ & $150.000^{\circ} \mathrm{C}$ \\
\cline { 2 - 5 } & 1666200 & 162749 & 27716 & 6963 \\
$0226-2$ & 16626 & 26907 & 6781 \\
\hline $0226-3$ & 1602700 & 157535 & 2695 \\
\hline
\end{tabular}

Table AT2. Pressure calibration of DVTPP, 7 June 2002. (See table notes.)

\begin{tabular}{|c|c|c|}
\hline & PXDCR 88587 & PXDCR 88579 \\
\hline \multicolumn{3}{|c|}{ Temperature coefficients } \\
\hline $\mathrm{U}_{0}(\mu \mathrm{s})$ & 5.833194 & 5.878972 \\
\hline $\mathrm{Y}_{1}\left({ }^{\circ} \mathrm{C} / \mu \mathrm{s}\right)$ & -4036.649 & -3969.749 \\
\hline $\mathrm{Y}_{2}\left({ }^{\circ} \mathrm{C} / \mu \mathrm{s}\right)$ & -12666.34 & -11880.87 \\
\hline$Y_{3}$ & 0 & 0 \\
\hline \multicolumn{3}{|c|}{ Pressure coefficients } \\
\hline $\mathrm{C}_{1}(\mathrm{psia})$ & -68866.77 & -66259.12 \\
\hline $\mathrm{C}_{2}(\mathrm{psia} / \mu \mathrm{s})$ & -694.2135 & -2504.110 \\
\hline $\mathrm{C}_{3}\left(\mathrm{psia} / \mu \mathrm{s}^{2}\right)$ & 255224.2 & 223122.2 \\
\hline $\mathrm{D}_{1}$ & 0.029732 & 0.030630 \\
\hline $\mathrm{D}_{2}$ & 0 & 0 \\
\hline $\mathrm{T}_{1}(\mathrm{psia})$ & 30.32667 & 30.23938 \\
\hline $\mathrm{T}_{2}(\mathrm{psia} / \mu \mathrm{s})$ & 1.025313 & 0.409012 \\
\hline $\mathrm{T}_{3}\left(\mathrm{psia} / \mu \mathrm{s}^{2}\right)$ & 62.84291 & 58.71868 \\
\hline $\mathrm{T}_{4}$ & 0 & 0 \\
\hline $\mathrm{T}_{5}$ & 0 & 0 \\
\hline
\end{tabular}

Notes: For internal temperature sensor, temperature $\left({ }^{\circ} \mathrm{C}\right)=\mathrm{Y}_{1} \mathrm{U}+\mathrm{Y}_{2} \mathrm{U}^{2}+\mathrm{Y}_{3} \mathrm{U}^{3}, \mathrm{U}_{0}=$ temperature signal period $(\mu \mathrm{s})$ at $25^{\circ} \mathrm{C}, \mathrm{U}=$ temperature signal period $-\mathrm{U}_{0}(\mu \mathrm{s})$. For pressure transducer, pressure $(\mathrm{psi})=\mathrm{C}\left(1-\mathrm{T}_{0}^{2} / \mathrm{T}^{2}\right)\left[1-\mathrm{D}\left(1-\mathrm{T}_{0}{ }^{2} / \mathrm{T}^{2}\right)\right], T=$ Pressure signal period $(\mu \mathrm{s}), \mathrm{U}_{0}=$ temperature signal period $(\mu \mathrm{s})$ at $25^{\circ} \mathrm{C}, \mathrm{C}=\mathrm{C}_{1}+\mathrm{C}_{2} \mathrm{U}+\mathrm{C}_{3} \mathrm{U}^{2}, \mathrm{D}=\mathrm{D}_{1}+\mathrm{D}_{2} \mathrm{U}, \mathrm{T}_{0}=\mathrm{T}_{1}+\mathrm{T}_{2} \mathrm{U}+\mathrm{T}_{3} \mathrm{U}^{2}+\mathrm{T}_{4} \mathrm{U}^{3}+\mathrm{T}_{5} \mathrm{U}^{4}$. 
Table AT3. Event summary of DVTPP Deployment 20, Hole U1322D, 175 mbsf. (See table notes.)

\begin{tabular}{lll}
\hline $\begin{array}{c}\text { Event } \\
\text { number }\end{array}$ & $\begin{array}{c}\text { Time } \\
\text { (GMT) }\end{array}$ & \multicolumn{1}{c}{$\begin{array}{c}\text { Event } \\
\text { description }\end{array}$} \\
\hline 1 & 1837 & Start lowering DVTPP downhole \\
2 & 1859 & Stop at mudline for 5 min \\
3 & 1900 & Start lowering probe \\
4 & 1904 & Move BHA to 7 m off BOH \\
5 & 1913 & CDS lands in BHA \\
6 & 1920 & Lower bit, start penetration of DVTPP into formation \\
7 & 1921 & End of penetration, bit on BOH \\
8 & 1921 & Raise BHA 2.4 m off BOH \\
9 & 2022 & Pull probe out of formation and uphole with wireline \\
10 & 2026 & Stop at mudline for 5 min \\
11 & 2031 & Pull DVTPP uphole with wireline \\
\hline
\end{tabular}

Notes: Measurements taken 2 July 2005. GMT = Greenwich Mean Time, DVTPP = Davis-Villinger Temperature-Pressure Probe, BHA $=$ bottomhole assembly, $\mathrm{BOH}=$ bottom of hole, $\mathrm{CDS}=$ colleted delivery system.

Table AT4. Event summary of DVTPP Deployment 1, Hole U1320A, 203.4 mbsf. (See table notes.)

\begin{tabular}{lll}
\hline $\begin{array}{c}\text { Event } \\
\text { number }\end{array}$ & $\begin{array}{c}\text { Time } \\
(\mathrm{GMT})\end{array}$ & \multicolumn{1}{c}{$\begin{array}{c}\text { Event } \\
\text { description }\end{array}$} \\
\hline 1 & 0850 & Start lowering DVTPP downhole \\
2 & 0901 & Stop at mudline for 10 min \\
3 & 0912 & Start lowering probe \\
4 & 0912 & Raise BHA 11 m off BOH \\
5 & 0916 & CDS lands in BHA \\
6 & 0927 & Lower bit, start penetration of DVTPP into formation \\
7 & 0931 & End of penetration, bit on BOH \\
8 & 0933 & Raise BHA 4 m off BOH \\
9 & 1013 & Pull probe out of formation and uphole with wireline
\end{tabular}

Notes: Measurements taken 9 June 2005. GMT $=$ Greenwich Mean Time, DVTPP $=$ Davis-Villinger Temperature-Pressure Probe, $\mathrm{BHA}=$ bottomhole assembly, $\mathrm{BOH}=$ bottom of hole, $\mathrm{CDS}=$ colleted delivery system.

Table AT5. Event summary of DVTPP Deployment 2, Hole U1320A, 289.9 mbsf. (See table notes.)

\begin{tabular}{lll}
\hline $\begin{array}{c}\text { Event } \\
\text { number }\end{array}$ & $\begin{array}{c}\text { Time } \\
\text { (GMT) }\end{array}$ & \multicolumn{1}{c}{$\begin{array}{c}\text { Event } \\
\text { description }\end{array}$} \\
\hline 1 & 1900 & Start lowering DVTPP downhole \\
2 & 1911 & Stop at mudline for 5 min \\
3 & 1917 & Start lowering probe \\
4 & 1917 & Raise BHA 16 m off BOH \\
5 & 1922 & CDS lands in BHA \\
6 & 1923 & Lower bit, start penetration of DVTPP into formation \\
7 & 1926 & End of penetration, bit on BOH \\
8 & 1928 & Raise BHA 6 m off BOH \\
9 & 1939 & Pull probe out of formation and uphole with wireline \\
10 & 1942 & Stop at mudline for 5 min \\
11 & 1948 & Pull DVTPP uphole with wireline \\
\hline
\end{tabular}

Notes: Measurements taken 9 June 2005. GMT = Greenwich Mean Time, DVTPP $=$ Davis-Villinger Temperature-Pressure Probe, $\mathrm{BHA}=$ bottomhole assembly, $\mathrm{BOH}=$ bottom of hole, $\mathrm{CDS}=$ colleted delivery system. 
Table AT6. Event summary of DVTPP Deployment 3, Hole U1324B, 229.1 mbsf. (See table notes.)

\begin{tabular}{|c|c|c|}
\hline $\begin{array}{l}\text { Event } \\
\text { number }\end{array}$ & $\begin{array}{l}\text { Time } \\
\text { (GMT) }\end{array}$ & $\begin{array}{c}\text { Event } \\
\text { description }\end{array}$ \\
\hline 1 & 0946 & Start lowering DVTPP downhole \\
\hline 2 & 1009 & Stop at mudline for $2 \mathrm{~min}$ \\
\hline 3 & 1011 & Start lowering probe \\
\hline 4 & & Raise BHA off $\mathrm{BOH}$ \\
\hline 5 & & CDS lands in BHA \\
\hline 6 & 1024 & Lower bit, start penetration of DVTPP into formation \\
\hline 7 & 1028 & End of penetration, bit on $\mathrm{BOH}$ \\
\hline 8 & & Raise $\mathrm{BHA}$ off $\mathrm{BOH}$ \\
\hline 9 & 1118 & Pull probe out of formation and uphole with wireline \\
\hline 10 & 1230 & Stop at mudline for $2 \mathrm{~min}$ \\
\hline 11 & 1232 & Pull DVTPP uphole with wireline \\
\hline
\end{tabular}

Notes: Measurements taken 22 June 2005. GMT = Greenwich Mean Time, DVTPP = Davis-Villinger Temperature-Pressure Probe, BHA = bottomhole assembly, $\mathrm{BOH}=$ bottom of hole, $\mathrm{CDS}=$ colleted delivery system.

Table AT7. Event summary of DVTPP Deployment 4, Hole U1324B, 362.4 mbsf. (See table notes.)

\begin{tabular}{|c|c|c|}
\hline $\begin{array}{l}\text { Event } \\
\text { number }\end{array}$ & $\begin{array}{l}\text { Time } \\
\text { (GMT) }\end{array}$ & $\begin{array}{c}\text { Event } \\
\text { description }\end{array}$ \\
\hline 1 & 0615 & Start lowering DVTPP downhole \\
\hline 2 & 0636 & Stop at mudline for $5 \mathrm{~min}$ \\
\hline 3 & 0641 & Start lowering probe \\
\hline 4 & & Raise BHA off $\mathrm{BOH}$ \\
\hline 5 & 0657 & CDS lands in BHA \\
\hline 6 & 0701 & Lower bit, start penetration of DVTPP into formation \\
\hline 7 & 0704 & End of penetration, bit on $\mathrm{BOH}$ \\
\hline 8 & & Raise $\mathrm{BHA}$ off $\mathrm{BOH}$ \\
\hline 9 & 0751 & Pull probe out of formation and uphole with wireline \\
\hline 10 & 0827 & Stop at mudline for $5 \mathrm{~min}$ \\
\hline 11 & 0832 & Pull DVTPP uphole slowly with wireline \\
\hline
\end{tabular}

Notes: Measurements taken 23 June 2005. GMT = Greenwich Mean Time, DVTPP $=$ Davis-Villinger Temperature-Pressure Probe, $\mathrm{BHA}=$ bottomhole assembly, $\mathrm{BOH}=$ bottom of hole, $\mathrm{CDS}=$ colleted delivery system.

Table AT8. Event summary of DVTPP Deployment 6, Hole U1324B, 464.3 mbsf. (See table notes.)

\begin{tabular}{|c|c|c|}
\hline $\begin{array}{c}\text { Event } \\
\text { number }\end{array}$ & $\begin{array}{c}\text { Time } \\
\text { (GMT) }\end{array}$ & $\begin{array}{c}\text { Event } \\
\text { description }\end{array}$ \\
\hline 1 & 0220 & Start lowering DVTPP downhole \\
\hline 2 & 0230 & Stop at mudline for $5 \mathrm{~min}$ \\
\hline 3 & 0235 & Start lowering probe \\
\hline 4 & & Raise BHA off $\mathrm{BOH}$ \\
\hline 5 & 0247 & CDS lands in BHA \\
\hline 6 & 0253 & Lower bit, start penetration of DVTPP into formation \\
\hline 7 & 0257 & End of penetration, bit on $\mathrm{BOH}$ \\
\hline 8 & & Raise $\mathrm{BHA}$ off $\mathrm{BOH}$ \\
\hline 9 & 0331 & Pull probe out of formation and uphole slowly with wireline \\
\hline 10 & 0338 & Stop at mudline for $5 \mathrm{~min}$ \\
\hline 11 & 0343 & Pull DVTPP uphole slowly with wireline \\
\hline
\end{tabular}

Notes: Measurements taken 24 June 2005. GMT = Greenwich Mean Time, DVTPP = Davis-Villinger Temperature-Pressure Probe, BHA = bottomhole assembly, $\mathrm{BOH}=$ bottom of hole, $\mathrm{CDS}=$ colleted delivery system. 
Table AT9. Event summary of DVTPP Deployment 7, Hole U1324B, 493.1 mbsf. (See table notes.)

\begin{tabular}{|c|c|c|}
\hline $\begin{array}{l}\text { Event } \\
\text { number }\end{array}$ & $\begin{array}{l}\text { Time } \\
\text { (GMT) }\end{array}$ & $\begin{array}{c}\text { Event } \\
\text { description }\end{array}$ \\
\hline 1 & 0735 & Start lowering DVTPP downhole \\
\hline 2 & 0743 & Stop at mudline for $5 \mathrm{~min}$ \\
\hline 3 & 0748 & Start lowering probe \\
\hline 4 & & Raise BHA off BOH \\
\hline 5 & 0755 & CDS lands in BHA \\
\hline 6 & 0757 & Lower bit, start penetration of DVTPP into formation \\
\hline 7 & 0801 & End of penetration, bit on $\mathrm{BOH}$ \\
\hline 8 & & Raise $\mathrm{BHA}$ off $\mathrm{BOH}$ \\
\hline 9 & 0832 & Pull probe out of formation and uphole with wireline \\
\hline 10 & 0839 & Stop at mudline for $5 \mathrm{~min}$ \\
\hline 11 & 0844 & Pull DVTPP uphole with wireline \\
\hline
\end{tabular}

Notes: Measurements taken 24 June 2005. GMT = Greenwich Mean Time, DVTPP = Davis-Villinger Temperature-Pressure Probe, BHA = bottomhole assembly, $\mathrm{BOH}=$ bottom of hole, $\mathrm{CDS}=$ colleted delivery system.

Table AT10. Event summary of DVTPP Deployment 8, Hole U1324B, 521.9 mbsf. (See table notes.)

\begin{tabular}{lll}
\hline $\begin{array}{c}\text { Event } \\
\text { number }\end{array}$ & $\begin{array}{c}\text { Time } \\
(\text { GMT })\end{array}$ & \multicolumn{1}{c}{$\begin{array}{c}\text { Event } \\
\text { description }\end{array}$} \\
\hline 1 & 1846 & Start lowering DVTPP downhole \\
2 & 1857 & Stop at mudline for 5 min \\
3 & 1902 & Start lowering probe \\
4 & 1856 & Raise BHA 17 m off BOH \\
5 & 1912 & CDS lands in BHA \\
6 & 1914 & Lower bit, start penetration of DVTPP into formation \\
7 & 1924 & End of penetration, bit on BOH \\
8 & 1930 & Raise BHA 4 m off BOH \\
9 & 2005 & Pull probe out of formation and uphole with wireline \\
10 & 2013 & Stop at mudline for 5 min \\
11 & 2018 & Pull DVTPP uphole with wireline \\
\hline
\end{tabular}

Notes: Measurements taken 24 June 2005. GMT = Greenwich Mean Time, DVTPP $=$ Davis-Villinger Temperature-Pressure Probe, $\mathrm{BHA}=$ bottomhole assembly, $\mathrm{BOH}=$ bottom of hole, $\mathrm{CDS}=$ colleted delivery system.

Table AT11. Event summary of DVTPP Deployment 10, Hole U1324B, 560.4 mbsf. (See table notes.)

\begin{tabular}{lll}
\hline $\begin{array}{c}\text { Event } \\
\text { number }\end{array}$ & $\begin{array}{c}\text { Time } \\
(\mathrm{GMT})\end{array}$ & \multicolumn{1}{c}{$\begin{array}{c}\text { Event } \\
\text { description }\end{array}$} \\
\hline 1 & 0720 & Start lowering DVTPP downhole \\
2 & 0731 & Stop at mudline for 5 min \\
3 & 0736 & Start lowering probe \\
4 & 0739 & Raise BHA 16 m off BOH \\
5 & 0742 & CDS lands in BHA \\
6 & 0742 & Lower bit, start penetration of DVTPP into formation \\
7 & 0747 & End of penetration, bit on BOH \\
8 & 0748 & Raise BHA 4 m off BOH \\
9 & 0819 & Pull probe out of formation and uphole with wireline \\
10 & 0827 & Stop at mudline for 5 min \\
11 & 0832 & Pull DVTPP uphole with wireline \\
\hline
\end{tabular}

Notes: Measurements taken 25 June 2005. GMT = Greenwich Mean Time, DVTPP = Davis-Villinger Temperature-Pressure Probe, BHA = bottomhole assembly, $\mathrm{BOH}=$ bottom of hole, $\mathrm{CDS}=$ colleted delivery system . 
Table AT12. Event summary of DVTPP Deployment 11, Hole U1324B, 589.2 mbsf. (See table notes.)

\begin{tabular}{lll}
\hline $\begin{array}{c}\text { Event } \\
\text { number }\end{array}$ & $\begin{array}{c}\text { Time } \\
(\text { GMT })\end{array}$ & \multicolumn{1}{c}{$\begin{array}{c}\text { Event } \\
\text { description }\end{array}$} \\
\hline 1 & 1402 & Start lowering DVTPP downhole \\
2 & 1411 & Stop at mudline for 5 min \\
3 & 1416 & Start lowering probe \\
4 & 1416 & Raise BHA 23 m off BOH \\
5 & 1423 & CDS lands in BHA \\
6 & 1423 & Lower bit, start penetration of DVTPP into formation \\
7 & 1430 & End of penetration, bit on BOH \\
8 & & Raise BHA off BOH \\
9 & 1515 & Pull probe out of formation and uphole with wireline \\
10 & 1522 & Stop at mudline for 5 min \\
11 & 1527 & Pull DVTPP uphole with wireline \\
\hline
\end{tabular}

Notes: Measurements taken 25 June 2005. GMT = Greenwich Mean Time, DVTPP $=$ Davis-Villinger Temperature-Pressure Probe, $\mathrm{BHA}=$ bottomhole assembly, $\mathrm{BOH}=$ bottom of hole, $\mathrm{CDS}=$ colleted delivery system.

Table AT13. Event summary of DVTPP Deployment 12, Hole U1324B, 608.2 mbsf. (See table notes.)

\begin{tabular}{lll}
\hline $\begin{array}{c}\text { Event } \\
\text { number }\end{array}$ & $\begin{array}{c}\text { Time } \\
(\text { GMT })\end{array}$ & \multicolumn{1}{c}{$\begin{array}{c}\text { Event } \\
\text { description }\end{array}$} \\
\hline 1 & 2248 & Start lowering DVTPP downhole \\
2 & 2305 & Stop at mudline for 5 min \\
3 & 2310 & Start lowering probe \\
4 & 2257 & Raise BHA 17 m off BOH \\
5 & 2318 & CDS lands in BHA \\
6 & 2329 & Lower bit, start penetration of DVTPP into formation \\
7 & 2334 & End of the first penetration, bit is $0.2 \mathrm{~m}$ off BOH \\
8 & 2334 & Raise BHA 4 m off BOH \\
9 & 2335 & Lower bit, start further penetration \\
10 & 2335 & End of penetration, bit on BOH \\
11 & 2336 & Raise BHA 3 m off BOH \\
12 & 0037 & Pull probe out of formation and uphole with wireline \\
13 & 0045 & Stop at mudline for 5 min \\
14 & 0050 & Pull DVTPP uphole with wireline \\
\hline
\end{tabular}

Notes: Measurements taken 25 June 2005. GMT = Greenwich Mean Time, DVTPP = Davis-Villinger Temperature-Pressure Probe, BHA = bottomhole assembly, $\mathrm{BOH}=$ bottom of hole, $\mathrm{CDS}=$ colleted delivery system.

Table AT14. Event summary of DVTPP Deployment 13, Hole U1324C, 250 mbsf. (See table notes.)

\begin{tabular}{lll}
\hline $\begin{array}{c}\text { Event } \\
\text { number }\end{array}$ & $\begin{array}{c}\text { Time } \\
\text { (GMT) }\end{array}$ & \multicolumn{1}{c}{$\begin{array}{c}\text { Event } \\
\text { description }\end{array}$} \\
\hline 1 & 0700 & Start lowering DVTPP downhole \\
2 & 0709 & Stop at mudline for 5 min \\
3 & 0714 & Start lowering probe \\
4 & 0716 & Raise BHA 14.5 m off BOH \\
5 & 0717 & CDS lands in BHA \\
6 & 0717 & Lower bit, start penetration of DVTPP into formation \\
7 & 0722 & End of first penetration, bit 0.15 m off BOH \\
8 & 0724 & Raise BHA 3.5 m off BOH \\
9 & 0724 & Lower bit, start further penetration \\
10 & 0725 & End of penetration, bit on BOH \\
11 & 0855 & Pull probe out of formation and uphole with wireline \\
12 & 0900 & Stop at mudline for 5 min \\
13 & 0904 & Pull DVTPP uphole with wireline \\
\hline
\end{tabular}

Notes: Measurements taken 27 June 2005. GMT = Greenwich Mean Time, DVTPP $=$ Davis-Villinger Temperature-Pressure Probe, $\mathrm{BHA}=$ bottomhole assembly, $\mathrm{BOH}=$ bottom of hole, $\mathrm{CDS}=$ colleted delivery system. 
Table AT15. Event summary of DVTPP Deployment 14, Hole U1324C, 405 mbsf. (See table notes.)

\begin{tabular}{lll}
\hline $\begin{array}{c}\text { Event } \\
\text { number }\end{array}$ & $\begin{array}{c}\text { Time } \\
(\text { GMT })\end{array}$ & \multicolumn{1}{c}{$\begin{array}{c}\text { Event } \\
\text { description }\end{array}$} \\
\hline 1 & 1752 & Start lowering DVTPP downhole \\
2 & 1800 & Stop at mudline for 5 min \\
3 & 1805 & Start lowering probe \\
4 & 1756 & Move BHA to 17 m off BOH \\
5 & 1812 & CDS lands in BHA \\
6 & 1822 & Lower bit, start penetration of DVTPP into formation \\
7 & 1826 & End of penetration, bit on BOH \\
8 & 1830 & Raise BHA 8.5 m off BOH \\
9 & 2000 & Pull probe out of formation and uphole with wireline \\
10 & 2007 & Stop at mudline for 5 min \\
11 & 2012 & Pull DVTPP uphole with wireline \\
\hline
\end{tabular}

Notes: Measurements taken 27 June 2005. GMT = Greenwich Mean Time, DVTPP = Davis-Villinger Temperature-Pressure Probe, BHA = bottomhole assembly, $\mathrm{BOH}=$ bottom of hole, $\mathrm{CDS}=$ colleted delivery system.

Table AT16. Event summary of DVTPP Deployment 15, Hole U1324C, 505 mbsf. (See table notes.)

\begin{tabular}{lll}
\hline $\begin{array}{c}\text { Event } \\
\text { number }\end{array}$ & $\begin{array}{c}\text { Time } \\
\text { (GMT) }\end{array}$ & \multicolumn{1}{c}{$\begin{array}{c}\text { Event } \\
\text { description }\end{array}$} \\
\hline 1 & 0030 & Start lowering DVTPP downhole \\
2 & 0043 & Stop at mudline for 5 min \\
3 & 0048 & Start lowering probe \\
4 & 0057 & CDS lands in BHA \\
5 & 0106 & Lower bit, start penetration of DVTPP into formation \\
6 & 0109 & End of penetration, bit on BOH \\
7 & 0112 & Raise BHA 6.4 m off BOH \\
8 & 0242 & Pull probe out of formation and uphole with wireline \\
9 & 0249 & Stop at mudline for 5 min \\
10 & 0254 & Pull DVTPP uphole with wireline \\
\hline
\end{tabular}

Notes: Measurements taken 28 June 2005. GMT = Greenwich Mean Time, DVTPP = Davis-Villinger Temperature-Pressure Probe, BHA = bottomhole assembly, $\mathrm{BOH}=$ bottom of hole, $\mathrm{CDS}=$ colleted delivery system.

Table AT17. Event summary of DVTPP Deployment 16, Hole U1322B, 166.7 mbsf. (See table notes.)

\begin{tabular}{lll}
\hline $\begin{array}{c}\text { Event } \\
\text { number }\end{array}$ & $\begin{array}{c}\text { Time } \\
(\text { GMT })\end{array}$ & \multicolumn{1}{c}{$\begin{array}{c}\text { Event } \\
\text { description }\end{array}$} \\
\hline 1 & 2242 & Start lowering DVTPP downhole \\
2 & 2257 & Stop at mudline for 5 min \\
3 & 2302 & Start lowering probe \\
4 & 2254 & Raise BHA 8 m off BOH \\
5 & 2310 & CDS lands in BHA, tip touched the formation \\
6 & 2320 & Lower bit, start penetration of DVTPP into formation \\
7 & 2322 & End of penetration, bit on BOH \\
8 & 2323 & Raise BHA 3 m off BOH \\
9 & 2324 & Move BHA back to BOH \\
10 & 0054 & Pull probe out of formation and uphole with wireline \\
11 & 0058 & Stop at mudline for 5 min \\
12 & 0103 & Pull DVTPP uphole with wireline \\
\hline
\end{tabular}

Notes: Measurements taken 29 June 2005. GMT = Greenwich Mean Time, DVTPP = Davis-Villinger Temperature-Pressure Probe, BHA = bottomhole assembly, $\mathrm{BOH}=$ bottom of hole, $\mathrm{CDS}=$ colleted delivery system. 
Table AT18. Event summary of DVTPP Deployment 17, Hole U1322C, 100 mbsf. (See table notes.)

\begin{tabular}{lll}
\hline $\begin{array}{c}\text { Event } \\
\text { number }\end{array}$ & $\begin{array}{c}\text { Time } \\
\text { (GMT) }\end{array}$ & \multicolumn{1}{c}{$\begin{array}{c}\text { Event } \\
\text { description }\end{array}$} \\
\hline 1 & 0152 & Start lowering DVTPP downhole \\
2 & 0211 & Stop at mudline for 5 min \\
3 & 0216 & Start lowering probe \\
4 & & Move BHA off BOH \\
5 & 0222 & CDS lands in BHA \\
6 & 0233 & Lower bit, start penetration of DVTPP into formation \\
7 & 0234 & End of penetration, bit on BOH \\
8 & 0235 & Raise BHA 4 m off BOH \\
9 & 0405 & Pull probe out of formation and uphole with wireline \\
10 & 0409 & Stop at mudline for 5 min \\
11 & 0414 & Pull DVTPP uphole with wireline \\
\hline
\end{tabular}

Notes: Measurements taken 1 July 2005. GMT = Greenwich Mean Time, DVTPP $=$ Davis-Villinger Temperature-Pressure Probe, BHA $=$ bottomhole assembly, $\mathrm{BOH}=$ bottom of hole, $\mathrm{CDS}=$ colleted delivery system.

Table AT19. Event summary of DVTPP Deployment 18, Hole U1322C, 220 mbsf. (See table notes.)

\begin{tabular}{lll}
\hline $\begin{array}{c}\text { Event } \\
\text { number }\end{array}$ & $\begin{array}{c}\text { Time } \\
\text { (GMT) }\end{array}$ & \multicolumn{1}{c}{$\begin{array}{c}\text { Event } \\
\text { description }\end{array}$} \\
\hline 1 & 1545 & Start lowering DVTPP downhole \\
2 & 1607 & Stop at mudline for 5 min \\
3 & 1612 & Start lowering probe \\
4 & & Move BHA to 16 m off BOH \\
5 & 1616 & CDS lands in BHA \\
6 & 1617 & Lower bit, start penetration of DVTPP into formation \\
7 & 1619 & End of penetration, bit on BOH \\
8 & 1619 & Raise BHA 5 m off BOH \\
9 & 1721 & Pull probe out of formation and uphole with wireline \\
10 & 1728 & Stop at mudline for 5 min \\
11 & 1733 & Pull DVTPP uphole with wireline \\
\hline
\end{tabular}

Notes: Measurements taken 1 July 2005. GMT = Greenwich Mean Time, DVTPP $=$ Davis-Villinger Temperature-Pressure Probe, BHA $=$ bottomhole assembly, $\mathrm{BOH}=$ bottom of hole, $\mathrm{CDS}=$ colleted delivery system.

Table AT20. Event summary of DVTPP Deployment 19, Hole U1322C, 238 mbsf. (See table notes.)

\begin{tabular}{lll}
\hline $\begin{array}{c}\text { Event } \\
\text { number }\end{array}$ & $\begin{array}{c}\text { Time } \\
(\text { GMT })\end{array}$ & \multicolumn{1}{c}{$\begin{array}{c}\text { Event } \\
\text { description }\end{array}$} \\
\hline 1 & 1901 & Start lowering DVTPP downhole \\
2 & 1923 & Stop at mudline for 5 min \\
3 & 1928 & Start lowering probe \\
4 & 1928 & Moving BHA to 11 m off BOH \\
5 & 1934 & CDS lands in BHA \\
6 & 1944 & Lower bit, start penetration of DVTPP into formation \\
7 & 1945 & End of penetration, bit on BOH \\
8 & 1946 & Raise BHA 2 m off BOH \\
9 & 1948 & Lower BHA back to BOH \\
10 & 1950 & Raise BHA 6 m off BOH \\
11 & 2118 & Pull probe out of formation and uphole with wireline \\
12 & 2124 & Stop at mudline for 5 min \\
13 & 2128 & Pull DVTPP uphole with wireline \\
\hline
\end{tabular}

Notes: Measurements taken 1 July 2005. GMT = Greenwich Mean Time, DVTPP = Davis-Villinger Temperature-Pressure Probe, BHA = bottomhole assembly, $\mathrm{BOH}=$ bottom of hole, $\mathrm{CDS}=$ colleted delivery system. 
Table AT21. Temperature calibration of T2P. A. Calibration coefficients for data loggers and thermistors. B. Actual thermistor calibration data.

Table AT21A. Calibration coefficients. (See table notes.)

\begin{tabular}{lrc}
\hline $\begin{array}{l}\text { Calibration } \\
\text { coefficient }\end{array}$ & Logger Sn 2 & \multicolumn{1}{c}{ Logger Sn 4 } \\
\hline$R_{1}$ & 1.000729 & 0.990307767 \\
$R_{2}$ & 176.136606 & -72.74909712 \\
\hline
\end{tabular}

\begin{tabular}{|c|c|c|c|c|c|c|}
\hline $\begin{array}{l}\text { Calibration } \\
\text { coefficient }\end{array}$ & $\begin{array}{c}\text { Thermistor } \\
0509-1\end{array}$ & $\begin{array}{c}\text { Thermistor } \\
0509-2\end{array}$ & $\begin{array}{c}\text { Thermistor } \\
0509-3\end{array}$ & $\begin{array}{c}\text { Thermistor } \\
0509-4\end{array}$ & $\begin{array}{c}\text { Thermistor } \\
0509-5\end{array}$ & $\begin{array}{c}\text { Thermistor } \\
0509-6\end{array}$ \\
\hline$A$ & $4.63276461 \mathrm{E}-04$ & $5.43051013 \mathrm{E}-04$ & 4.75887900E-04 & $4.82495572 \mathrm{E}-04$ & $4.82688206 \mathrm{E}-04$ & $4.71824656 \mathrm{E}-04$ \\
\hline$B$ & 2.10947147E-04 & 1.99981837E-04 & $2.08557612 \mathrm{E}-04$ & $2.09282474 \mathrm{E}-04$ & $2.08833095 \mathrm{E}-04$ & $2.09263995 \mathrm{E}-04$ \\
\hline C & $6.19690000 \mathrm{E}-08$ & $8.35910000 \mathrm{E}-08$ & $6.34430000 \mathrm{E}-08$ & $6.20870000 \mathrm{E}-08$ & $6.40080000 \mathrm{E}-08$ & $6.27480000 \mathrm{E}-08$ \\
\hline
\end{tabular}

Notes: For temperature channel calibration (counts to ohms), $R_{\mathrm{t}}{ }^{\prime}=R_{1} \times[5 /(x / 65535 \times 3.5 / 24900)-24900]+R_{2}$, where $x=$ counts and $R_{\mathrm{t}}{ }^{\prime}=$ thermistor resistance in ohms. For thermistor calibration (ohms to Kelvin [Steinhart and Hart]), $1 / t=A+B \times \operatorname{Ln}\left(R_{\mathrm{t}}{ }^{\prime}\right)+C \times \operatorname{Ln}\left(R_{\mathrm{t}}\right)^{3}{ }^{3}$, where $t\left({ }^{\circ} \mathrm{C}\right)=$ $\mathrm{K}-273.15$ and $R_{\mathrm{t}}^{\prime}=$ thermistor resistance in ohms.

Table AT21B. Temperature vs. resistance.

\begin{tabular}{lcccc}
\hline & \multicolumn{4}{c}{ Resistance $(\Omega)$} \\
\cline { 2 - 5 } Serial \# & $0.000^{\circ} \mathrm{C}$ & $30.000^{\circ} \mathrm{C}$ & $60.000^{\circ} \mathrm{C}$ & $100.000^{\circ} \mathrm{C}$ \\
\hline $0509-1$ & 1795000 & 406620 & 116210 & 28980 \\
$0509-2$ & 1720000 & 389890 & 114500 & 27795 \\
$0509-3$ & 1740000 & 394200 & 112590 & 28035 \\
$0509-4$ & 1651000 & 373340 & 106560 & 26535 \\
$0509-5$ & 1655000 & 375720 & 107480 & 26810 \\
$0509-6$ & 1712000 & 388430 & 111130 & 27740 \\
\hline
\end{tabular}

Table AT22. Onboard pressure calibration of T2P, June 2005. (See table note.)

\begin{tabular}{|c|c|c|c|}
\hline $\begin{array}{l}\text { Transducer } \\
\text { number }\end{array}$ & $\begin{array}{l}\text { Slope } \\
\text { (psi/bit) }\end{array}$ & $\begin{array}{l}\text { Intersection } \\
\quad \text { (psi) }\end{array}$ & $R_{2}$ \\
\hline S50-73 & 0.11768162 & 64.28686942 & 0.99999094 \\
\hline $550-74^{*}$ & 0.12469840 & 209.49786126 & 0.99995831 \\
\hline $\mathrm{S} 50-74^{\dagger}$ & 0.12473479 & 161.99347791 & 0.99999663 \\
\hline S50-75 & 0.13043403 & 221.74997847 & 0.99999299 \\
\hline Z59-72* & 0.11819436 & 26.92982866 & 0.99997830 \\
\hline Z59-72 & 0.11816986 & -490.20091995 & 0.99997433 \\
\hline Y67-16 & 0.11944345 & 99.71216680 & 0.99999905 \\
\hline
\end{tabular}

Note: ${ }^{*}=$ pressure calibration before being flooded, $\dagger=$ pressure calibration after oven drying. 
Table AT23. Event summary of T2P Deployment 1, Hole 1319A. (See table notes.)

\begin{tabular}{lll}
\hline $\begin{array}{c}\text { Event } \\
\text { number }\end{array}$ & $\begin{array}{c}\text { Time } \\
(\mathrm{GMT})\end{array}$ & \\
\hline 1 & 2331 & \multicolumn{1}{c}{ Start data logger at 1 Hz } \\
2 & 0146 & T2P on rig floor \\
3 & 0210 & Raise T2P vertically \\
4 & 0210 & Remove pressure response chamber from T2P tip \\
5 & 0210 & Place shroud over T2P tip \\
6 & 0211 & Place T2P in drill pipe \\
7 & 0213 & Connect T2P to spacer \\
8 & 0216 & Connect CDS to spacer \\
9 & 0216 & CDS in extended position \\
10 & 0220 & Start lowering T2P downhole \\
11 & 0232 & Stop at 511 mbsl \\
12 & 0235 & Start lowering probe \\
13 & 0241 & Stop at 1011 mbsl \\
14 & 0244 & Start lowering probe \\
15 & 0255 & Stop at 1388 mbsl \\
16 & 0301 & Start pulling T2P uphole \\
17 & 0316 & Stop at 1010 mbsl \\
18 & 0319 & Continue pulling T2P uphole \\
19 & 0323 & Stop at 511 mbsl \\
20 & 0325 & Continue pulling T2P uphole \\
21 & 0341 & T2P on rig floor \\
22 & 0341 & T2P tip in pressure response chamber \\
23 & 0346 & Pressure response test \\
24 & 0358 & Download data from data logger \\
25 & 0440 & Remove battery from T2P \\
\hline & & \\
& &
\end{tabular}

Notes: Tool test in water column, 7 June 2005. GMT = Greenwich Mean Time, T2P = temperature/dual pressure probe, CDS $=$ colleted delivery system. 
Table AT24. Event summary of T2P Deployment 2, Hole U1319A, 80.5 mbsf. (See table notes.)

\begin{tabular}{lll}
\hline $\begin{array}{c}\text { Event } \\
\text { number }\end{array}$ & $\begin{array}{c}\text { Time } \\
(\mathrm{GMT})\end{array}$ & \\
\hline 1 & 0607 & \multicolumn{1}{c}{ Start data logger at 1 Hz } \\
2 & 1313 & T2P on rig floor \\
3 & 1315 & Raise T2P vertically \\
4 & 1316 & Remove pressure response chamber from T2P tip \\
5 & 1316 & Place shroud over T2P tip \\
6 & 1319 & Place T2P in drill pipe \\
7 & 1320 & Connect T2P to spacer \\
8 & 1323 & Connect CDS to spacer \\
9 & 1325 & CDS in extended position \\
10 & 1326 & Start lowering T2P downhole, pumps on \\
11 & 1335 & Stop at 511 mbsl, pumps off \\
12 & 1337 & Start lowering probe, pumps on \\
13 & 1344 & Stop at 1012 mbsl, pumps off \\
14 & 1346 & Start lowering probe, pumps on \\
15 & 1352 & Stop at 1431 mbsl, pumps off \\
16 & 1355 & Start lowering probe \\
17 & 1358 & Pass T2P through LFV \\
18 & 1405 & CDS lands in BHA \\
19 & 1408 & Start penetration of T2P into sediment \\
20 & 1415 & End of T2P penetration \\
21 & 1427 & Pumps on at 10 spm \\
22 & 1447 & Start pulling T2P uphole \\
23 & 1448 & Stop pulling at 1509 mbsl \\
24 & 1449 & Pull/release winch to free CDS from BHA \\
25 & 1452 & Start pulling T2P uphole \\
26 & 1509 & Stop at 511 mbsl, pumps off \\
27 & 1511 & Start pulling T2P uphole \\
28 & 1520 & Detach CDS from wireline \\
29 & 1527 & Detach CDS from spacer \\
30 & 1530 & Detach spacer from T2P \\
31 & 1530 & T2P on rig floor \\
32 & 1531 & T2P tip in pressure response chamber \\
33 & 1539 & T2P in workroom \\
34 & 1549 & Remove battery from T2P \\
35 & 1604 & Connect T2P to DC power \\
36 & 1605 & Download data from data logger \\
\hline & & \\
& &
\end{tabular}

Notes: Measurements taken 7 June 2005. GMT = Greenwich Mean Time, T2P = temperature/dual pressure probe, CDS $=$ colleted delivery system, $\mathrm{LFV}=$ lockable float valve, spm = strokes per minute, $\mathrm{BHA}=$ bottom-hole assembly, $\mathrm{DC}=$ direct current. 
Table AT25. Event summary of T2P Deployment 3, Hole U1320A, 126.3 mbsf. (See table notes.)

\begin{tabular}{lll}
\hline $\begin{array}{c}\text { Event } \\
\text { number }\end{array}$ & $\begin{array}{c}\text { Time } \\
\text { (GMT) }\end{array}$ & \\
\hline 1 & & \multicolumn{1}{c}{ Start data logger at 1 Hz description } \\
2 & 2308 & T2P on rig floor \\
3 & 2314 & Remove pressure response chamber from T2P tip \\
4 & 2314 & Place shroud over T2P tip \\
5 & 2315 & Connect T2P to spacer \\
6 & 2317 & Connect CDS to spacer \\
7 & 2322 & Connect CDS to wireline \\
8 & 2323 & Start lowering T2P downhole, pumps on \\
9 & 2330 & Stop at 511 mbsl, pumps off \\
10 & 2333 & Start lowering probe, pumps on \\
11 & 2340 & Stop at 1011 mbsl, pumps off \\
12 & 2343 & Start lowering probe, pumps on \\
13 & 2344 & Pump at 13 spm \\
14 & 2350 & Stop at 1490 mbsl, pumps off \\
15 & 2353 & Start lowering probe, pumps on at 13 spm \\
16 & 2357 & Pumps off \\
17 & 0000 & CDS lands in BHA \\
18 & 0000 & Raise BHA to 2 m off BOH \\
19 & 0002 & Start penetration of T2P into sediment, 2m advance of BHA \\
20 & 0003 & End of T2P penetration \\
21 & 0004 & Raise BHA 3m off BOH \\
22 & 0007 & Pump at 10 spm \\
23 & 0055 & Pull T2P uphole slowly 10 $\mathrm{m}$ \\
24 & 0059 & 10 m pull completed \\
25 & 0059 & Pull T2P uphole, pump at 10 spm \\
26 & 0105 & Stop at 511 mbsl, pumps off \\
27 & 0109 & Pull T2P uphole, pumps on \\
28 & 0113 & Detach CDS from wireline \\
29 & 0116 & Detach CDS from spacer \\
30 & 0118 & Detach spacer from T2P \\
31 & 0118 & T2P on rig floor \\
32 & 0118 & T2P tip in pressure response chamber \\
33 & 0126 & T2P in workroom \\
34 & 0146 & Remove battery from T2P \\
35 & 0146 & Connect T2P to DC power \\
& & Download data from data logger \\
\hline & &
\end{tabular}

Notes: Measurements taken 8-9 June 2005. GMT = Greenwich Mean Time, T2P $=$ temperature/dual pressure probe, CDS $=$ colleted delivery system, $\mathrm{spm}=$ strokes per minute, $\mathrm{BHA}=$ bottom-hole assembly, $\mathrm{BOH}=$ bottom of hole, $\mathrm{DC}=$ direct current. 
Table AT26. Event summary of T2P Deployment 4, Hole U1320A, 213.0 mbsf. (See table notes.)

\begin{tabular}{|c|c|c|}
\hline $\begin{array}{c}\text { Event } \\
\text { number }\end{array}$ & $\begin{array}{c}\text { Time } \\
\text { (GMT) }\end{array}$ & Event description \\
\hline 1 & & Start data logger at $1 \mathrm{~Hz}$ \\
\hline 2 & 1124 & T2P on rig floor \\
\hline 3 & 1129 & Remove pressure response chamber from $\mathrm{T} 2 \mathrm{P}$ tip \\
\hline 4 & 1129 & Place shroud over T2P tip \\
\hline 5 & 1131 & $\mathrm{~T} 2 \mathrm{P}$ in drill pipe \\
\hline 6 & 1132 & Connect $\mathrm{T} 2 \mathrm{P}$ to spacer \\
\hline 7 & 1134 & Connect CDS to spacer \\
\hline 8 & 1137 & Connect CDS to wireline \\
\hline 9 & 1139 & Start lowering T2P downhole, pumps on \\
\hline 10 & 1144 & Stop at $511 \mathrm{mbsl}$, pumps off \\
\hline 11 & 1146 & Start lowering probe, pumps on \\
\hline 12 & 1152 & Stop at $1011 \mathrm{mbsl}$, pumps off \\
\hline 13 & 1154 & Start lowering probe, pumps on \\
\hline 14 & 1200 & Stop at $1471 \mathrm{mbsl}$, pumps off \\
\hline 15 & 1203 & Position drill bit $0.5-0.75 \mathrm{~m}$ off $\mathrm{BOH}$ \\
\hline 16 & 1212 & CDS lands in $\mathrm{BHA}$, probe in formation \\
\hline 17 & 1212 & Raise BHA $2.5 \mathrm{~m}$ \\
\hline 18 & 1217 & Pump at $10 \mathrm{spm}$ \\
\hline 19 & 1236 & Pull T2P uphole to disengage CDS \\
\hline 20 & 1237 & Pull T2P uphole \\
\hline 21 & 1251 & T2P tip at $372 \mathrm{mbsl}$ \\
\hline 22 & 1254 & Lower T2P to $511 \mathrm{mbsl}$, pumps off \\
\hline 23 & 1256 & Pull T2P uphole \\
\hline 24 & 1305 & Lower CDS to retracted position \\
\hline 25 & 1308 & Detach CDS from spacer \\
\hline 26 & 1309 & Detach T2P from spacer \\
\hline 27 & 1309 & $\mathrm{~T} 2 \mathrm{P}$ tip in pressure response chamber \\
\hline 28 & 1316 & T2P in workroom \\
\hline 29 & & Remove battery from T2P \\
\hline 30 & & Connect T2P to DC power \\
\hline 31 & & Download data from data logger \\
\hline
\end{tabular}

Notes: Measurements taken 9 June 2005. GMT $=$ Greenwich Mean Time, T2P $=$ temperature/dual pressure probe, CDS $=$ colleted delivery system, $\mathrm{BOH}=$ bottom of hole, $\mathrm{BHA}=$ bottom-hole assembly, $\mathrm{spm}=$ strokes per minute, $\mathrm{DC}=$ direct current. 
Table AT27. Event summary of T2P Deployment 5, Hole U1324B, 51.3 mbsf. (See table notes.)

\begin{tabular}{lll}
\hline $\begin{array}{c}\text { Event } \\
\text { number }\end{array}$ & $\begin{array}{c}\text { Time } \\
(\text { GMT) }\end{array}$ & \\
\hline 1 & & \multicolumn{1}{c}{ Event description } \\
2 & 1140 & Start data logger at 1 Hz \\
3 & 1147 & Remove pressure response chamber from T2P tip \\
4 & 1147 & Place shroud over T2P tip \\
5 & 1148 & Connect T2P to spacer \\
6 & 1150 & Connect CDS to spacer \\
7 & 1155 & Start lowering T2P downhole, pumps on \\
8 & 1204 & Stop at 515 mbsl, pumps off \\
9 & 1208 & Start lowering probe, pumps on \\
10 & 1212 & Stop at 768 mbsl, pumps off \\
11 & 1214 & Start lowering probe, pumps on \\
12 & 1219 & Stop at 1066 mbsl, pumps off \\
13 & 1222 & Start lowering probe, pumps on at 18 spm \\
14 & 1223 & Bit is 0.5 m off BOH \\
15 & 1224 & Start lowering probe to land in BHA \\
16 & 1225 & CDS lands in BHA, pumps off \\
17 & 1225 & Raise BHA to 2 $\mathrm{m}$ off BOH \\
18 & 1226 & Start penetration of T2P into sediment, 2 m advance of BHA \\
19 & 1227 & End of T2P penetration, bit 0.25 m off BOH \\
20 & 1227 & Raise BHA 2 m off BOH \\
21 & 1232 & Pump at 11 spm \\
22 & 1257 & Pull T2P uphole slowly with wireline \\
23 & 1258 & CDS clear of BHA \\
24 & 1300 & Stop at 1067 mbsl, pumps off \\
25 & 1304 & Pull T2P uphole slowly with wireline \\
26 & 1309 & Stop at 767 mbsl, pumps off \\
27 & 1311 & Pull T2P uphole slowly with wireline \\
28 & 1315 & Stop at 516 mbsl, pumps off \\
29 & 1317 & Pull T2P uphole slowly with wireline \\
30 & 1325 & Disconnect wireline from CDS \\
31 & 1325 & Extend CDS \\
32 & 1328 & Disconnect CDS from spacer \\
33 & 1328 & Disconnect spacer from CDS \\
34 & 1330 & Disconnect T2P from spacer \\
35 & 1333 & T2P out of pipe \\
36 & & Download data from data logger \\
\hline & &
\end{tabular}

Notes: Measurements taken 21 June 2005. GMT = Greenwich Mean Time, T2P = temperature/dual pressure probe, CDS $=$ colleted delivery system, $\mathrm{spm}=$ strokes per minute, $\mathrm{BOH}=$ bottom of hole, $\mathrm{BHA}=$ bottom-hole assembly. 
Table AT28. Event summary of T2P Deployment 6, Hole U1324B, 89.3 mbsf. (See table notes.)

\begin{tabular}{|c|c|c|}
\hline $\begin{array}{l}\text { Event } \\
\text { number }\end{array}$ & $\begin{array}{l}\text { Time } \\
(\mathrm{GMT})\end{array}$ & Event description \\
\hline 1 & 1417 & Start data logger at $1 \mathrm{~Hz}$ \\
\hline 2 & 1615 & $\mathrm{~T} 2 \mathrm{P}$ on rig floor \\
\hline 3 & 1647 & Start lowering T2P downhole, pumps on \\
\hline 4 & 1656 & Stop at $511 \mathrm{mbsl}$, pumps off \\
\hline 5 & 1657 & Start lowering probe, pumps on \\
\hline 6 & 1703 & Stop at $761 \mathrm{mbsl}$, pumps off \\
\hline 7 & 1704 & Start lowering probe, pumps on \\
\hline 8 & 1710 & Stop at $1058 \mathrm{mbsl}$, pumps off \\
\hline 9 & 1716 & Start lowering probe \\
\hline 10 & 1718 & Stop at 1135 mbsl, pumps off \\
\hline 11 & 1720 & Start lowering probe to land in $\mathrm{BHA}$ \\
\hline 12 & 1722 & CDS lands in BHA, pumps off \\
\hline 13 & 1731 & Start penetration of T2P into sediment \\
\hline 14 & 1733 & End of T2P penetration, bit $1 \mathrm{~m}$ off $\mathrm{BOH}$ \\
\hline 15 & 1736 & Raise BHA 2 m off $\mathrm{BOH}$ \\
\hline 16 & 1742 & Pump at 11 spm \\
\hline 17 & 1808 & Pull T2P uphole slowly with wireline \\
\hline 18 & 1811 & CDS clear of $\mathrm{BHA}$ \\
\hline 19 & 1813 & Stop at $1058 \mathrm{mbsl}$, pumps off \\
\hline 20 & 1815 & Pull T2P uphole slowly with wireline \\
\hline 21 & 1818 & Stop at $760 \mathrm{mbsl}$, pumps off \\
\hline 22 & 1820 & Pull T2P uphole slowly with wireline \\
\hline 23 & 1823 & Stop at $511 \mathrm{mbsl}$, pumps off \\
\hline 24 & 1825 & Pull T2P uphole slowly with wireline \\
\hline 25 & 1831 & Disconnect wireline from CDS \\
\hline 26 & 1832 & Retract CDS \\
\hline 27 & 1835 & Disconnect CDS from spacer \\
\hline 28 & 1837 & Disconnect spacer from CDS \\
\hline 29 & 1838 & T2P out of pipe \\
\hline 30 & 1850 & Download data from data logger \\
\hline
\end{tabular}

Notes: Measurements taken 21 June 2005. GMT = Greenwich Mean Time, T2P = temperature/dual pressure probe, BHA = bottom-hole assembly, $\mathrm{CDS}=$ colleted delivery system, $\mathrm{BOH}=$ bottom of hole, $\mathrm{spm}=$ strokes per minute. 
Table AT29. Event summary of T2P Deployment 7, Hole U1324B, 117.8 mbsf. (See table notes.)

\begin{tabular}{ccl}
\hline $\begin{array}{c}\text { Event } \\
\text { number }\end{array}$ & $\begin{array}{c}\text { Time } \\
(\text { GMT) }\end{array}$ & \\
\hline 1 & 2018 & \multicolumn{1}{c}{ Event description } \\
2 & 2056 & T2P on rig floor \\
3 & 2107 & Start lowering T2P downhole, pumps on \\
4 & 2115 & Stop at 511 mbsl, pumps off \\
5 & 2117 & Start lowering probe, pumps on \\
6 & 2120 & Stop at 761 mbsl, pumps off \\
7 & 2122 & Start lowering probe, pumps on \\
8 & 2126 & Stop at 1058 mbsl, pumps off \\
9 & 2130 & Start lowering probe \\
10 & 2133 & Stop at 1164 mbsl, pumps off \\
11 & 2140 & Start lowering probe to land in BHA \\
12 & 2144 & CDS lands in BHA, pumps off \\
13 & 2147 & Start penetration of T2P into sediment \\
14 & 2148 & End of T2P penetration, bit 1 m off BOH \\
15 & 2152 & Raise BHA 2 m off BOH \\
16 & 2158 & Pump at 14 spm \\
17 & 2228 & Pull T2P uphole slowly with wireline \\
18 & 2233 & CDS clear of BHA \\
19 & 2234 & Stop at 1058 mbsl, pumps off \\
20 & 2236 & Pull T2P uphole slowly with wireline \\
21 & 2240 & Stop at 760 mbsl, pumps off \\
22 & 2242 & Pull T2P uphole slowly with wireline \\
23 & 2246 & Stop at 511 mbsl, pumps off \\
24 & 2248 & Pull T2P uphole slowly with wireline \\
25 & 2255 & Disconnect wireline from CDS \\
26 & 2256 & Retract CDS \\
27 & 2258 & Disconnect CDS from spacer \\
28 & 2259 & Disconnect spacer from CDS \\
29 & 2301 & T2P out of pipe \\
30 & 2308 & Download data from data logger \\
\hline & & \\
\hline & & \\
13 & &
\end{tabular}

Notes: Measurements taken 21 June 2005. GMT = Greenwich Mean Time, T2P = temperature/dual pressure probe, BHA = bottom-hole assembly, $\mathrm{CDS}=$ colleted delivery system, $\mathrm{BOH}=$ bottom of hole, $\mathrm{spm}=$ strokes per minute. 
Table AT30. Event summary of T2P Deployment 8, Hole U1324B, 136.3 mbsf. (See table notes.)

\begin{tabular}{|c|c|c|}
\hline $\begin{array}{l}\text { Event } \\
\text { number }\end{array}$ & $\begin{array}{l}\text { Time } \\
(\mathrm{GMT})\end{array}$ & Event description \\
\hline 1 & 0028 & Start data logger at $1 \mathrm{~Hz}$ \\
\hline 2 & 0145 & $\mathrm{~T} 2 \mathrm{P}$ on rig floor \\
\hline 3 & 0158 & Start lowering T2P downhole, pumps on \\
\hline 4 & 0208 & Stop at $511 \mathrm{mbsl}$, pumps off \\
\hline 5 & 0210 & Start lowering probe, pumps on \\
\hline 6 & 0214 & Stop at $761 \mathrm{mbsl}$, pumps off \\
\hline 7 & 0217 & Start lowering probe, pumps on \\
\hline 8 & 0221 & Stop at $1058 \mathrm{mbsl}$, pumps off \\
\hline 9 & 0223 & Start lowering probe \\
\hline 10 & 0227 & Stop at $1151 \mathrm{mbsl}$, pumps off \\
\hline 11 & 0232 & Start lowering probe \\
\hline 12 & 0234 & Stop at $1181 \mathrm{mbsl}$, pumps off \\
\hline 13 & 0238 & Start lowering probe \\
\hline 14 & 0243 & CDS lands in BHA, pumps off \\
\hline 15 & 0243 & Start penetration of T2P into sediment \\
\hline 16 & 0244 & End of $\mathrm{T} 2 \mathrm{P}$ penetration, bit at $\mathrm{BOH}$ \\
\hline 17 & 0245 & Raise BHA $1.5 \mathrm{~m}$ off $\mathrm{BOH}$ \\
\hline 18 & 0316 & Pull T2P uphole slowly with wireline \\
\hline 19 & 0318 & CDS clear of BHA \\
\hline 20 & 0320 & Stop at $1058 \mathrm{mbsl}$, pumps off \\
\hline 21 & 0323 & Pull T2P uphole slowly with wireline \\
\hline 22 & 0327 & Stop at $761 \mathrm{mbsl}$, pumps off \\
\hline 23 & 0330 & Pull T2P uphole slowly with wireline \\
\hline 24 & 0333 & Stop at $511 \mathrm{mbsl}$, pumps off \\
\hline 25 & 0336 & Pull T2P uphole slowly with wireline \\
\hline 26 & 0342 & Disconnect wireline from CDS \\
\hline 27 & 0345 & Disconnect CDS from spacer \\
\hline 28 & 0346 & Disconnect spacer from CDS \\
\hline 29 & 0347 & T2P out of pipe \\
\hline 30 & 0411 & Download data from data logger \\
\hline
\end{tabular}

Notes: Measurements taken 22 June 2005. GMT = Greenwich Mean Time, T2P = temperature/dual pressure probe, CDS = colleted delivery system, $\mathrm{BHA}=$ bottom-hole assembly, $\mathrm{BOH}=$ bottom of hole.

Table AT31. Event summary of T2P Deployment 9, Hole U1324B, 368.0 mbsf. (See table notes.)

\begin{tabular}{|c|c|c|}
\hline $\begin{array}{l}\text { Event } \\
\text { number }\end{array}$ & $\begin{array}{l}\text { Time } \\
\text { (GMT) }\end{array}$ & Event description \\
\hline 1 & 1328 & Start data logger at $1 \mathrm{~Hz}$ \\
\hline 2 & 1457 & T2P on rig floor \\
\hline 3 & 1511 & Start lowering T2P downhole, pumps on \\
\hline 4 & 1528 & Stop at $1058 \mathrm{mbsl}$, pumps off \\
\hline 5 & 1533 & Start lowering probe \\
\hline 6 & 1545 & Stop at $1432 \mathrm{mbsl}$, pumps off \\
\hline 7 & 1549 & Start lowering probe \\
\hline 8 & 1553 & CDS lands in BHA, pumps off \\
\hline 9 & 1554 & Start penetration of $\mathrm{T} 2 \mathrm{P}$ into sediment \\
\hline 10 & 1558 & End of $\mathrm{T} 2 \mathrm{P}$ penetration, bit at $\mathrm{BOH}$ \\
\hline 11 & 1559 & Raise $\mathrm{BHA} 2 \mathrm{~m}$ off $\mathrm{BOH}$ \\
\hline 12 & 1640 & Pull T2P uphole slowly with wireline \\
\hline 13 & 1648 & Stop at $1058 \mathrm{mbsl}$, pumps off \\
\hline 14 & 1651 & Pull T2P uphole slowly with wireline \\
\hline 15 & 1701 & Disconnect wireline from CDS \\
\hline 16 & 1704 & Disconnect CDS from spacer \\
\hline 17 & 1706 & Disconnect spacer from CDS \\
\hline 18 & 1708 & T2P out of pipe \\
\hline 19 & 1730 & Download data from data logger \\
\hline
\end{tabular}

Notes: Measurements taken 23 June 2005. GMT = Greenwich Mean Time, T2P $=$ temperature/dual pressure probe, CDS $=$ colleted delivery system, $\mathrm{BHA}=$ bottom-hole assembly, $\mathrm{BOH}=$ bottom of hole. 
Table AT32. Event summary of T2P Deployment 11, Hole U1324B, 593.2 mbsf. (See table notes.)

\begin{tabular}{lll}
\hline $\begin{array}{c}\text { Event } \\
\text { number }\end{array}$ & $\begin{array}{c}\text { Time } \\
(\mathrm{GMT})\end{array}$ & \multicolumn{1}{c}{ Event description } \\
\hline 1 & 1802 & Start data logger at 1 Hz \\
2 & 1818 & T2P on rig floor \\
3 & 1831 & Start lowering T2P downhole, pumps on \\
4 & 1842 & Stop at 1068 mbsl, pumps off \\
5 & 1845 & Start lowering probe \\
6 & 1850 & Stop at 1510 mbsl, pumps off \\
7 & 1856 & Start lowering probe \\
8 & 1858 & CDS lands in BHA, pumps off \\
9 & 1914 & Pull T2P uphole slowly with wireline \\
10 & 1925 & Stop at 1067 mbsl, pumps off \\
11 & 1928 & Pull T2P uphole slowly with wireline \\
12 & 1934 & Disconnect wireline from CDS \\
13 & 1938 & Disconnect CDS from spacer \\
14 & 1940 & Disconnect spacer from CDS \\
15 & 1946 & T2P out of pipe \\
16 & 2010 & Download data from data logger \\
\hline
\end{tabular}

Notes: Measurements taken 25 June 2005. GMT = Greenwich Mean Time, T2P = temperature/dual pressure probe, CDS $=$ colleted delivery system, $\mathrm{BHA}=$ bottom-hole assembly.

Table AT33. Event summary of T2P Deployment 12, Hole U1324C, 50.0 mbsf. (See table notes.)

\begin{tabular}{|c|c|c|}
\hline $\begin{array}{c}\text { Event } \\
\text { number }\end{array}$ & $\begin{array}{l}\text { Time } \\
(\mathrm{GMT})\end{array}$ & Event description \\
\hline 1 & & Start data logger at $1 \mathrm{~Hz}$ \\
\hline 2 & 1044 & $\mathrm{~T} 2 \mathrm{P}$ on rig floor \\
\hline 3 & 1052 & Start lowering T2P downhole, pumps on \\
\hline 4 & 1109 & Stop at $491 \mathrm{mbsl}$, pumps off \\
\hline 5 & 1111 & Start lowering probe \\
\hline 6 & 1114 & Stop at $741 \mathrm{mbsl}$, pumps off \\
\hline 7 & 1119 & Stop at $1057 \mathrm{mbsl}$, pumps off \\
\hline 8 & 1122 & Stop at $1095 \mathrm{mbsl}$, pumps off \\
\hline 9 & 1128 & Start lowering probe \\
\hline 10 & 1129 & CDS lands in BHA, pumps off \\
\hline 11 & 1132 & Start penetration of $\mathrm{T} 2 \mathrm{P}$ into sediment \\
\hline 12 & 1140 & End of $\mathrm{T} 2 \mathrm{P}$ penetration, bit on $\mathrm{BOH}$ \\
\hline 13 & 1140 & Raise BHA $4.5 \mathrm{~m}$ off $\mathrm{BOH}$ \\
\hline 14 & 1241 & Pull T2P uphole slowly with wireline \\
\hline 15 & 1244 & Stop at 1057 mbsl, pumps off \\
\hline 16 & 1248 & Pull T2P uphole slowly with wireline \\
\hline 17 & 1254 & Stop at $741 \mathrm{mbsl}$, pumps off \\
\hline 18 & 1256 & Pull T2P uphole slowly with wireline \\
\hline 19 & 1300 & Stop at $491 \mathrm{mbsl}$, pumps off \\
\hline 20 & 1302 & Pull T2P uphole slowly with wireline \\
\hline 21 & & Download data from data logger \\
\hline
\end{tabular}

Notes: Measurements taken 26 June 2005. GMT = Greenwich Mean Time, T2P = temperature/dual pressure probe, CDS $=$ colleted delivery system, $\mathrm{BHA}=$ bottom-hole assembly, $\mathrm{BOH}=$ bottom of hole. 
Table AT34. Event summary of T2P Deployment 13, Hole U1324C, 100.0 mbsf. (See table notes.)

\begin{tabular}{lll}
\hline $\begin{array}{c}\text { Event } \\
\text { number }\end{array}$ & $\begin{array}{c}\text { Time } \\
(\mathrm{GMT})\end{array}$ & \multicolumn{1}{c}{ Event description } \\
\hline 1 & 1442 & Start data logger at 1 Hz \\
2 & 1618 & T2P on rig floor \\
3 & 1628 & Start lowering T2P downhole, pumps on \\
4 & 1644 & Stop at 741 mbsl, pumps off \\
5 & 1646 & Start lowering probe \\
6 & 1652 & Stop at 1057 mbsl, pumps off \\
7 & 1654 & Start lowering probe \\
8 & 1703 & CDS lands in BHA, pumps off \\
9 & 1704 & Start penetration of T2P into sediment \\
10 & 1705 & End of T2P penetration, bit 1 m off BOH \\
11 & 1706 & Raise BHA 2 m off BOH \\
12 & 1808 & Pull T2P uphole slowly with wireline \\
13 & 1811 & Stop at 1057 mbsl, pumps off \\
14 & 1813 & Pull T2P uphole slowly with wireline \\
15 & 1817 & Stop at 741 mbsl, pumps off \\
16 & 1819 & Pull T2P uphole slowly with wireline \\
17 & 1822 & Stop at 491 mbsl, pumps off \\
18 & 1824 & Pull T2P uphole slowly with wireline \\
19 & 1830 & Disconnect wireline from CDS \\
20 & 1834 & Disconnect CDS from spacer \\
21 & 1836 & Disconnect spacer from CDS \\
22 & 1836 & T2P out of pipe \\
23 & & Download data from data logger \\
\hline & &
\end{tabular}

Notes: Measurements taken 26 June 2005. GMT = Greenwich Mean Time, T2P $=$ temperature/dual pressure probe, CDS $=$ colleted delivery system, $\mathrm{BHA}=$ bottom-hole assembly, $\mathrm{BOH}=$ bottom of hole.

Table AT35. Event summary of T2P Deployment 14, Hole U1324C, 150.0 mbsf. (See table notes.)

\begin{tabular}{|c|c|c|}
\hline $\begin{array}{c}\text { Event } \\
\text { number }\end{array}$ & $\begin{array}{l}\text { Time } \\
\text { (GMT) }\end{array}$ & Event description \\
\hline 1 & & Start data logger at $1 \mathrm{~Hz}$ \\
\hline 2 & 2128 & Stop at $491 \mathrm{mbsl}$, pumps off \\
\hline 3 & 2130 & Start lowering T2P \\
\hline 4 & 2135 & Stop at $741 \mathrm{mbsl}$, pumps off \\
\hline 5 & 2137 & Start lowering $\mathrm{T} 2 \mathrm{P}$ \\
\hline 6 & 2143 & Stop at $1057 \mathrm{mbsl}$, pumps off \\
\hline 7 & 2145 & Start lowering T2P \\
\hline 8 & 2149 & Stop at $1195 \mathrm{mbsl}$, pumps off \\
\hline 9 & 2152 & Start lowering T2P \\
\hline 10 & 2155 & CDS lands in BHA, pumps off \\
\hline 11 & 2156 & Start penetration of $\mathrm{T} 2 \mathrm{P}$ into sediment \\
\hline 12 & 2157 & End of $\mathrm{T} 2 \mathrm{P}$ penetration, bit on $\mathrm{BOH}$ \\
\hline 13 & 2157 & Raise BHA 2.5 m off $\mathrm{BOH}$ \\
\hline 14 & 2302 & Pull T2P uphole slowly with wireline \\
\hline 15 & 2309 & Stop at $1057 \mathrm{mbsl}$, pumps off \\
\hline 16 & 2314 & Pull T2P uphole slowly with wireline \\
\hline 17 & 2318 & Stop at $741 \mathrm{mbsl}$, pumps off \\
\hline 18 & 2321 & Pull T2P uphole slowly with wireline \\
\hline 19 & 2324 & Stop at $491 \mathrm{mbsl}$, pumps off \\
\hline 20 & 2326 & Pull T2P uphole slowly with wireline \\
\hline 21 & & Download data from data logger \\
\hline
\end{tabular}

Notes: Measurements taken 26 June 2005. GMT = Greenwich Mean Time, T2P $=$ temperature/dual pressure probe, CDS $=$ colleted delivery system, $\mathrm{BHA}=$ bottom-hole assembly, $\mathrm{BOH}=$ bottom of hole. 
Table AT36. Event summary of T2P Deployment 15, Hole U1324C, 200.0 mbsf. (See table notes.)

\begin{tabular}{lll}
\hline $\begin{array}{c}\text { Event } \\
\text { number }\end{array}$ & $\begin{array}{c}\text { Time } \\
\text { (GMT) }\end{array}$ & \multicolumn{1}{c}{ Event description } \\
\hline 1 & 0049 & Start data logger at 1 Hz \\
2 & 0156 & T2P on rig floor \\
3 & 0209 & Start lowering T2P downhole, pumps on \\
4 & 0217 & Stop at 491 mbsl, pumps off \\
5 & 0219 & Start lowering probe \\
6 & 0224 & Stop at 741 mbsl, pumps off \\
7 & 0226 & Start lowering probe \\
8 & 0232 & Stop at 1057 mbsl, pumps off \\
9 & 0235 & Start lowering probe \\
10 & 0240 & Stop at 1245 mbsl, pumps off \\
11 & 0243 & Start lowering probe \\
12 & 0247 & CDS lands in BHA, pumps off \\
13 & 0248 & Start penetration of T2P into sediment \\
14 & 0249 & End of T2P penetration, bit 1 m off BOH \\
15 & 0252 & Raise BHA 4.5 m off BOH \\
16 & 0353 & Pull T2P uphole slowly with wireline \\
17 & 0356 & Stop at 1057 mbsl, pumps off \\
18 & 0359 & Pull T2P uphole slowly with wireline \\
19 & 0402 & Stop at 741 mbsl, pumps off \\
20 & 0405 & Pull T2P uphole slowly with wireline \\
21 & 0407 & Stop at 491 mbsl, pumps off \\
22 & 0410 & Pull T2P uphole slowly with wireline \\
23 & 0415 & Disconnect wireline from CDS \\
24 & 0417 & Disconnect CDS from spacer \\
25 & 0419 & Disconnect spacer from CDS \\
26 & 0421 & T2P out of pipe \\
27 & & Download data from data logger \\
\hline & & \\
\end{tabular}

Notes: Measurements taken 27 June 2005. GMT = Greenwich Mean Time, T2P = temperature/dual pressure probe, CDS $=$ colleted delivery system, $\mathrm{BHA}=$ bottom-hole assembly, $\mathrm{BOH}=$ bottom of hole.

Table AT37. Event summary of T2P Deployment 16, Hole U1324C, 300.0 mbsf. (See table notes.)

\begin{tabular}{lll}
\hline $\begin{array}{c}\text { Event } \\
\text { number }\end{array}$ & $\begin{array}{c}\text { Time } \\
\text { (GMT) }\end{array}$ & \multicolumn{1}{c}{ Event description } \\
\hline 1 & & Start data logger at 1 Hz \\
2 & 1118 & Start lowering T2P downhole, pumps on \\
3 & 1137 & Stop at 491 mbsl, pumps off \\
4 & 1139 & Start lowering probe \\
5 & 1143 & Stop at 741 mbsl, pumps off \\
6 & 1145 & Start lowering probe \\
7 & 1149 & Stop at 1057 mbsl, pumps off \\
8 & 1152 & Start lowering probe \\
9 & 1157 & Stop at 1345 mbsl, pumps off \\
10 & 1159 & Start lowering probe \\
11 & 1205 & Start penetration of T2P into sediment \\
12 & 1217 & End of T2P penetration, bit on BOH \\
13 & 1222 & Raise BHA 4m off BOH \\
14 & 1347 & Pull T2P uphole slowly with wireline \\
15 & 1354 & Stop at 1057 mbsl, pumps off \\
16 & 1357 & Pull T2P uphole slowly with wireline \\
17 & 1402 & Stop at 741 mbsl, pumps off \\
18 & 1404 & Pull T2P uphole slowly with wireline \\
19 & 1409 & Stop at 491 mbsl, pumps off \\
20 & 1411 & Pull T2P uphole slowly with wireline \\
21 & & Download data from data logger \\
\hline
\end{tabular}

Notes: Measurements taken 27 June 2005. GMT = Greenwich Mean Time, T2P = temperature/dual pressure probe, $\mathrm{BOH}=$ bottom of hole, BHA = bottom-hole assembly. 
Table AT38. Event summary of T2P Deployment 17, Hole U1322B, 42.0 mbsf. (See table notes.)

\begin{tabular}{lll}
\hline $\begin{array}{c}\text { Event } \\
\text { number }\end{array}$ & $\begin{array}{c}\text { Time } \\
(\mathrm{GMT})\end{array}$ & \multicolumn{1}{c}{ Event description } \\
\hline 1 & 1839 & Start data logger at 1 Hz \\
2 & 2010 & T2P on rig floor \\
3 & 2022 & Start lowering T2P downhole, pumps on \\
4 & 2029 & Stop at 491 mbsl, pumps off \\
5 & 2031 & Start lowering probe \\
6 & 2035 & Stop at 741 mbsl, pumps off \\
7 & 2037 & Start lowering probe \\
8 & 2043 & Stop at 1321 mbsl, pumps off \\
9 & 2046 & Start lowering probe \\
10 & 2048 & Stop at 1351 mbsl, pumps off \\
11 & 2050 & Start lowering probe \\
12 & 2057 & CDS lands in BHA, pumps off \\
13 & 2057 & Start penetration of T2P into sediment \\
14 & 2100 & End of T2P penetration, bit on BOH \\
15 & 2100 & Raise BHA 4.0 m off BOH \\
16 & 2207 & Pull T2P uphole slowly with wireline \\
17 & 2210 & Stop at 1321 mbsl, pumps off \\
18 & 2213 & Pull T2P uphole slowly with wireline \\
19 & 2219 & Stop at 741 mbsl, pumps off \\
20 & 2221 & Pull T2P uphole slowly with wireline \\
21 & 2226 & Stop at 491 mbsl, pumps off \\
22 & 2228 & Pull T2P uphole slowly with wireline \\
23 & 2232 & Disconnect wireline from CDS \\
24 & 2235 & Disconnect CDS from spacer \\
25 & 2237 & Disconnect spacer from CDS \\
26 & 2238 & T2P out of pipe \\
27 & & Download data from data logger \\
\hline & & \\
\hline & & \\
& & \\
19 & &
\end{tabular}

Notes: Measurements taken 28 June 2005. GMT = Greenwich Mean Time, T2P $=$ temperature/dual pressure probe, CDS $=$ colleted delivery system, $\mathrm{BHA}=$ bottom-hole assembly, $\mathrm{BOH}=$ bottom of hole.

Table AT39. Event summary of T2P Deployment 19, Hole U1322B, 134.3 mbsf. (See table notes.)

\begin{tabular}{ccl}
\hline $\begin{array}{c}\text { Event } \\
\text { number }\end{array}$ & $\begin{array}{c}\text { Time } \\
(\mathrm{GMT})\end{array}$ & \multicolumn{1}{c}{ Event description } \\
\hline 1 & & Start data logger at 1 Hz \\
2 & 1230 & Start lowering T2P downhole, pumps on \\
3 & 1236 & Stop at 491 mbsl, pumps off \\
4 & 1238 & Start lowering probe \\
5 & 1244 & Stop at 741 mbsl, pumps off \\
6 & 1246 & Start lowering probe \\
7 & 1303 & Stop at 1321 mbsl, pumps off \\
8 & 1307 & Start lowering probe \\
9 & 1334 & Stop at 1443 mbsl, pumps off \\
10 & 1336 & Start lowering probe \\
11 & 1341 & CDS lands in BHA, pumps off \\
12 & 1352 & Start penetration of T2P into sediment \\
13 & 1354 & End of T2P penetration, bit on BOH \\
14 & 1354 & Raise BHA 4.0 m off BOH \\
15 & 1425 & Pull T2P uphole slowly with wireline \\
16 & 1429 & Stop at 1321 mbsl, pumps off \\
17 & 1431 & Pull T2P uphole slowly with wireline \\
18 & 1440 & Stop at 741 mbsl, pumps off \\
19 & 1441 & Pull T2P uphole slowly with wireline \\
20 & 1446 & Stop at 491 mbsl, pumps off \\
21 & 1447 & Pull T2P uphole slowly with wireline \\
22 & & Download data from data logger \\
& &
\end{tabular}

Notes: Measurements taken 29 June 2005. GMT = Greenwich Mean Time, T2P $=$ temperature/dual pressure probe, CDS $=$ colleted delivery system, $\mathrm{BHA}=$ bottom-hole assembly, $\mathrm{BOH}=$ bottom of hole. 
Table AT40. Event summary of T2P Deployment 20, Hole U1322B, 157.8 mbsf. (See table notes.)

\begin{tabular}{|c|c|c|}
\hline $\begin{array}{c}\text { Event } \\
\text { number }\end{array}$ & $\begin{array}{l}\text { Time } \\
\text { (GMT) }\end{array}$ & Event description \\
\hline 1 & & Start data logger at $1 \mathrm{~Hz}$ \\
\hline 2 & 1815 & $\mathrm{~T} 2 \mathrm{P}$ on rig floor \\
\hline 3 & 1838 & Start lowering T2P downhole, pumps on \\
\hline 4 & 1846 & Stop at $491 \mathrm{mbsl}$, pumps off \\
\hline 5 & 1849 & Start lowering probe \\
\hline 6 & 1854 & Stop at $741 \mathrm{mbsl}$, pumps off \\
\hline 7 & 1857 & Start lowering probe \\
\hline 8 & 1905 & Stop at $1321 \mathrm{mbsl}$, pumps off \\
\hline 9 & 1908 & Start lowering probe \\
\hline 10 & 1913 & Stop at $1467 \mathrm{mbsl}$, pumps off \\
\hline 11 & 1919 & Start lowering probe \\
\hline 12 & 1936 & CDS lands in BHA, pumps off \\
\hline 13 & 1936 & Start penetration of $\mathrm{T} 2 \mathrm{P}$ into sediment \\
\hline 14 & 1937 & End of $\mathrm{T} 2 \mathrm{P}$ penetration, bit on $\mathrm{BOH}$ \\
\hline 15 & 1937 & Raise $\mathrm{BHA} 4.0 \mathrm{~m}$ off $\mathrm{BOH}$ \\
\hline 16 & 2043 & Pull T2P uphole slowly with wireline \\
\hline 17 & 2110 & Disconnect wireline from CDS \\
\hline 18 & 2113 & Disconnect CDS from spacer \\
\hline 19 & 2114 & Disconnect spacer from CDS \\
\hline 20 & 2215 & T2P out of pipe \\
\hline 21 & & Download data from data logger \\
\hline
\end{tabular}

Notes: Measurements taken 29 June 2005. GMT = Greenwich Mean Time, T2P $=$ temperature/dual pressure probe, CDS $=$ colleted delivery system, $\mathrm{BHA}=$ bottom-hole assembly, $\mathrm{BOH}=$ bottom of hole.

Table AT41. Event summary of T2P Deployment 23, Hole U1322C, 150.0 mbsf. (See table notes.)

\begin{tabular}{|c|c|c|}
\hline $\begin{array}{l}\text { Event } \\
\text { number }\end{array}$ & $\begin{array}{l}\text { Time } \\
\text { (GMT) }\end{array}$ & Event description \\
\hline 1 & & Start data logger at $1 \mathrm{~Hz}$ \\
\hline 2 & 0651 & $\mathrm{~T} 2 \mathrm{P}$ on rig floor \\
\hline 3 & 0701 & Start lowering T2P downhole, pumps on \\
\hline 4 & 0709 & Stop at $491 \mathrm{mbsl}$, pumps off \\
\hline 5 & 0712 & Start lowering probe \\
\hline 6 & 0717 & Stop at $741 \mathrm{mbsl}$, pumps off \\
\hline 7 & 0719 & Start lowering probe \\
\hline 8 & 0729 & Stop at $1321 \mathrm{mbsl}$, pumps off \\
\hline 9 & 0743 & Start lowering probe \\
\hline 10 & 0752 & Stop at $1459 \mathrm{mbsl}$, pumps off \\
\hline 11 & 0754 & Start lowering probe \\
\hline 12 & 0758 & CDS lands in BHA, pumps off \\
\hline 13 & 0758 & Start penetration of $\mathrm{T} 2 \mathrm{P}$ into sediment \\
\hline 14 & 0802 & End of T2P penetration, bit $1 \mathrm{~m}$ off $\mathrm{BOH}$ \\
\hline 15 & 0803 & Raise BHA $4.0 \mathrm{~m}$ off $\mathrm{BOH}$ \\
\hline 16 & 0905 & Pull T2P uphole slowly with wireline \\
\hline 17 & 0912 & Stop at $1321 \mathrm{mbsl}$, pumps off \\
\hline 18 & 0914 & Pull T2P uphole slowly with wireline \\
\hline 19 & 0924 & Stop at $741 \mathrm{mbsl}$, pumps off \\
\hline 20 & 0926 & Pull T2P uphole slowly with wireline \\
\hline 21 & 0932 & Stop at $491 \mathrm{mbsl}$, pumps off \\
\hline 22 & 0934 & Pull T2P uphole slowly with wireline \\
\hline 23 & & Download data from data logger \\
\hline
\end{tabular}

Notes: Measurements taken 1 July 2005. GMT = Greenwich Mean Time, T2P = temperature/dual pressure probe, CDS = colleted delivery system, $\mathrm{BHA}=$ bottom-hole assembly, $\mathrm{BOH}=$ bottom of hole. 
Table AT42. Event summary of T2P Deployment 24, Hole U1322C, 200.0 mbsf. (See table notes.)

\begin{tabular}{lll}
\hline $\begin{array}{c}\text { Event } \\
\text { number }\end{array}$ & $\begin{array}{c}\text { Time } \\
\text { (GMT) }\end{array}$ & \multicolumn{1}{c}{ Event description } \\
\hline 1 & 1201 & Stop at $491 \mathrm{mbsl}$ for 2 min \\
2 & 1208 & Stop at 741 mbsl for 2.5 min \\
3 & 1222 & Stop at 1321 mbsl for 3 min \\
4 & 1226 & Stop at 1367 mbsl for 7 min \\
5 & 1239 & Stop at 1509 mbsl, pumps off \\
6 & 1212 & Start lowering probe \\
7 & 1248 & CDS lands in BHA \\
8 & 1249 & Lowering BHA, start penetration \\
9 & 1251 & End of T2P penetration, bit 1 m off BOH \\
10 & 1251 & Raise BHA 5 m off BOH \\
11 & 1351 & Pull T2P uphole slowly with wireline \\
12 & 1357 & Stop at 1321 mbsl for 2.5 min, pumps off \\
13 & 1409 & Stop at 741 mbsl for 2 min, pumps off \\
14 & 1414 & Stop at 491 mbsl for 3 min, pumps off \\
15 & 1416 & Pull T2P uphole slowly with wireline \\
\hline & &
\end{tabular}

Notes: Measurements taken 1 July 2005. GMT = Greenwich Mean Time, CDS = colleted delivery system, BHA = bottom-hole assembly, T2P $=$ temperature/dual pressure probe, $\mathrm{BOH}=$ bottom of hole.

Table AT43. Event summary of T2P Deployment 25, Hole U1322D, 40.0 mbsf. (See table notes.)

\begin{tabular}{lll}
\hline $\begin{array}{c}\text { Event } \\
\text { number }\end{array}$ & $\begin{array}{c}\text { Time } \\
\text { (GMT) }\end{array}$ & \multicolumn{1}{c}{ Event description } \\
\hline 1 & & Start data logger at 1 Hz \\
2 & 0206 & Start lowering T2P downhole, pumps on \\
3 & 0214 & Stop at 491 mbsl, pumps off \\
4 & 0221 & Stop at 741 mbsl, pumps off \\
5 & 0232 & Stop at 1321 mbsl, pumps off \\
6 & 0238 & Stop at 1349 mbsl, pumps off \\
7 & 0240 & Start lowering probe \\
8 & 0245 & CDS lands in BHA, pumps off \\
9 & 0246 & Start penetration of T2P into sediment \\
10 & 0246 & End of T2P penetration, bit 0.8 m off BOH \\
11 & 0246 & Raise BHA 4.0 m off BOH \\
12 & 0349 & Pull T2P uphole slowly with wireline \\
13 & 0352 & Stop at 1321 mbsl, pumps off \\
14 & 0355 & Pull T2P uphole slowly with wireline \\
15 & 0402 & Stop at 741 mbsl, pumps off \\
16 & 0404 & Pull T2P uphole slowly with wireline \\
17 & 0408 & Stop at 491 mbsl, pumps off \\
18 & 0410 & Pull T2P uphole slowly with wireline \\
19 & & Download data from data logger \\
\hline & &
\end{tabular}

Notes: Measurements taken 2 July 2005. GMT = Greenwich Mean Time, T2P = temperature/dual pressure probe, CDS = colleted delivery system, $\mathrm{BHA}=$ bottom-hole assembly, $\mathrm{BOH}=$ bottom of hole. 
Table AT44. Event summary of T2P Deployment 26, Hole U1322D, 70.0 mbsf. (See table notes.)

\begin{tabular}{|c|c|c|}
\hline $\begin{array}{c}\text { Event } \\
\text { number }\end{array}$ & $\begin{array}{l}\text { Time } \\
(\mathrm{GMT})\end{array}$ & Event description \\
\hline 1 & & Start data logger at $1 \mathrm{~Hz}$ \\
\hline 2 & 0632 & $\mathrm{~T} 2 \mathrm{P}$ on rig floor \\
\hline 3 & 0656 & Stop at $741 \mathrm{mbsl}$, pumps off \\
\hline 4 & 0707 & Stop at $1321 \mathrm{mbsl}$, pumps off \\
\hline 5 & 0718 & Stop at $1386 \mathrm{mbsl}$, pumps off \\
\hline 6 & 0720 & Start lowering probe \\
\hline 7 & 0724 & CDS lands in BHA, pumps off \\
\hline 8 & 0726 & Start penetration of T2P into sediment \\
\hline 9 & 0727 & End of $\mathrm{T} 2 \mathrm{P}$ penetration, bit $0.8 \mathrm{~m}$ off $\mathrm{BOH}$ \\
\hline 10 & 0727 & Raise BHA 4.0 m off $\mathrm{BOH}$ \\
\hline 11 & 0814 & Pull T2P uphole slowly with wireline \\
\hline 12 & 0816 & Stop at $1321 \mathrm{mbsl}$, pumps off \\
\hline 13 & 0826 & Stop at $741 \mathrm{mbsl}$, pumps off \\
\hline 14 & 0832 & Stop at $491 \mathrm{mbsl}$, pumps off \\
\hline 15 & & Download data from data logger \\
\hline
\end{tabular}

Notes: Measurements taken 2 July 2005. GMT = Greenwich Mean Time, T2P = temperature/dual pressure probe, CDS $=$ colleted delivery system, $\mathrm{BHA}=$ bottom-hole assembly, $\mathrm{BOH}=$ bottom of hole.

Table AT45. Event summary of T2P Deployment 27, Hole U1322D, 100.0 mbsf. (See table notes.)

\begin{tabular}{ccl}
\hline $\begin{array}{c}\text { Event } \\
\text { number }\end{array}$ & $\begin{array}{c}\text { Time } \\
\text { (GMT) }\end{array}$ & \multicolumn{1}{c}{ Event description } \\
\hline 1 & & Start data logger at 1 Hz \\
2 & 1104 & Stop at 491 mbsl, pumps off \\
3 & 1115 & Stop at 741 mbsl, pumps off \\
4 & 1115 & Stop at 1321 mbsl, pumps off \\
5 & 1124 & Stop at 1409 mbsl, pumps off \\
6 & 1126 & Start lowering T2P \\
7 & 1129 & CDS lands in BHA, pumps off \\
8 & 1129 & Start penetration of T2P into sediment \\
9 & 1130 & End of T2P penetration, bit 0.8 $\mathrm{m}$ off BOH \\
10 & 1130 & Raise BHA 4.0m off BOH \\
11 & 1216 & Pull T2P uphole slowly with wireline \\
12 & 1219 & Stop at 1321 mbsl, pumps off \\
13 & 1228 & Stop at 741 mbsl, pumps off \\
14 & 1235 & Stop at 491 mbsl, pumps off \\
15 & & Download data from data logger \\
\hline
\end{tabular}

Notes: Measurements taken 2 July 2005. GMT = Greenwich Mean Time, T2P = temperature/dual pressure probe, CDS = colleted delivery system, $\mathrm{BHA}=$ bottom-hole assembly, $\mathrm{BOH}=$ bottom of hole.

Table AT46. Event summary of T2P Deployment 28, Hole U1322D, 134.0 mbsf. (See table notes.)

\begin{tabular}{|c|c|c|}
\hline $\begin{array}{c}\text { Event } \\
\text { number }\end{array}$ & $\begin{array}{l}\text { Time } \\
\text { (GMT) }\end{array}$ & Event description \\
\hline 1 & & Start data logger at $1 \mathrm{~Hz}$ \\
\hline 2 & 1452 & $\mathrm{~T} 2 \mathrm{P}$ on rig floor \\
\hline 3 & 1510 & Stop at $491 \mathrm{mbsl}$, pumps off \\
\hline 4 & 1512 & Start lowering probe \\
\hline 5 & 1515 & Stop at $741 \mathrm{mbsl}$, pumps off \\
\hline 6 & 1516 & Start lowering probe \\
\hline 7 & & Download data from data logger \\
\hline
\end{tabular}

Notes: Measurements taken 2 July 2005. GMT = Greenwich Mean Time, T2P = temperature/dual pressure probe. 